\title{
MHC control of virus immunity through NK cells
}

\author{
Xuefang Xie
}

Changle, Fujian, China

B.S. Zhejiang University 2003

A Dissertation presented to the Graduate Faculty of the University of Virginia in Candidacy for the Degree of Doctor of Philosophy

Department of Microbiology

University of Virginia

May 2009

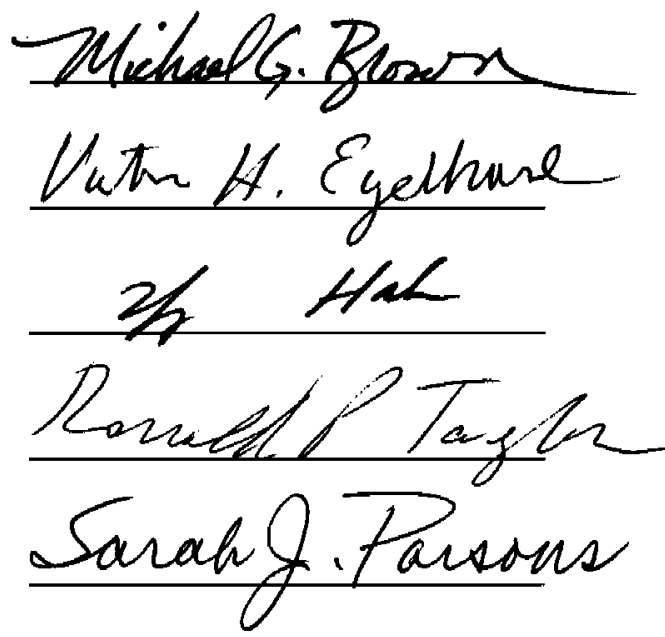




\section{Table of Contents}

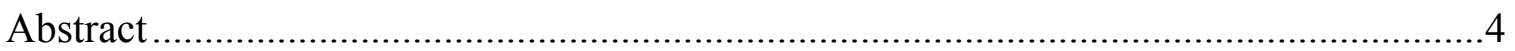

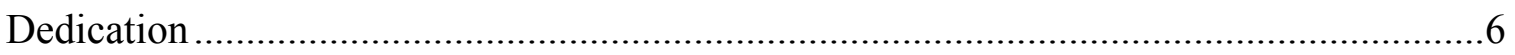

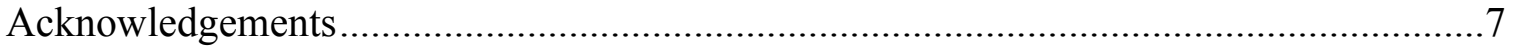

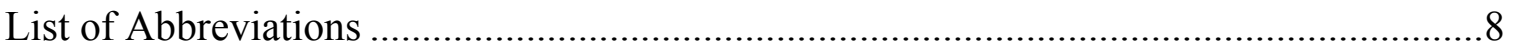

\section{Chapter I: Introduction}

Natural killer cells and their role in virus immunity ............................................... 10

NK cells in humans and mice ........................................................................ 10

Functional control through NK cell surface receptors and their MHC class I / class

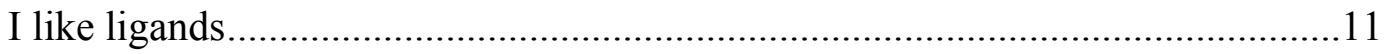

Role of NK cells in virus infection ............................................................13

Murine cytomegalovirus: a model pathogen for genetic analysis of disease resistance....14

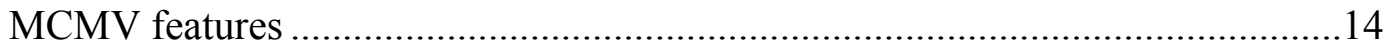

Genetics of MCMV resistance among inbred mouse strains ............................16

Major MCMV resistance loci mapped............................................................17

Role of NK cells in MCMV resistance .....................................................................19

MCMV susceptibility in experimental NK cell deficiency models ....................19

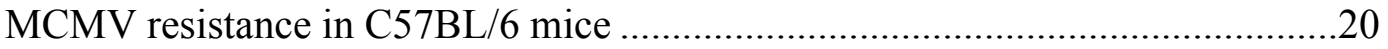

NK-mediated MCMV resistance in other inbred strains ..................................24

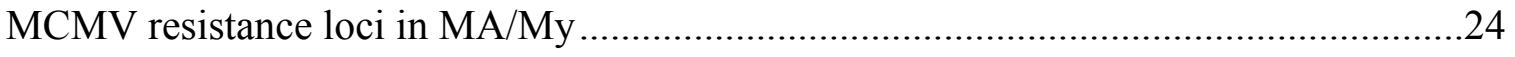

Features of MCMV resistance in MA/My mice ............................................24

Genetic mapping of a MA/My $\mathrm{Cmv}^{\mathrm{r}}$ locus in the $\mathrm{MHC} \mathrm{H}-2^{\mathrm{k}}$ region ..................25

A Ly49P-D ${ }^{\mathrm{k}}$ model for MCMV control.........................................................27

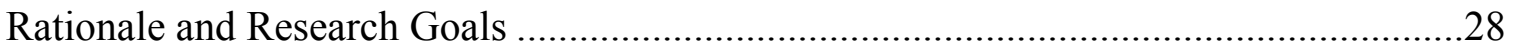


Chapter II: Deficient MHC-linked Antiviral NK Immunity in MA/My.L-H2 ${ }^{\mathrm{b}}$ Mice and MCMV Downregulation of ${\mathrm{H}-2^{\mathrm{k}}}^{\mathrm{C}}$ Class I Proteins

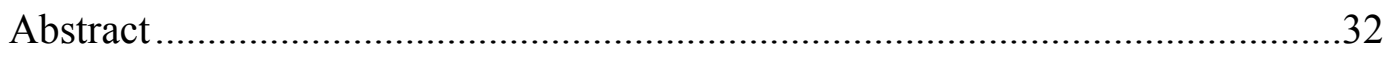

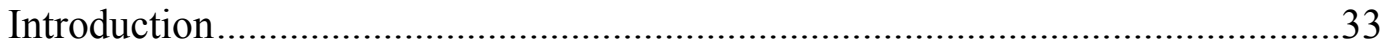

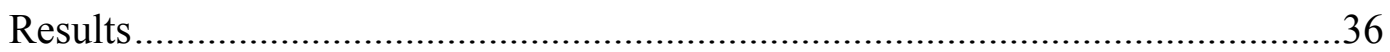

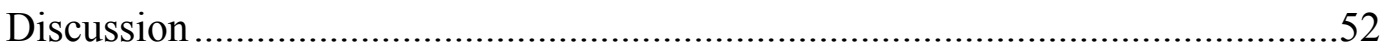

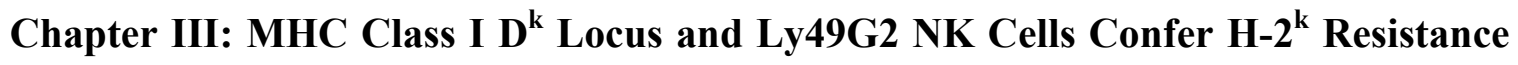
to Murine Cytomegalovirus

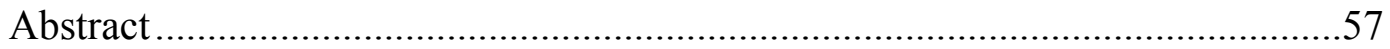

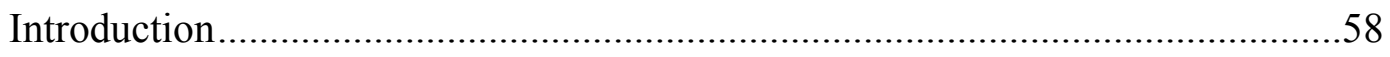

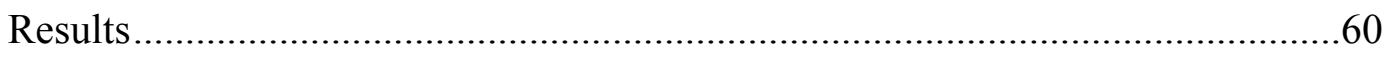

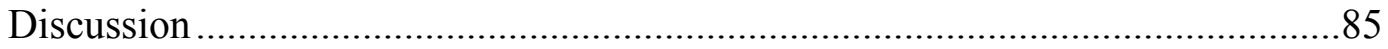

Chapter IV: Transgenic Expression of H-2 $D^{k}$ in Susceptible H-2 ${ }^{b}$ Mice Confers MCMV Resistance

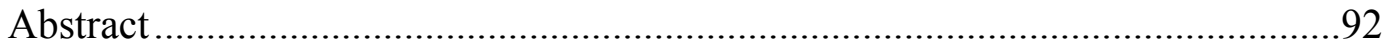

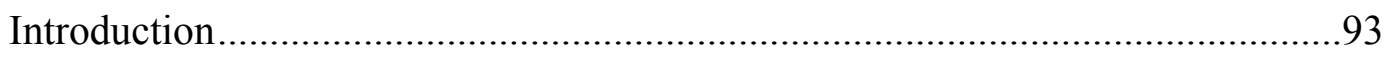

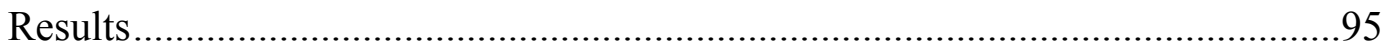

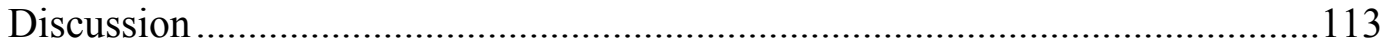

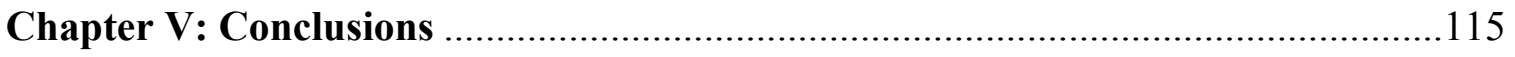

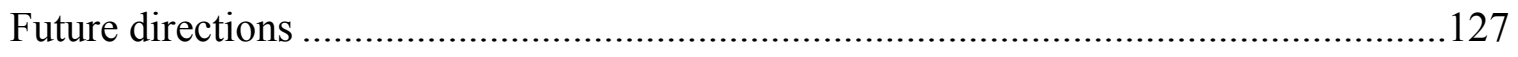

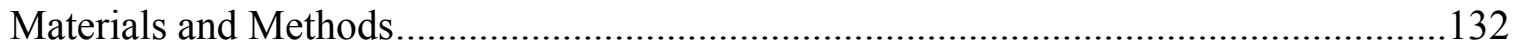

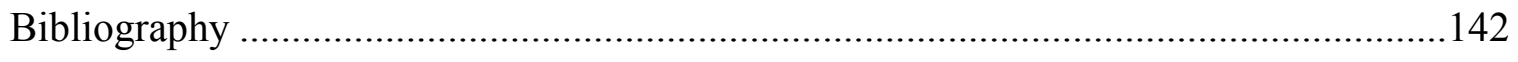

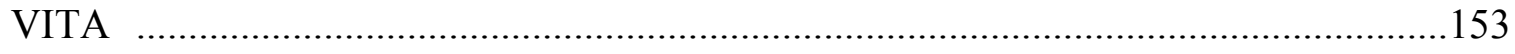




\begin{abstract}
NK cells play an essential role in host defense against MCMV infection. Although the control mechanism in C57BL/6 mice has been extensively studied, mechanisms utilized by NK cells to recognize MCMV in other genetic systems are mostly unknown. Previous work has shown that NK cells mediate $\mathrm{H}-2^{\mathrm{k}}$ dependent MCMV control in MA/My mice. This dissertation was designed to identify the $\mathrm{H}-2^{\mathrm{k}}$ linked resistance locus $\left(\mathrm{Cmv}^{\mathrm{r}}\right)$ and to better understand the role of interaction between $\mathrm{NK}$ cells and $\mathrm{H}-2 \mathrm{Cmv}^{\mathrm{r}}$ in $\mathrm{MCMV}$ control.
\end{abstract}

First, the essential role of $\mathrm{H}-2^{\mathrm{k}}$ was confirmed in the H-2 congenic MA/My.L-H2 ${ }^{\mathrm{b}}$ strain. Further, a panel of intra-H2 recombinant congenic strains was produced and $\mathrm{Cmv}^{\mathrm{r}}$ was precisely mapped to a $0.3-\mathrm{Mb}$ interval in the H-2 D subregion. Since NK Ly49 receptors recognize MHC class I proteins, the class $\mathrm{I}^{\mathrm{k}}$ gene was considered an excellent relevant positional candidate. Finally, $\mathrm{D}^{\mathrm{k}}$ transgenic mice were generated and studied for innate MCMV immunity. We proved that $\mathrm{D}^{\mathrm{k}}$ alone is sufficient to confer NK cell dependent MCMV resistance.

Since MCMV infection efficiently downregulates $\mathrm{H}-2^{\mathrm{k}}$ class I proteins, inhibitory Ly49 receptors that recognize $\mathrm{MHC}$ class I deficiency were brought to our attention. Interestingly, we found that a receptor for MHC-I D ${ }^{\mathrm{k}}$, Ly49G2, was responsible for NK mediated MCMV control in $\mathrm{H}-2^{\mathrm{k}}$ congenic $\mathrm{R} 7$ and $\mathrm{D}^{\mathrm{k}}$ transgenic mice. In support of this finding, selective expansion and activation of the Ly49G2+ subset was only found in $\mathrm{D}^{\mathrm{k}}$ expressing mice. Thus, NK cell recognition of MCMV infected cells may involve a Ly49G2-D ${ }^{\mathrm{k}}$ interaction. 
This dissertation identifies $\mathrm{D}^{\mathrm{k}}$ as the $\mathrm{H}-2^{\mathrm{k}} \mathrm{Cmv}^{\mathrm{r}}$ locus and determines a critical role for the inhibitory Ly49G2 receptor in virus immunity by acting through a particular class I allele, $\mathrm{D}^{\mathrm{k}}$. This finding has important implications for how the MHC shapes NK immunity. 


\section{Dedication}

This dissertation is dedicated to my family. It has been a long journey from my life in a coastal town in Southeast China. My family's prayers and support give me strength across a vast ocean. My parents worked hard to raise five children. And I especially want to thank my mother; without her love and inspiration I could never imagine being here today. My sisters and brother always gave me spiritual support and comfort during difficult times. And my two little nephews are so cute that they can always bring me happiness and laughter! Finally, I thank my grandmother for her love and care as she helped to raise me and my sisters. I can never thank my family enough for all they have given to me.

\section{献词}

我将这篇毕业论文题献给我的家人。从我生活长大的中国东南沿海一个小镇到这里 求学是一个漫长的旅程。在大洋彼岸家人的祈祷和支持赋予我力量让我坚持完成学 位。我的父母勤俭持家抚养大我们五个孩子, 特别是我母亲, 没有她的关爱和启发 , 我无法想象今天能站在这里。在我面对困难和挫折的时候, 我的兄弟姐妹总是在 精神上给我支持和安慰。我的两个小外甥是如此的可爱, 他们总是给我带来欢乐和 笑声。最后, 我感谢我的外婆, 她在家里困难的时候给我们的关怀和照顾。对于家 人所给予的我永远都感激不尽。 


\section{Acknowledgements}

I would like to express my deep gratitude and appreciation to my mentor, Dr. Michael Brown, for his guidance and support throughout my graduate studies. His critical thinking and passion for science have enormously influenced me. I also want to thank all my colleagues, former and current Brown lab members, Patty Clark, Abhijit Dighe, Pearl Sabastion, Mari Rodriguez, Virginia Carroll, Michael Stadnisky, Alyssa Lundgren, Corinne Abalos, Jessica Prince, Noel Noh and Jun Lee. I am particularly grateful to Abhijit Dighe and Michael Stadnisky for their contribution to this research project.

My dissertation committee members, Dr. Victor Engelhard, Dr. Young Hahn, Dr. Sarah Parsons and Dr. Ronald Taylor, provided an essential and helpful review of my work. For their input and ideas, I am truly in their debt.

In addition, I would like to express my appreciation to other labs at U.Va. for their technical support and expertise: Dr. Joe Sung for his advice and helpful reagents; Dr. Umesh Deshmukh for assisting me with IP and western blot; Dr. Rahul Sharma for his technical assistance; Alex Ward from David Rekosh's lab for helping me with BAC DNA purification; Robert Hontz from Jeffery Smith's lab for assistance with the PFGE apparatus; Fanny Ewann and Michelle Warthan from Paul Hoffman's lab for assistance with electroporation; Dr. Ann Sutherland and her students as well as Guofeng Xu for their careful assistance in embryo photography and evaluation of transgenic embryo loss; and the U.Va. GTTF facility team for their careful work in generating transgenic mice.

I would like to thank Dr. Ulrich Koszinowski for the $\Delta \mathrm{m} 04, \Delta \mathrm{m} 06$ and $\Delta \mathrm{m} 152$ mutant MCMV, Dr. Stipan Jonjic for the anti-ie1 mAb and Dr. Ann Hill for the anti-gp34 rabbit serum.

And I would like to thank all the Rheumatology members for their support and help.

Finally, I want to thank my good friend, John Lee Holmes, for his support throughout my American journey and his help with my studies, including proofreading my thesis proposal and dissertation documents and listening to my numerous practice presentations. 


\section{List of abbreviations}

Bacterial artificial chromosome

- BAC

Beige

- bg

Bone marrow

- BM

C57BL/6

- B6

C57BL/10

- B10

(C57L x MA/My) $F_{1}$

- L/MF 1

C57L.M-H2 ${ }^{k}$

- L.M-H2 $2^{k}$

C57L.M-H2 ${ }^{k}(\mathrm{R} 2)$

- R2

C57L.M-H2 ${ }^{k}(\mathrm{R} 7)$

- R7

C57L.M-H2k (R12)

- R12

Chediak-Higashi syndrome

- CHS

Cytomegalovirus

- CMV

C-type lectin domain family 2

- Clec2

Cytomegalovirus resistant

Cytomegalovirus susceptible

- CMV

Cytotoxic T lymphocytes

$-\mathrm{CMV}^{\mathrm{s}}$

Days post infection

- CTL

- dpi

Dendritic cells

- DCs

DNAX-activating protein 10

- DAP-10

DNAX-activating protein 12

- DAP-12

Glycoprotein

- gp

Green fluorescent protein

- GFP

Granulocyte macrophage colony-stimulating factor

- GM-CSF

Hepatitis $C$ virus

$-\mathrm{HCV}$

Histocompatibility-2

$-\mathrm{H}-2$

Human leukocyte antigen

- HLA

Human cytomegalovirus

- HCMV

Immunoreceptor tyrosine-based activation motif

- ITAM

Immunoreceptor tyrosine-based inhibitory motif

- ITIM

Interferon-gamma

- IFN- $\gamma$

Interleukin-12

- IL-12

Intraperitoneal

- i.p.

Killer cell immunoglobulin (Ig)-like receptors

$-\mathrm{KIR}$

Lethal dose that causes $50 \%$ mortality

$-\mathrm{LD}_{50}$

Littermate

- LM 
Major histocompatibility complex

- MHC

MHC class I

- MHC-I

(MA/My x C57L) $\mathrm{F}_{1}$

$-\mathrm{M} / \mathrm{LF}_{1}$

MA/My.L-H2 ${ }^{b}$

(M.L-H2 ${ }^{b} \times$ C57L) $F_{1}$

$-\mathrm{M} . \mathrm{L}-\mathrm{H} 2^{b}$

$-\mathrm{MLF}_{1} \cdot \mathrm{H} 2^{b}$

M/L F1.H2 ${ }^{b}-\operatorname{Tg} 3\left(D^{\mathrm{k}}\right) \times \mathrm{C} 57 \mathrm{~L}$

- Tg3LN2

$\mathrm{M} / \mathrm{L} F 1 . H 2^{b}-\mathrm{Tg} 3\left(\mathrm{D}^{\mathrm{k}}\right) \times \mathrm{M} \cdot \mathrm{L}-\mathrm{H} 2^{b}$

- Tg3MN2

Megabase

Mean fluorescence intensity

Monoclonal antibody

Mouse embryonic fibroblast

Murine cytomegalovirus

Multiplicity of infection

Natural cytotoxicity receptors

$-\mathrm{Mb}$

$-\mathrm{MFI}$

$-m A b$

- MEF

- MCMV

- MOI

- NCRs

Natural killer cells

- NK cells

NK cell deficiency

- NKD

Natural killer gene complex

- NKC

Natural killer receptor - protein 1

- NKR-P1

Natural-killer group 2, member D

- NKG2D

New Zealand black

- NZB

New Zealand white

- NZW

$\mathrm{N}$-ethyl-N-nitrosourea

- ENU

Peripheral blood mononuclear cells

- PBMCs

Plaque Forming Unit

- PFU

Polymerase chain reaction

- PCR

Pulse field gel electrophoresis

- PFGE

Quantitative real-time PCR

- QPCR

Recombinant inbred

- RI

Salivary gland virus

- SGV

Simple sequence length polymorphisms

- SSLPS

Single nucleotide polymorphisms

- SNPS

Transgenic

- $\mathrm{Tg}$

Tumor necrosis factor

- TNF

Untranslated region

- UTR

Wild type

- WT 


\section{Chapter I}

\section{Natural killer cells and their role in virus immunity}

\section{NK cells in humans and mice}

NK cells are the third largest lymphocyte population that differs from $\mathrm{T}$ and $\mathrm{B}$ cells in their ability to lyse target cells without initial priming. NK cells primarily participate in innate immunity and also play important roles in bridging innate and adaptive immune systems. Due to these features, NK cells are recognized as 'multitasking' cells (1). By discriminating self and non-self, NK cells can eliminate transformed and virus infected cells and reject bone marrow (BM) transplantation through cytolytic function $(2,3)$. Since NK cells can secrete cytokines (IFN- $\gamma$, TNF and GM-CSF) and chemokines, they also play a role in tissue inflammation and activation of dendritic cells (DCs) to prime adaptive lymphocytes $(4,5)$. In addition to these activities, NK cells are also implicated in immunopathology, such as autoimmunity (6) and viral hepatitis (7).

Both human and mouse NK cells develop and differentiate mainly in the BM and migrate to the periphery after maturation (8). Mature NK cells are primarily located in the spleen, liver, lung and blood. Although NK cells only constitute $2-15 \%$ of leukocyte population in the peripheral tissues, they can immediately respond to a stimulus and perform effector functions within minutes. Indeed, resting NK cells constitutively express mRNA pools of IFN- $\gamma(9)$, perforin and granzyme B (10). This allows them to bypass transcription and initiate translation of these effector proteins upon activation. Through receptor/ligand recognition, NK cytotoxicity can be induced by cytokines (type I IFNs, IL-12, IL-15 and 
IL-18), immune complexes, adhesion molecules, stress-induced ligands as well as pathogen or tumor ligands (11). When NK cells are activated by target cells, cytotoxic granules carrying effector proteins, perforin and granzymes, are released onto the surface of bound targets so that these cytotoxic proteins penetrate the cell membrane and induce programmed cell death.

\section{Functional control through interaction between NK cell surface receptors and their MHC class I / class I like ligands}

Although NK cells resemble T cells in their cytolytic and cytokine secreting functions, they differ from $\mathrm{T}$ cells by expressing a repertoire of germ-line encoded receptors that do not require somatic recombination (12). NK cells express both activating and inhibitory receptors. Upon ligation, activating receptors signal through adaptor molecules bearing tyrosine-based activation motif (ITAM) (including Fc\&RI $\gamma, \mathrm{CD} 3 \zeta$ and DAP12) or YXXM motif (DAP10), while inhibitory receptors engaged by their ligands can dampen activation signals using their tyrosine-based inhibitory motif (ITIM) to modulate NK cell responses. In other words, a balance between activating and inhibitory signals determines NK cell activation status.

Diverse NK cell surface receptors include activating and inhibitory members encoded by clustered gene families located in the natural killer gene complex (NKC) and leukocyte receptor complex (LRC). Inhibitory NKG2/CD94, Ly49 and KIR cell surface receptors recognize MHC class I proteins as their ligands. These NK receptor-ligand interactions are important in tolerizing NK cells to self-MHC class I expression and for alerting NK cells when cells in the body have altered or missing MHC class I expression. For 
example, Ly49A delivers an inhibitory signal when binding to $\mathrm{D}^{\mathrm{d}}$ or $\mathrm{D}^{\mathrm{k}}(13)$. One the other hand, the activating receptors, which bind to MHC-I related ligands, are also critical for tumor surveillance and viral recognition. For example, the NKG2D receptor recognizes stress- or transformation- induced class I like proteins REA1, H60 and MULT-1 in mice or MICA and MICB in humans (14); the Ly49H receptor is activated by a MCMV encoded MHC-I homolog, $\mathrm{m} 157(15,16)$.

Among NK receptors, Ly49 and KIR are diverse and polymorphic receptors due to their specificity for MHC class I and class I-like proteins, although Ly49s are C-type lectin receptors while KIRs belong to the immunoglobulin superfamily. To date, 14 Ly49 receptors have been discovered in the well-characterized B6 and 129 strains and most of them are inhibitory receptors $(17,18)$. Since inhibitory Ly49s and KIRs are engaged by self MHC I ligands, they are critical in monitoring NK cell responses; they can lyse cells with aberrant class I expression without attacking normal cells. The abilities of self MHC antigens to inhibit NK killing of certain tumors were first noted by Kärre and colleagues $(19,20)$. Based on their findings, the 'missing self' hypothesis was later proposed that NK cells express receptors that receive an inhibitory signal upon binding to self MHC-I molecules on the target. Thus, NK cells can recognize and eliminate abnormal cells with no or downregulated MHC-I expression due to a release of inhibition, a phenomenon often seen in transformed or virally infected cells (21). This hypothesis is further supported by experiments showing that NK cells reject tumor cells and BM cells lacking a MHC-I transgene $(22,23)$ or MHC class I deficient $(\beta 2 \mathrm{~m}-/-)$ hematopoietic transplants (24). Karlhofer and colleagues first formally demonstrated that an inhibitory Ly49 receptor (known as Ly49A) on NK cells is responsible for 'missing-self' attack by 
sensing lack of class I $\mathrm{D}^{\mathrm{d}}$ expression on tumor cells (13). However, since NK cells can be activated to lyse some targets with normal MHC I expression, the 'missing-self' hypothesis was later modified to "NK cells patrol for abnormal cells that lack MHC class I or that overexpress ligands for activating NK cell receptors" (12).

Similar to other lymphocytes, NK cells learn to sense abnormal (transformed, infected or stressed) cells but tolerate normal cells. Several studies have shown that self MHC-I interaction with NK KIR or Ly49 receptors enables NK cells in human and mouse to acquire full functional competence, while NK cells without receptors for self MHC-I ligands are rendered hyporesponsive (25-28). For example, Ly49A+ NK cells from mice expressing its ligand $\mathrm{D}^{\mathrm{d}}$ are more potent IFN- $\gamma$ producer upon crosslinking of activation receptors, such as NK1.1, and have better capacity to kill MHC-I deficient cells or tumor cells than those from $\mathrm{H}-2^{\mathrm{b}}$ mice that do not express $\mathrm{D}^{\mathrm{d}}$. In support, NK cells from class I deficient mice (e.g. $\beta 2 \mathrm{~m}-/-$ ) respond poorly to in vitro stimulation or to the tumor targets. Thus, MHC class I molecules are not only important to regulate NK cell responses but also essential for NK cell education through interaction with their cognate NK inhibitory receptors. However, the mechanisms of NK cell education by self MHC class I proteins during development are yet to be revealed.

\section{Role of NK cells in virus infection}

NK cells provide the firstline defense against a variety of virus infections (29). Humans deficient in NK cells are more susceptible to viral infections, particularly herpes virus infections (30). NK cell sensing of virus infection includes both nonspecific and specific responses. Virus induced type I IFNs and other innate cytokines, such as IL-12 and IL- 
18, are important to induce NK cytotoxicity, IFN- $\gamma$ production and proliferation (31). On the other hand, specific recognition of viral signatures is achieved by NK surface inhibitory and activating receptors, some of which directly bind viral proteins on the targets (29). For example, the B6 Ly49H receptor recognizes MCMV glycoprotein m157 displayed on infected cells; NKp46 recognizes haemagglutinins of influenza and Sendai viruses. Moreover, inhibitory NK receptors can sense downregulation of MHC class I proteins which commonly occurs during virus infection. By producing cytokines and performing cytotoxicity toward infected targets, NK cells are able to rapidly control virus spread and replication.

\section{Murine cytomegalovirus: a model pathogen for genetic analysis of disease resistance}

\section{MCMV features}

Cytomegalovirus is a prevalent viral pathogen. It infects more than half of the world population (32). CMV infection in healthy adults usually does not cause any symptoms, but it is a threat to immuno-compromised or immuno-suppressed individuals and can cause severe morbidity and mortality (33-35). Congenital CMV infection also poses a problem to the developing fetus and may cause disabilities or even death $(36,37)$. Although transplacental transmission is not reported in MCMV infection, HCMV and MCMV infections share many biological features: 1) highly restricted host specificity; 2) broad tissue tropism and target cell types $(38,39)$; 3) causing acute, latent and recurrent infection. Moreover, genomes for these viruses have highly significant sequence similarity and share gene counterparts not only involved in viral replication but also in immune evasion $(40,41)$. For these reasons and also because HCMV is tropic for human 
tissues, MCMV infection of mice has been used as a model to study HCMV.

$\mathrm{CMV}$, a beta-herpesvirus, carries a large dsDNA genome ( $230 \mathrm{~kb}$ in length). Genome analysis and mutagenesis shows that only $1 / 3$ of predicted HCMV gene products are essential for viral replication (41). Due to highly conserved MCMV genome compared to $\operatorname{HCMV}(40,41)$, it can be estimated that a large percentage of the total 170 gene products encoded by MCMV are also committed to modulate cellular and host immune responses to infection rather than the tasks of viral replication. Indeed, many MCMV glycoproteins have been reported to modulate host defense to infection, including both innate and adaptive immune responses $(37,41)$. The retention of these immuno-evasion proteins, referred as immunoevasins, also reflects pressures at work which have shaped MCMV as it has evolved along with its host. Thus, MCMV infection of mice offers an excellent model to study host genetic variations that influence virus control and the interplay between host defense and viral evasion. Indeed, the MCMV model has been adopted to genetically dissect and identify innate resistance components using a forward genetic approach based on ENU mutagenesis (42).

MCMV encodes three glycoproteins, m04/gp34, m06/gp48 and m152/gp40, and they are expressed during the early phase of viral replication to interfere with MHC class I antigen presentation. Glycoprotien gp48 binds tightly to MHC-I molecules and relocates them to lysosomes for degradation (43); gp40 retains MHC-I complexes in the ER-Golgi compartment (44); gp34 forms a stable complex with class I on the cell surface (45) and was shown to inhibit $\mathrm{K}^{\mathrm{b}}$ - but not $\mathrm{D}^{\mathrm{b}}$ - restricted CTL recognition (46). In a more comprehensive study by Holtappels et al., gp34 was found to positively regulate CTL 
responses (restricted by either $\mathrm{H}-2^{\mathrm{d}}$ or $\mathrm{H}-2^{\mathrm{b}}$ class I alleles) by antagonizing the inhibitory role of gp 40 ; this positive regulation is completely counteracted by the negative regulator gp48 (47). Nonetheless, CTLs can not mount effective response to WT infected targets in large part due to abrogated surface MHC-I expression $(46,47)$. In fact, CD8 T cells control an MCMV mutant lacking these three genes 10 fold more effectively than wild type (WT) MCMV in the salivary gland (48). Since NK cells recognize MHC class I deficiency, class I downregulation by MCMV apparently renders infected cells open to NK cell attack. However, decreased class I expression may be counteracted by MCMV encoded class I homolog, m144, which was shown to contribute to evasion of NK cell recognition in vivo (49). Because diverse Ly49 receptors discriminate class I allelic determinants (12), m144 is unlikely to be a pan surrogate for various class I ligands to inhibit NK cells. Thus, NK inhibitory receptors can still play a role in recognition of MCMV-mediated class I downregulation because of host genetic variations.

\section{Genetics of MCMV resistance among inbred mouse strains}

Inbred mouse strains differ greatly in their susceptibility to MCMV infection. Resistance to lethal MCMV infection is under complex genetic control of both $\mathrm{H}-2$ and non-H2 genes $(50,51) . \mathrm{H}-2^{\mathrm{k}}$ strains, such as $\mathrm{C} 3 \mathrm{H}$ and $\mathrm{CBA}$, are generally more resistant than those with $\mathrm{b}$ or $\mathrm{d}$ haplotypes ((50) and Table I); BALB.K $\left(\mathrm{H}-2^{\mathrm{k}}\right.$ congenic BALB/c) is 10 times more resistant than BALB/c $\left(\mathrm{H}-2^{\mathrm{d}}\right)$ or other congenic strains with $\mathrm{b}$ or g haplotypes as measured by $\mathrm{LD}_{50}$ (a virus dose that causes $50 \%$ mortality). A non-H2 effect was found in the B6 and B10 strains with 3-4 fold higher $\mathrm{LD}_{50}$ than BALB/c (Table I).

$\mathrm{H}-2$ and non-H-2 genetic factors also regulate viral replication levels in the major target 
organs, such as the spleen $(53,54)$. After i.p. infection with $10^{5}$ PFU MCMV, resistant strains (eg. $\mathrm{C} 3 \mathrm{H})$ start to control viral spread at 1 day post-infection (dpi) and spleen virus levels decline rapidly at 2 dpi; BALB.K mice with intermediate resistance only begin to control the virus at $2 \mathrm{dpi}$; spleen virus levels in the susceptible BALB/c continue to increase and peak at 4 dpi (54). Thus, mortality rates generally correlate well with the spleen virus replication levels at the early phase, day 3-4. By studying virus replication in the spleen, Scalzo et al found that most inbred mouse strains are susceptible to MCMV infection with at least 100 fold higher viral loads than resistant strains, such as B6 and MA/My (55). Later, two additional strains, New Zealand White (NZW) and a wildderived inbred strain PKW, were also shown to have better abilities to limit virus replication in the spleen $(56,57)$.

\section{Major MCMV resistance loci mapped}

In B6 mice, the non-H-2 resistance locus $\mathrm{Cmvl}$ was mapped to the NK gene complex (NKC) on chromosome 6 (52) and later identified as a single gene, Ly49H $(58,59)$. Unlike a single locus in B6, genetic linkage analysis of NZB and NZW hybrids revealed that multiple loci (together referred to as $\mathrm{Cmv} 2$ ), unrelated to $\mathrm{H}-2$ and $\mathrm{NKC}$, contribute to MCMV control in the resistant NZW strain (56). Similar to Cmv1, Cmv4 was also mapped to the NKC in PWK using (PWK $x \mathrm{BALB} / \mathrm{c}$ ) $\mathrm{F}_{2}$ offspring (57). It was thought that Cmvl was also responsible for MCMV resistance in the MA/My strain (55). However, two major resistance loci that regulate virus replication in the spleen have since been mapped to the MHC and NKC $(\mathrm{Cmv} 3)$ in MA/My $\left(\mathrm{H}-2^{\mathrm{k}}\right)(60,61)$. 
Table I. Relative resistance of various inbred and MHC congenic mouse strains to lethal infection with MCMV

\begin{tabular}{|c|c|c|c|c|c|}
\hline \multirow[t]{2}{*}{ Strain } & \multirow[t]{2}{*}{ Background } & \multirow[t]{2}{*}{ H-2 } & \multicolumn{3}{|c|}{ Relative LD $_{50}{ }^{a}$} \\
\hline & & & Exp. $^{\text {b }}$ & Exp.2 $2^{b}$ & Exp.3 \\
\hline B10.BR & $\mathrm{B} 10$ & $\mathrm{k}$ & 34 & & \\
\hline B10 & $\mathrm{B} 10$ & $\mathrm{~b}$ & 4.1 & & \\
\hline B6 & B6 & $\mathrm{b}$ & & 4 & 5 \\
\hline $\mathrm{C} 3 \mathrm{H}$ & $\mathrm{C} 3 \mathrm{H}$ & $\mathrm{k}$ & 26 & 14 & \\
\hline BALB.K & $\mathrm{BALB} / \mathrm{c}$ & $\mathrm{k}$ & 10 & & \\
\hline BALB/c & $\mathrm{BALB} / \mathrm{c}$ & d & 1 & 1 & 1 \\
\hline BALB.B & $\mathrm{BALB} / \mathrm{c}$ & $\mathrm{b}$ & 1.3 & & \\
\hline BALB.G & $\mathrm{BALB} / \mathrm{c}$ & g & 1.2 & & \\
\hline
\end{tabular}

${ }^{a}$ Relative $\mathrm{LD}_{50}$ refers to $\mathrm{LD}_{50}$ of the given strain compared with that of the BALB/c strain arbitrarily assigned the value 1.0

${ }^{\mathrm{b}}$ Data are adapted from $\operatorname{Ref}(51)$

${ }^{\mathrm{c}}$ Data are adapted from $\operatorname{Ref}(52)$ 


\section{Role of NK Cells in MCMV resistance}

\section{MCMV susceptibility in experimental NK cell deficiency models}

Several NK cell deficiency models have been used to study the role of NK cells in MCMV control. Beige mutation in mice $(\mathrm{bg} / \mathrm{bg})$ causes a genetic disorder that is considered a homolog of human Chediak-Higashi syndrome (CHS). The mutated gene was identified as LYST/CHS1 $(62,63)$ and encodes a cytoplasmic protein that regulates vesicular trafficking. Due to disruptive granule trafficking, NK cells in Beige mice and CHS patients have defective cytolytic functions (64-68). Consequently, beige mice are highly susceptible to MCMV infection with high levels of virus replication in the major target organs including spleen, liver and kidney, compared to WT B6 mice (69). Despite normal numbers of NK cells, NK cytolytic activities in beige mice are very low in response to sublethal MCMV infection (69). Thus, NK cells are critical for efficient control of MCMV infection.

In addition to the beige mouse, a natural killer cell-deficient (NKD) mouse model is also utilized to assess the importance of NK cells in MCMV infection. Despite functionally normal NKT and T cells, the NKD mouse displays impaired in vivo tumor rejection due to the small number of peripheral NK cells and defects in NK cytolytic function (70). The genetic deficiency is linked to an unexpected insertion of a Ly49A transgene into a transcription factor gene, ATF-2, resulting in arrested NK development in the bone marrow (71). Upon MCMV infection, NKD mice exhibit profound susceptibility to MCMV induced mortality, uncontrolled virus replication in the spleen and liver and 
inability to clear the virus (72).

Similarly, mice deficient in NK effector proteins, such as IFN- $\gamma$, perforin or granzymes, also show increased susceptibility to MCMV infection, including enhanced virus replication in the major organs and/or less resistance to virus induced lethality (72-76). Taken together, these NK deficiency models highlight the importance of NK cells and their effector functions in virus control. However, these models are not helpful in dissecting the mechanisms of NK recognition of virus infection involving receptor-ligand interaction.

\section{MCMV resistance $(\mathrm{Cmv} 1)$ in $\mathrm{C} 57 \mathrm{BL} / 6$ mice}

\section{Cmv1 genetic mapping to the NK gene complex}

Scalzo and colleagues first established linkage studies using $F_{2}$ offspring of B6 (resistant) and BALB/c (susceptible) to map the non-H-2 loci for MCMV control on the B6 background (52). Due to a Mendelian 3:1 segregation of resistance and susceptibility traits, respectively, a single dominant resistant locus was designated $C m v 1$, which maps to the NKC on chromosome 6 (52). Since at least four clusters of NK cell surface receptor multigene families (i.e. $N k r p 1, C l e c 2, N k g 2$ and $L y 49$ ) and still other NK lectinlike receptor genes are found in the NKC (Fig. 1), further attempts were made to precisely locate $C m v 1$ within the $\operatorname{NKC}(55,77-79)$.

BXD-8, a recombinant inbred (RI) mouse strain derived from an outcross of C57BL/6 $\left(C m v^{r}\right)$ and $\mathrm{DBA} / 2\left(\mathrm{Cmv}^{s}\right)$ progenitor strains, carries an $\mathrm{NKC}^{\mathrm{b} 6}$ genotype but rather displays MCMV susceptibility (55). By taking advantage of BXD-8, two groups found 
Figure 1. Gene structure of the C57BL/6 mouse NKC. Shown is a schematic diagram of the gene organization in the C57BL/6 NKC on chromosome 6. Small rectangular boxes represent individual genes. Individual genes within the Nkrp1, Clec2, Nkg2 and Ly49 gene clusters are named. 


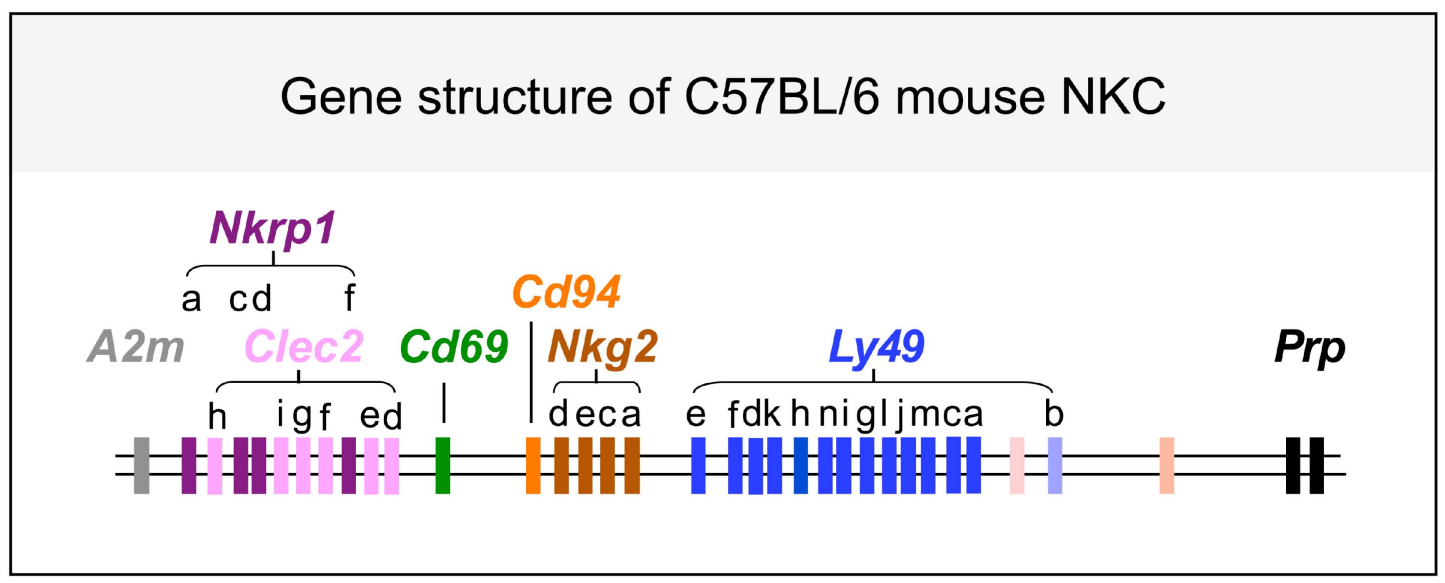


that Ly49H gene is deleted and accounts for MCMV susceptibility in the strain $(58,59)$. Ly49H is an activating NK receptor expressed in B6 but not in BXD-8 or DBA. Blocking of $\mathrm{Ly} 49 \mathrm{H}$ receptor in vivo with a specific mAb 3D10 (58) or signaling disruption of DAP-12 co-receptor (80) leads to loss of MCMV resistance in B6 mice, as is seen after NK depletion with the PK136 mAb. The role of Ly49H is further confirmed by the fact that transgenic expression of Ly49H in MCMV susceptible strains confers MCMV resistance (81). In accord, $\mathrm{Ly} 49 \mathrm{H}+$ subset was a more potent IFN- $\gamma$ producer at the site of infection and depletion of Ly49H subset substantially enhanced virus titers in the spleen and liver (82). Moreover, Ly49H+ subset in the spleen and liver selectively proliferated at a later phase (day 6-7) in response to MCMV infection $(81,83)$. Together these data demonstrated that the Ly49H receptor mediates NK-dependent MCMV control in B6 mice and is likely activated by a stimulatory signal upon MCMV infection.

\section{The Ly49H stimulatory NK receptor and its MCMV m157 ligand}

Since most Ly49 receptors recognize MHC class I molecules, it was speculated that Ly49H might also recognize a class I or class I related molecule induced by the virus. Indeed, a class I like MCMV glycoprotein, m157, was identified as the ligand for the stimulatory Ly49H receptor $(15,16)$. M157 is expressed on the surface of infected cells

and is able to stimulate $\mathrm{NK}$ cells to produce IFN- $\gamma$ through engagement of $\mathrm{Ly} 49 \mathrm{H}$ receptor $(15,16)$. Ly49H-m157 interaction is specific because B6 NK cells can not control an MCMV mutant with targeted deletion of the m157 gene (84). Ly49H NK cells are able to limit MCMV infection in recognition of m157 on infected cells. However, MCMV can undergo rapid mutation within the m157 gene under the pressure of NK 
cells, leading to emergence of m157 mutants that can escape NK cell recognition (85, 86). Thus, specific interaction between the Ly49H receptor and viral $\mathrm{m} 157$ presents an effective mechanism for NK cells to recognize MCMV.

\section{NK-mediated MCMV resistance in other inbred strains}

Although the $\mathrm{Cmvl} \mathrm{I}^{r}$ control mechanism has been extensively studied in B6 mice, $\mathrm{Cmv} \mathrm{I}^{r}$ like resistance is rare in laboratory inbred mouse strains (55) or wild mouse populations (87). Among the several resistant inbred strains, NK cells also mediate critical MCMV control but through unknown Ly49H-independent mechanisms. Cmv2 was not mapped to the NKC in MCMV resistant NZW, but NK cells are required to limit MCMV replication in the spleen (56). This indicates that NK antiviral immunity is likely regulated by other background genes in this genetic setting. Under the genetic control of $\mathrm{Cmv} 4$ (linked to the NKC), the MCMV resistant phenotype is also dependent on NK cells in PWK and appears to be independent of Ly49H (57). In H-2 ${ }^{\mathrm{k}}$ linked MCMV resistance (see Table I), the importance of NK cells was implicated by highly augmented NK activities found in infected $\mathrm{C} 3 \mathrm{H}$ and $\mathrm{CBA}$ strains (88) and confirmed in the NK deficient CBA bg/bg mice (89). However, further dissection of NK cell control mechanisms was not pursued in these $\mathrm{H}-2^{\mathrm{k}}$ strains.

\section{MCMV resistance loci in MA/My}

\section{Features of MCMV resistance in MA/My mice}

Similar to B6, MA/My mice were also shown to have a $C m v 1$-like phenotype, low virus replication in the spleen at 4 dpi, which is dependent on NK cells (55). Surprisingly, a 
genealogically related C57L strain $\left(\mathrm{H}-2^{\mathrm{b}}\right)$ shares the NKC-Ly49 haplotype with MA/My (90) but displays a MCMV susceptible phenotype (55). This discrepancy could be explained by their different $\mathrm{H}-2$ haplotypes and the possibility that MA/My NK cells use a Ly49H-independent pathway to control MCMV. Indeed, the latter idea is substantiated by previous data that neither MA/My nor C57L express 3D10-binding Ly49H receptor and that MA/My NK cells are able to effectively control a m157 mutant virus (61). In contrast to the dominant $\mathrm{Cmvl}^{r}$ trait in (B6 $\left.\times \mathrm{BALB} / \mathrm{c}\right) \mathrm{F}_{1}$ mice, the (MA/My $\times \mathrm{BALB} / \mathrm{c}$ ) $F_{1}$ are susceptible to MCMV infection. This further supports the idea that a Ly49Hindependent mechanism accounts for MCMV resistance in MA/My. On the other hand, (C57L x MA/My) $F_{1}$ hybrids control MCMV infection even more effectively than MA/My, suggesting that the BALB/c background but not C57L can mask the MA/My resistance trait.

\section{Genetic mapping of a MA/My $C m v^{r}$ locus to the $\mathrm{MHC} \mathrm{H}_{-2}^{\mathrm{k}}$ region}

\section{MCMV resistance under ${\mathrm{H}-2^{\mathrm{k}}}^{\mathrm{g}}$ genetic control in (MA/My $\mathrm{x}$ C57L) offspring}

To locate the genetic loci associated with MCMV resistance in MA/My, (MA/My x C57L) hybrid offspring were produced and examined for innate MCMV immunity. Interestingly, (C57L x MA/My)F 1 x MA/My backcross offspring were all resistant to MCMV infection, whereas spleen virus levels in $\left(\mathrm{C} 57 \mathrm{~L}\right.$ x MA/My) $F_{1} \times C 57 \mathrm{~L}$ offspring displayed a bimodal distribution of low (MA/My-like) and high (C57L-like) MCMV with a ratio close to $1: 1$, suggesting that MCMV resistance is linked to a single dominant locus. Examination of H-2 and NKC haplotypes in the C57L backcross mice revealed that high virus replication is associated with homozygous $\mathrm{H}-2^{\mathrm{b}}$ whereas low virus 
replication is linked to $\mathrm{H}-2^{\mathrm{k} / \mathrm{b}}$ heterozygosity. However, no NKC association was found in these backcross offspring due to a similar NKC-Ly49 haplotype in MA/My and C57L.

Spleen virus levels and genotypes determined by SSLP marker-assisted genome-wide screening were studied in backcross or intercross mice for quantitative genetic analysis. We found that H-2 linked genes contribute to $\sim 50 \%$ and $\sim 35 \%$ of trait variance in the backcross and intercross cohorts, respectively. The H-2 resistance loci appeared to be linked with two markers, 17UVA09 (distal to the MHC) and 17UVA12 within the MHC (see Fig. 7). Moreover, $\mathrm{H}-2^{\mathrm{k}}$-conferred MCMV resistance in the $\mathrm{H}-2$ congenic strain, C57L.M-H2 ${ }^{k}$, has illustrated the importance of H-2 linked genes in MCMV control.

\section{Epistasis between H-2 and NKC-Ly49 loci affects MCMV control (60)}

Genetic studies of MCMV resistance in MA/My were also performed using crosses with BALB/c and BALB.K strains. Upon MCMV infection, spleen virus titers of (MA/My x BALB.K) $F_{1}$ mice are intermediate between MA/My (low) and BALB.K (high), suggesting a codominant effect of non-H-2 gene(s). Linkage analysis of (MA/My x BALB.K) $F_{2}$ mice found that MCMV-resistance strongly associates with marker genes $N k g 2 d$ and $L y 49 e$ (also called Klrk1 and Klra5, respectively) within the NKC (60). This NKC linked resistance locus, named $C m v 3$, explains $\sim 37 \%$ of trait variance (60). To assess the role of $\mathrm{H}-2$ in MA/My MCMV resistance, hybrids of MA/My $\left(\mathrm{H}-2^{\mathrm{k}}\right)$ and $\mathrm{BALB} / \mathrm{c}\left(\mathrm{H}-2^{\mathrm{d}}\right)$ were used for genetic mapping. In the cross, animals with homozygous $\mathrm{H}-2^{\mathrm{k}}$ and $\mathrm{NKC}^{\text {mamy }}$ displayed the most effective MCMV control and resistance is associated with a genetic interaction between $\mathrm{H}-2$ and NKC. Thus, an $\mathrm{H}-2$ locus regulates NK cell immunity through NKC genes, likely NK cell surface receptors. 


\section{A Ly49P-D ${ }^{\mathrm{k}}$ model for MCMV control}

$N k g 2 d$ and other $L y 49$ genes were considered as $C m v 3$ candidates based on the genetic mapping results (60). However, MA/My and BALB/c NKG2D cDNA sequences are identical and are equally expressed in both strains, suggesting that NKG2D is unlikely a Cmv3 candidate. To further test Ly49 receptors that may be involved in MCMV recognition, a panel of activating Ly49 receptors from MA/My, including Ly49P, Ly49U and Ly49R, were cloned and expressed in a $\mathrm{T}$ cell reporter system (60). Interestingly, only Ly49P expressing reporter cells were stimulated by infected MEFs from MA/My and BALB.K but not those from other strains with different $\mathrm{H}-2$ haplotypes (d, q or b) or by uninfected cells. This suggested that the Ly49P receptor recognizes an $\mathrm{H}-2^{\mathrm{k}}$ encoded gene product that is induced or modified by MCMV infection. Since Ly49 receptors recognize $\mathrm{MHC}$ class $\mathrm{I}$ or class I like proteins, $\mathrm{K}^{\mathrm{k}}$ and $\mathrm{D}^{\mathrm{k}}$ were further studied as candidates for the Ly49P ligand (60). Antibody blocking of $\mathrm{D}^{\mathrm{k}}$ but not $\mathrm{K}^{\mathrm{k}}$ on infected cells as well as blocking of Ly49P on reporter cells by a Ly49A/P-crossreactive mAb, YE1/48, abrogated reporter cell activation. Thus, Ly49P specifically binds to $\mathrm{D}^{\mathrm{k}}$ on MCMV infected cells. Based on this finding, it was proposed that MA/My NK cells recognize and efficiently control MCMV infection through Ly49P-D ${ }^{\mathrm{k}}$ interaction (60). However, the impact of this interaction in MCMV resistance has not been studied in vivo. 


\section{Rationale and Research Goals}

In MA/My, innate MCMV resistance is dependent on NK cells. Based on previous linkage studies in our laboratory, the MCMV resistance loci $\left(\mathrm{Cm}^{r}\right)$ in MA/My are linked to $\mathrm{H}-2^{\mathrm{k}}(61)$. Two major loci were implicated: one mapped inside the MHC and the other is distal to the MHC. Thus, we hypothesized that 1) H-2 linked MCMV resistance is functional through NK cells; and that 2) there are at least two MHC linked loci that contribute to MCMV resistance. Among MHC-linked genes, class I genes are particularly interesting because NK cell 'missing-self' attack is caused by reduced interaction between inhibitory Ly49 and MHC-I, while MCMV infection downregulates surface

MHC-I expression (e.g. $\mathrm{H}-2^{\mathrm{b}}$ and $\mathrm{H}-2^{\mathrm{d}}$ ). To take one step further, our group also hypothesized that MCMV may regulate $\mathrm{H}-2^{\mathrm{k}}$ class I proteins in an allele-specific manner, and this in turn could affect NK signaling through inhibitory Ly49 receptors. To test our hypotheses, the following research goals have been proposed:

\section{Specific Aim 1: Determine whether H-2 linked MCMV resistance in C57L.M-H2 ${ }^{k}$ -} $N K C^{\text {mamy }}$ congenic mice requires NK cells. We have shown that $\mathrm{H}-2^{\mathrm{k}}$-linked genes are sufficient to confer MCMV resistance on the C57L $\left(\mathrm{Cmv}^{\mathrm{s}}\right)$ background, which seemed to be at least partly mediated by NK cells (61). It was not clear, however, whether this incomplete phenotype is due to an additional H-2 control mechanism(s) independent of NK cells or to inefficient NK depletion in the previous study. Since NK cells with $\mathrm{NKC}^{\mathrm{c} 571}$ are refractory to PK136-mediated immunodepletion, we can test the latter

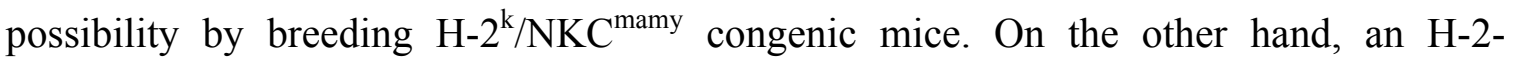
independent role was also implicated in previous (C57L x MA/My) $\mathrm{F}_{2}$ studies. It is 
important to confirm whether $\mathrm{H}-2^{\mathrm{k}}$ is necessary for MCMV resistance by replacing MA/My H-2 $2^{\mathrm{k}}$ with $\mathrm{C} 57 \mathrm{~L} \mathrm{H}-2^{\mathrm{b}}$ and to compare the functional response (such as IFN- $\gamma$ ) of NK cells during MCMV infection in $\mathrm{H}-2^{\mathrm{k}}$ and $\mathrm{H}-2^{\mathrm{b}}$ mice.

\section{Specific Aim 2: Generate intra-H-2 recombinant congenic strains to pinpoint critical}

H-2 resistance loci. The previously mapped H-2-linked resistance interval spans at least $10 \mathrm{Mb}$ on chromosome 17 . Moreover, MCMV resistance was strongly associated with marker Uva09 in the backcross cohort, but with marker Uval2 (located between $\mathrm{K}$ and $\mathrm{D}$ loci) in the $F_{2}$ cohort [(61) and Fig. 7]. In order to narrow the H-2 linked region and locate $\mathrm{Cmv}^{r}$, we aimed to generate a panel of intra-H-2 recombinant congenic strains, ideally with recombination breakpoints separating K, D and Uva09 (Fig. 7). Although high linkage disequilibrium is documented for MHC linked genes, intra-H-2 recombinant strains have been successfully produced on different genetic backgrounds [(51) and Handbook on JAX Mice]. If produced, the $\mathrm{H}-2$ recombinants would be a useful genetic tool to dissect $\mathrm{H}-2^{\mathrm{k}}$ linked genes and study NK cell immunity influenced by $\mathrm{H}-2$ genes.

\section{Specific Aim 3: Study viral modulation of $H-2 K^{k}$ and $D^{k}$ class I proteins to further} understand NK recognition of MCMV infection. To escape CD8 T cell detection, MCMV efficiently downregulates class I surface expression. Decreased class I expression during MCMV infection however can be recognized by NK inhibitory receptors. In addition, allele specific modulation of class I expression by immunoevasins was noticed under certain conditions $(46,91)$. It is important to study MCMV regulation of $\mathrm{D}^{\mathrm{k}}$ and $\mathrm{K}^{\mathrm{k}}$ expression for the following reasons: 1) $\mathrm{D}^{\mathrm{k}}$ and $\mathrm{K}^{\mathrm{k}}$ are relevant $\mathrm{Cmv}^{\mathrm{r}}$ candidates; 2) MCMV regulation of $\mathrm{H}-2^{\mathrm{k}}$ class I expression has not been previously 
characterized; 3) this study may have important implications for $\mathrm{MHC}$ regulated $\mathrm{NK}$ recognition of MCMV infection. 


\section{Chapter II}

Deficient MHC-linked Antiviral NK Immunity in MA/My.L-H2 ${ }^{b}$ Mice and MCMV Downregulation of ${\mathrm{H}-2^{\mathrm{k}}}^{\mathrm{C}}$ Class I Proteins ${ }^{1}$

\footnotetext{
${ }^{1}$ Journal of Virology (2007) Vol. 81:229-236, January 1: Amended here with permission from American Society for Microbiology, Copyright (C) 2007.
} 


\begin{abstract}
NK cells are key effectors of innate immunity and host survival during CMV infection. Innate murine $(\mathrm{M}) \mathrm{CMV}$ resistance in MA/My mice requires Ly49H/m157 independent $\mathrm{H}-2^{\mathrm{k}}$ linked NK cell control. Here we show that replacement of MA/My H-2 ${ }^{\mathrm{k}}$ with $\mathrm{C} 57 \mathrm{~L}$ $\mathrm{H}-2^{\mathrm{b}}$ susceptibility genes led to a remarkable loss of innate virus immunity, though intracellular NK IFN- $\gamma$ was induced in $\mathrm{H}-2^{\mathrm{b}}$ and $\mathrm{H}-2^{\mathrm{k}}$ strains shortly after infection. Thus, $\mathrm{H}-2^{\mathrm{b}}$ genes expressed in C57L and MA/My.L-H2 ${ }^{b}$ are sufficient in alerting NK cells to intrusion but fail to support NK restraint of viral infection. In addition, novel $\mathrm{H}-2$ recombinant strains were produced and utilized in further refinement of a critical genetic interval controlling innate $\mathrm{H}-2^{\mathrm{k}}$-linked MCMV resistance. Importantly, this analysis excluded the $\mathrm{K}^{\mathrm{k}}$ class I through class II gene interval. The responsible gene(s) therefore resides in an interval spanning $\mathrm{D}^{\mathrm{k}}$ class Ia and more distal MHC non-classical class $\mathrm{Ib}$ genes. Recently, the NK activation receptor Ly49P, and MHC class I D ${ }^{\mathrm{k}}$ proteins were genetically implicated in MCMV resistance, in part because Ly49P expressing reporter T cells could specifically bind $\mathrm{D}^{\mathrm{k}}$ molecules on MCMV infected mouse embryonic fibroblasts (MEFs). However, as we found that $\mathrm{H}-2^{\mathrm{k}}$ innate resistance differs in the C57L or MA/My backgrounds and because MCMV very efficiently downregulates $\mathrm{H}-2^{\mathrm{k}}$ class I proteins in L929 cells and primary MEFs shortly after infection, a Ly49P / $\mathrm{D}^{\mathrm{k}}$ model that NK cells recognize MCMV infection through a Ly49P-D ${ }^{\mathrm{k}}$ interaction cannot fully explain $\mathrm{H}-2^{\mathrm{k}}$-linked MCMV resistance. Thus, we propose that inhibitory NK receptors for self MHC-I ligands on target cells may be also involved in MCMV recognition.
\end{abstract}




\section{Introduction}

Cytomegaloviruses (CMV) are betaherpesviruses that display species-specific tropism. Because human CMV (HCMV) and murine CMV (MCMV) cause severe infections in immunodeficient or immunologically immature hosts and share many biological features in their natural host settings, MCMV is an important model system for studies of innate viral immunity (37). Additionally, because NK cells provide critical innate immune defenses in CMV infections (30), the MCMV infection model is also useful for understanding the role of NK cells and their capacity to recognize virus targets.

Chalmer et al. noted a survival role for $\mathrm{H}-2^{\mathrm{k}}$ after high-dose $\mathrm{MCMV}$ infection in $\mathrm{C} 3 \mathrm{H}$, CBA, and BALB.K inbred mice (50). Further study revealed similar levels of MCMV infection and replication in mouse embryonic fibroblasts (MEFs) of different $\mathrm{H}-2$ haplotypes, including $\mathrm{H}-2^{\mathrm{b}}$ and $\mathrm{H}-2^{\mathrm{k}}(50)$. NK cells were also implicated, since enhanced NK cytotoxicity is a general feature of MCMV infection in more-resistant $\mathrm{H}-2^{\mathrm{k}}$ mouse strains (88). Scalzo et al. (55) later documented a primary role for NK cells in innate MCMV immunity in MA/My through immunodepleting NK cells with anti-NK1.1 monoclonal antibody (mAb) before infection. Elsewhere, we confirmed the importance of NK cells in innate MA/My MCMV immunity and extended our previous findings by demonstrating that $\mathrm{H}-2^{\mathrm{k}}$ introgression onto the C57L genetic background in C57L.M-H2 ${ }^{k}$ (L.M-H2 $2^{k}$ congenic mice was sufficient to convert MCMV susceptibility to resistance through NK control (61). An epistatic genetic interaction between Cmv3 (Ly49P) and H$2^{\mathrm{k}}$ was recently noted, and because Ly49P-transduced reporter $\mathrm{T}$ cells specifically bind class $\mathrm{I} \mathrm{D}^{\mathrm{k}}$ proteins on MCMV-infected MEFs, the receptor-ligand interaction is 
implicated in MA/My resistance (60). However, other unknown genetic factors clearly contribute, since $\mathrm{H}-2^{\mathrm{k}}$ substantially reduces spleen virus replication (55) and mortality

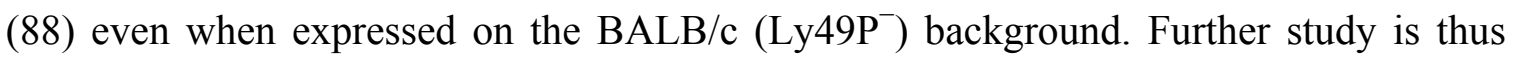
required to elucidate the mechanisms that govern the effectual NK recognition of MCMV-infected targets leading to innate major histocompatibility complex (MHC)linked control in $\mathrm{H}-2^{\mathrm{k}}$ mice.

Because NK cells also express inhibitory receptors for MHC class I molecules and their effector functions are determined through integration of stimulatory and inhibitory signals (12), an alternate hypothesis also involves NK recognition of MHC class I deficiency, as often occurs in viral infection. Cell surface expression of $\mathrm{H}-2^{\mathrm{b}}$ and $\mathrm{H}-2^{\mathrm{d}}$ class I proteins are specifically and dramatically altered by MCMV in vitro $(43,44,91)$. MCMV gp48 hijacks nascent MHC class I proteins for lysosomal degradation (43), gp40 blocks endoplasmic reticulum-Golgi MHC class I export (44), and gp34 escorts class I molecules to the cell surface to interfere with cytotoxic T-lymphocyte recognition (45, 46). Although the mechanisms are distinct, HCMV likewise utilizes several gene products to specifically alter HLA class I expression (37). However, HCMV also stabilizes HLA-E proteins with class I signal peptide-related UL40 leader peptide (92), presumably to bind inhibitory CD94/NKG2A receptors on NK cells and evade attack (9395). Additionally, HCMV utilizes UL141 and UL142 to directly interfere with NK recognition and attack $(96,97)$. Taken together, the data show that $\mathrm{H}-2^{\mathrm{k}}$ resistance may require altered $\mathrm{MHC}$ class I or class I-related protein recognition through inhibitory receptor sensing in addition to direct stimulation. 
To assess the role of $\mathrm{H}-2^{\mathrm{k}}$ in MCMV resistance, we replaced it in MA/My mice with the $\mathrm{H}-2^{\mathrm{b}}$ susceptibility locus of C57L. We examined MCMV infectivity and replication in MEFs derived from the resistant or susceptible strains, and innate MCMV immunity phenotypes were also analyzed. To also examine the role of NK cells, intracellular gamma interferon (IFN- $\gamma$ ) was quantified for comparison in $\mathrm{H}-2^{\mathrm{k}}$ and $\mathrm{H}-2^{\mathrm{b}}$ strains over a 3.5-day (d) time course following infection. Further, since the regulation of $\mathrm{H}-2^{\mathrm{k}}$ class I proteins by MCMV has not been previously characterized, we also examined $\mathrm{K}^{\mathrm{k}}$ and $\mathrm{D}^{\mathrm{k}}$ class I proteins on $\mathrm{L} 929$ cells and primary $(\mathrm{C} 57 \mathrm{~L} \times \mathrm{MA} / \mathrm{My}) \mathrm{F}_{1} \mathrm{MEFs}$ shortly after virus infection. We provide evidence indicating that a $\mathrm{Ly} 49 \mathrm{P} / \mathrm{D}^{\mathrm{k}}$ model is inadequate to fully account for MA/My MCMV resistance. 


\section{Results}

\section{H-2 ${ }^{b}$ linked genes fail to support innate MCMV immunity through NK cells}

We previously noted that multiple genes contribute vital Ly49H-independent immunity shortly after MCMV infection in New Zealand White or MA/My mice $(56,61)$. Because $\mathrm{H}-2^{\mathrm{k}}$-linked genes were shown to contribute substantially to MA/My virus resistance (60, 61) and also converted susceptibility to full resistance in C57L.M-H2 $2^{k}$ congenic mice (61), we examined whether they are also essential to innate immunity in this model system. We replaced $\mathrm{H}-2^{\mathrm{k}}$ in MA/My with $\mathrm{H}-2^{\mathrm{b}}$ from MCMV-susceptible C57L by use of SSLP marker-assisted selection to obtain $\mathrm{H}-2^{\mathrm{b}}$ donor alleles on a MA/My background (Fig. 2A). H-2 ${ }^{\mathrm{b}}$ introgression was confirmed using allele-specific anti-MHC class I mAbs to stain MA/My.L-H2 $2^{b}$ (M.L-H2 $2^{b}$ ) splenocytes (not shown).

We assessed innate MCMV immunity in M.L-H2 ${ }^{b}$ by measuring virus levels in spleens and livers. These mice displayed remarkable susceptibility that was even more severe than that of C57L (Fig. 2B and C). By comparison, similarly infected L.M-H2k/b and control MA/My mice were fully protected by $\mathrm{H}-2^{\mathrm{k}}$. Thus, $\mathrm{H}-2^{\mathrm{k}}-$ linked gene expression is essential for innate MCMV protection through NK cells in MA/My, whereas $\mathrm{H}-2^{\mathrm{b}}$ linked gene expression is not adequate for effective NK control. While previous work indicated that an additional genetic factor beyond the MHC or the NK gene complex can contribute to innate MCMV control (61), we also evaluated immunity in $(\mathrm{MA} / \mathrm{My} \times \mathrm{C} 57 \mathrm{~L}) \mathrm{F}_{1}$ hybrids and their heterozygous congenics, M.L-H2 $2^{b / k}$ mice (Fig. 2D). As expected, virus levels in littermate control $\left(\mathrm{H}-2^{\mathrm{k}}\right)$ spleens were comparable with those for MA/My. Intriguingly, however, virus levels in M.L- $H 2^{b / k}$ spleens were actually intermediate 
Figure 2. Deficient innate MCMV immunity in MA/My.L-H2 ${ }^{b}\left(M . L-H 2^{b}\right)$. A. The D17Mit57-D17Mit93 chromosome 17 interval in M.L-H2 $2^{b}$ is depicted at top with informative SSLP markers used in genetic screening and selection also shown. Physical map locations (in megabases) are indicated. The H-2 complex and $\mathrm{K}$ and D class I genes are also shown. Spleen virus levels in MCMV-infected (d 3.5) M.L-H2 ${ }^{b}$, L.M-H2 ${ }^{k}$ and control mice were quantitated by QPCR $(\mathbf{B})$ or virus plaque assay $(\mathbf{C})$. The plaque assay detection level is indicated by the broken line in C. Four to eight animals were studied per group. D. Spleen (filled symbols) and liver (open symbols) virus levels also were quantitated in similarly infected (MA/My x C57L) $\mathrm{F}_{1}$, M.L- $H 2^{b / k}$ and their non-congenic H-2 $2^{k}$ litter mates (M.H-2 ${ }^{k}$, and C57L control mice by QPCR. E. Spleen virus levels in MCMV-infected (M.L-H2 ${ }^{b}(\mathrm{R} 1)$ x MA/My) x C57L hybrids segregated by H-2 genotype (as designated) and control strains quantitated in QPCR are shown. Data are representative of two independent experiments. 
A.

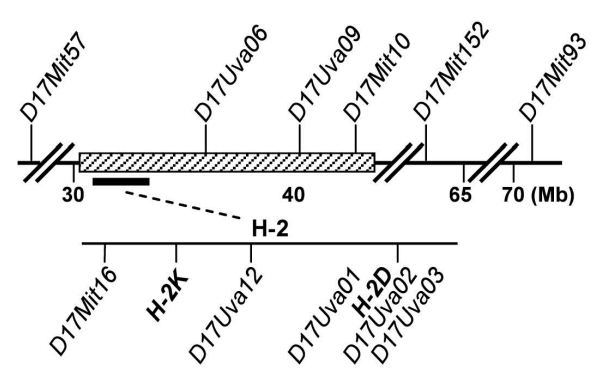

B.

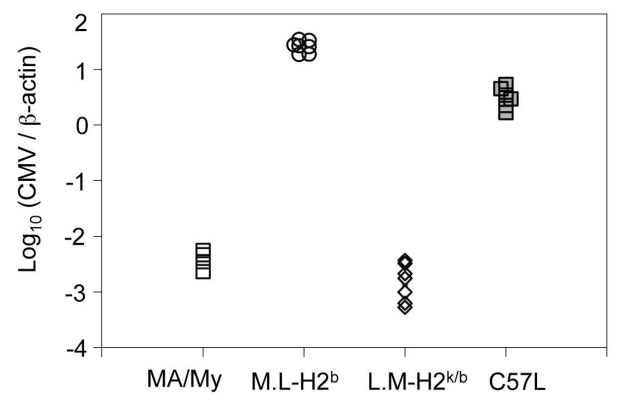

C.

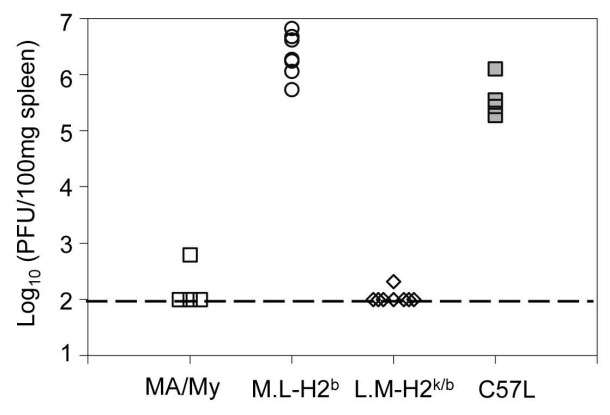

D.

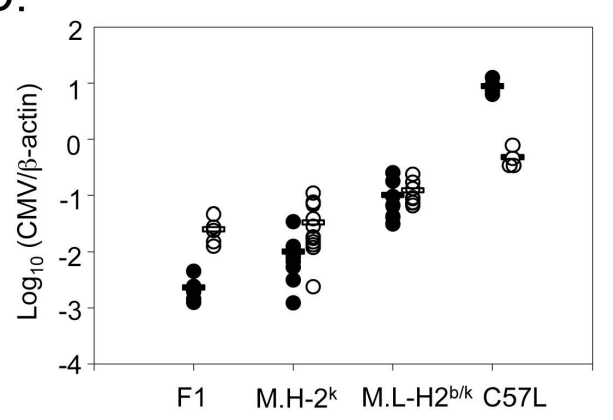

E.

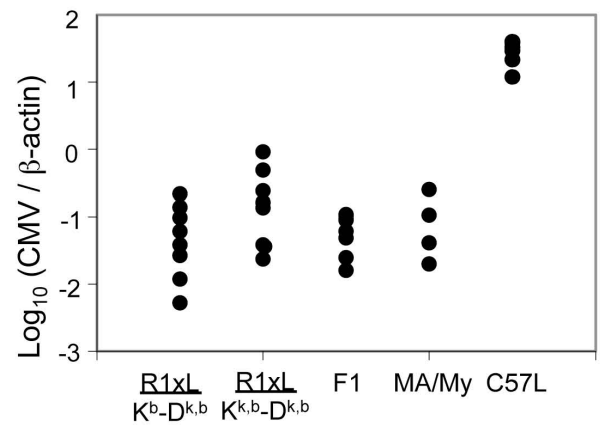


between those of the progenitor strains. This finding indicates that heterozygous $\mathrm{H}-2^{\mathrm{k}}$ is not fully protective on the MA/My genetic background. Instead, $\mathrm{H}-2^{\mathrm{k}}$ homozygosity is required to fully establish innate MCMV resistance on the MA/My background. Moreover, since differences in MCMV control in $\mathrm{H}-2$ heterozygous mice strictly correlated with their genetic background (compare L.M-H2 $2^{k / b}$ and M.L-H2 $2^{b / k}$ in Fig. 2B and D, respectively), an additional factor(s) coming from C57L must increase the extent of innate virus resistance afforded by the $\mathrm{H}-2^{\mathrm{k}}$ haplotype.

To further delimit an $\mathrm{H}-2^{\mathrm{k}}$-linked critical region, novel $\mathrm{H}-2$ recombinant mice were produced from the M.L- $H 2^{b}$ and L.M- $H 2^{k}$ strains. One strain, M.L-H2 $2^{b}(\mathrm{R} 1)$, was identified as containing an informative recombination breakpoint between the $\mathrm{H}-2 \mathrm{~K}$ and D genes. Importantly, this strain retains the expression of $\mathrm{K}^{\mathrm{b}}$ and $\mathrm{C} 57 \mathrm{~L}$-derived $\mathrm{MHC}$ class II proteins (not depicted) but also expresses MA/My-derived class I $D^{\mathrm{k}}$ molecules. We crossed $\left(\mathrm{MA} / \mathrm{My} \times \mathrm{M} . \mathrm{L}-H 2^{b}(\mathrm{R} 1)\right)_{\mathrm{N} 9}$ backcross mice with C57L and studied MCMV control in their hybrid offspring. As expected, a 1:1 Mendelian distribution of homozygous $\left(\mathrm{K}^{\mathrm{b}}\right.$ to $\mathrm{I}-\mathrm{E}^{\mathrm{b}}$ region) and fully heterozygous $\left(\mathrm{H}-2^{\mathrm{k}, \mathrm{b}}\right)$ progeny on $\mathrm{F}_{1}$ genetic backgrounds was observed. The corresponding innate MCMV immunities in the two groups shown in Fig. 2E indicate that $\mathrm{K}^{\mathrm{k}}$ expression is not needed to limit MCMV in the spleen. The $\mathrm{H}-2^{\mathrm{k}}$-linked critical region should therefore reside distal to SSLP marker 17 Uval2 and the class II genes while overlapping $\mathrm{D}^{\mathrm{k}}$ class $\mathrm{I}$ and more distal $\mathrm{H}-2$ nonclassical class Ib genes.

\section{Similar MCMV infectivity and replication in susceptible C57L or resistant C57L.M-} $\boldsymbol{H} 2^{k}$ strain derived MEFs. Though previous work has shown that MCMV infectivity and 
replication kinetics are similar in $\mathrm{H}-2^{\mathrm{b}}-$ and $\mathrm{H}-2^{\mathrm{k}}$-derived MEFs (50), Harnett and Shellam (98) noted high MCMV susceptibility in BALB/c $\left(H-2^{\mathrm{d}}\right)$ and B6 $\left(\mathrm{H}-2^{\mathrm{b}}\right)$ strainderived MEFs compared with that for MEFs from $\mathrm{H}-2^{\mathrm{k}}$ strains $\mathrm{C} 3 \mathrm{H}$ and $\mathrm{CBA}$. Thus, we also analyzed viral growth kinetics in MEFs prepared from embryos of MCMV-resistant and -susceptible strains. Figure 3A shows that MCMV grew exponentially from d 1 to $\mathrm{d} 5$ with similar kinetics in MEFs derived from either strain. In addition, comparable levels of infectious virions were released into the MEF supernatants after d 2 and through $\mathrm{d} 6$ (Fig. 3B). Furthermore, we did not observe significant differences in viral replication, plaque size, or viral cytopathic effect in comparison with MA/My MEFs (not shown). In agreement with Chalmer et al. (50), we conclude that $\mathrm{H}-2$-linked genetic differences in innate MCMV immunity are not controlled at the level of MCMV infectivity or replication within host cells.

\section{NK cells from both $\mathrm{Cmv}^{\mathrm{r}}\left(\mathrm{MA} / \mathrm{My}\right.$ and L.M-H2 $2^{k}$ and $\mathrm{Cmv}^{\mathrm{s}}\left(\mathrm{C} 57 \mathrm{~L}\right.$ and M.L-H2 $\left.{ }^{b}\right)$} strains were equally induced to produce IFN- $\gamma$ shortly after infection. To delineate whether an inherent defect in $\mathrm{H}-2^{\mathrm{b}} \mathrm{NK}$ virus sensing might explain an inability to restrain viral replication, we examined NK IFN- $\gamma$ shortly after infection, as this cytokine is rapidly induced in NK cells of MCMV-resistant C57BL/6 mice during MCMV infection (99). Spleen cellularity was generally maintained as the steady state (uninfected) with either the MA/My or the C57L genetic background through the first $39 \mathrm{~h}$ of infection (Fig. 4). By $90 \mathrm{~h}$ after infection, however, splenocyte numbers dropped precipitously in homozygous $\mathrm{H}-2^{\mathrm{b}}$ strains and also in M.L-H2 $2^{b / k}$ littermate controls (Fig. 4A). Thus, splenocyte numbers were not absolutely correlated with high or low virus levels, but in mice without the $\mathrm{H}-2^{\mathrm{k}}$ haplotype, substantial losses were always noted. Also consistent 
Figure 3. Multistep virus growth curves in $\mathbf{H - 2}{ }^{\mathbf{b}}$ or $\mathbf{H}-2^{\mathbf{k}}$ MEFs. C57L or C57L.M$H 2^{k}$ MEFs were infected with MCMV at a moi of 0.08 pfu per cell and the virus titers in the supernatants were detected daily by plaque assay on 3T12 cells (A) and quantitative realtime PCR was performed using DNA isolated from the remaining monolayers (B). MCMV shows similar virus productivity in C57L (closed symbol) or C57L.M-H2 ${ }^{k}$ (open symbol) MEFs. 


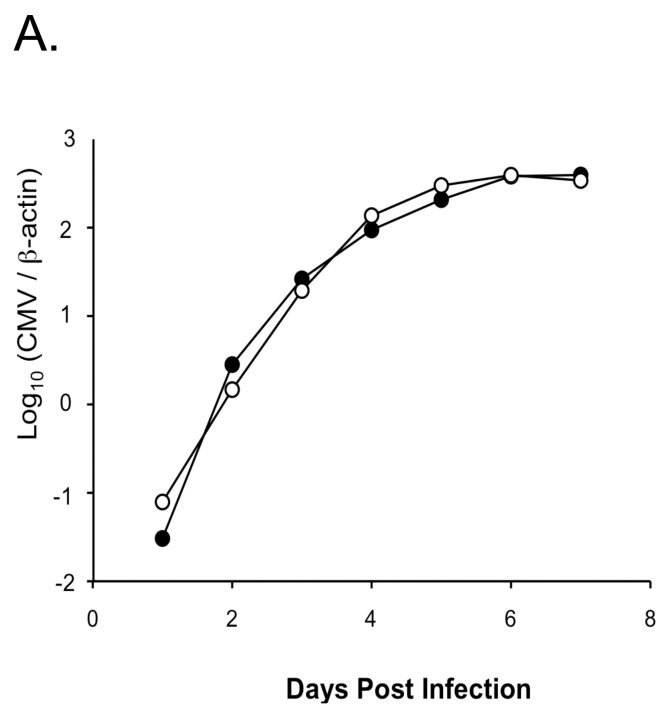

B.

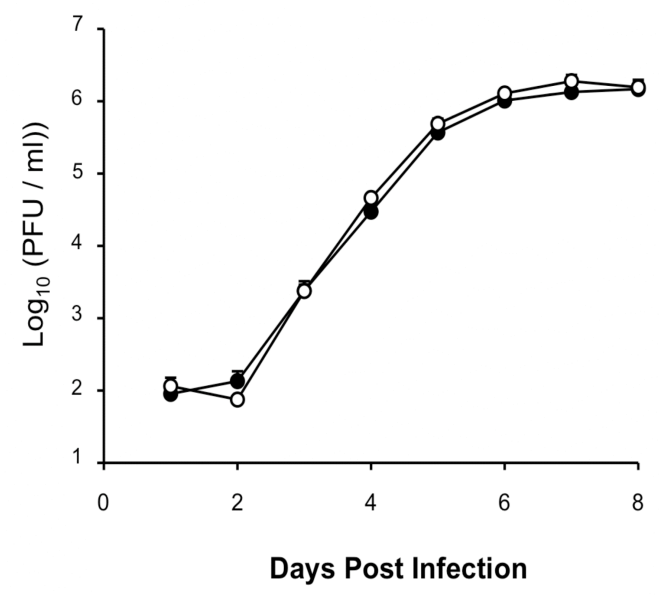


Figure 4. Quantification of NK IFN- $\gamma$ in MCMV-infected MA/My.L- $H 2^{b}$ and C57L.M-H2 ${ }^{k}$ congenic strains. A. Spleen leukocytes of uninfected (no fill) and $39 \mathrm{~h}$ (gray fill) or $90 \mathrm{~h}$ (black fill) MCMV-infected mice (strains designated) were compared. B. Gated CD3- NK1.1+ IFN- $\gamma+$ spleen cells from uninfected (no fill) and $39 \mathrm{~h}$ (gray fill) or $90 \mathrm{~h}$ (black fill) MCMV-infected mice are also shown. Shown are average values (2-7 mice / group) compiled from 3 independent experiments. Error bars indicate standard deviations. 

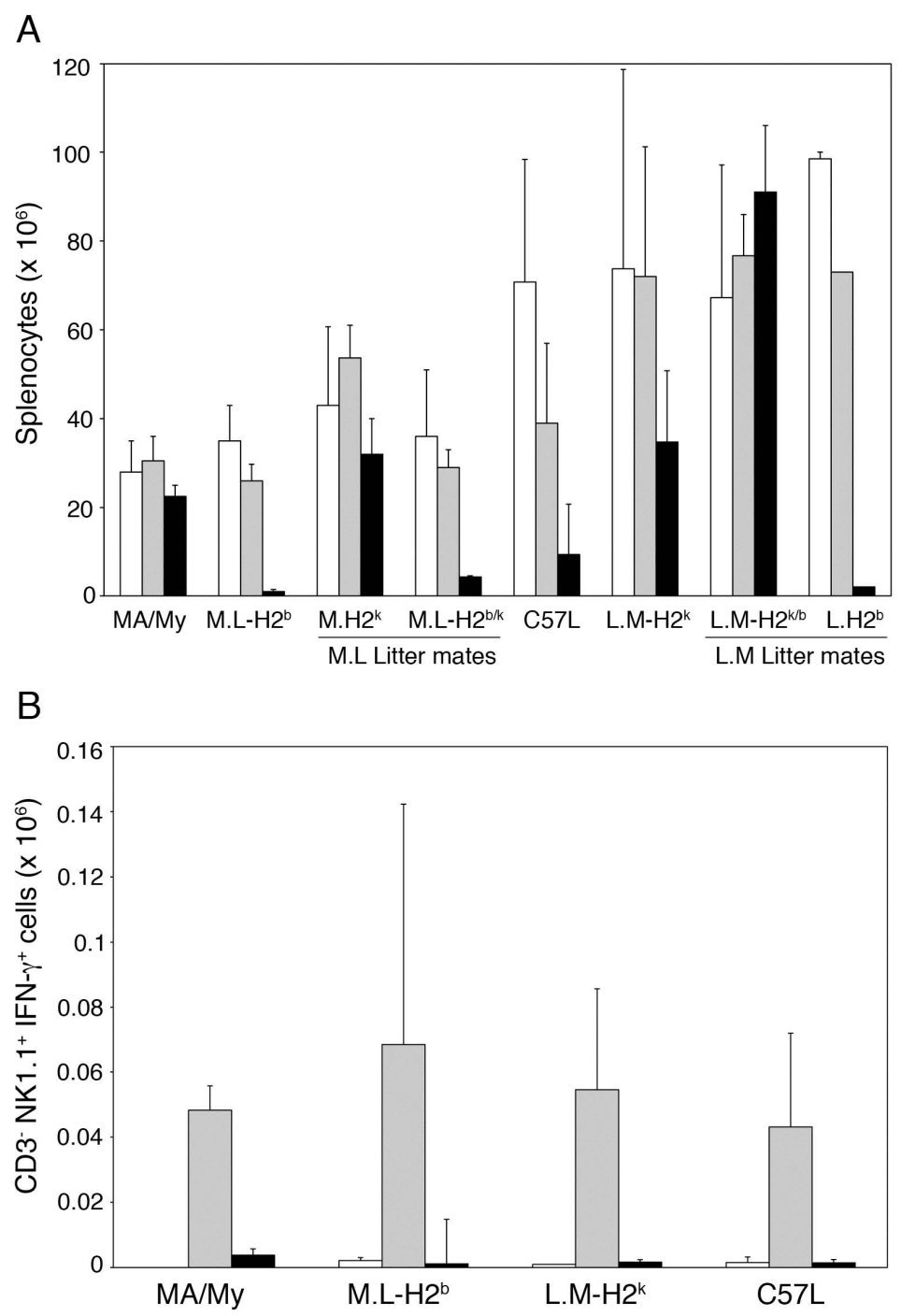
with previous findings $(61,82,83)$, NK cell numbers drop similarly through the first $39 \mathrm{~h}$ after infection in resistant and susceptible strains (not depicted). Moreover, similar numbers of spleen NK cells were producing IFN- $\gamma$ with maximal induction in strains studied by the same time point (Fig. 4B). Notably, NK cells did not produce IFN- $\gamma$ after injection of heat- or UV-inactivated MCMV into the $\mathrm{H}-2^{\mathrm{k}}$ or $\mathrm{H}-2^{\mathrm{b}}$ strains under study (not depicted). After $90 \mathrm{~h}$, spleen NK cell IFN- $\gamma$ levels were diminished considerably in resistant and susceptible mice and did not correlate with MCMV control traits. Thus, independent of H-2-linked genes, NK cells from both resistant and susceptible strains are equally capable of producing IFN- $\gamma$ during MCMV infection.

Role of $\mathbf{H}^{2} \mathbf{2}^{\mathrm{k}}$ class $\mathbf{I}$ expression in MCMV infection. H-2-linked control in innate MCMV immunity suggested that MHC class I molecules might have a role in NK cell control. As regulation of $\mathrm{K}^{\mathrm{k}}$ and $\mathrm{D}^{\mathrm{k}}$ class I proteins by MCMV has not been previously characterized, we also examined their expression on L929 $\left(\mathrm{H}-2^{\mathrm{k}}\right)$ cells and primary $(\mathrm{C} 57 \mathrm{~L} \times \mathrm{MA} / \mathrm{My}) \mathrm{F}_{1} \mathrm{MEFs}$ shortly after virus infection. We utilized a reporter MCMV virus (MCMV- $\Delta$ m157/EGFP [(61)]) to directly visualize infected cells by flow cytometry. Although more virus is required to infect L929 $\left(\mathrm{H}-2^{\mathrm{k}}\right)$ than NIH $3 \mathrm{~T} 3$ cells, flow cytometric analysis revealed that $24 \%$ of $\mathrm{L} 929$ cells $(\mathrm{MOI}=10)$ were $\mathrm{GFP}^{+}$ MCMV-infected cells by $24 \mathrm{~h}$ after infection (not shown). Under these conditions, $\mathrm{K}^{\mathrm{k}}$ and $\mathrm{D}^{\mathrm{k}}$ proteins on L929 cells were significantly decreased only on infected $\left(\mathrm{GFP}^{+}\right)$cells (Fig. $5 \mathrm{~A})$. However, $\mathrm{K}^{\mathrm{k}}$ ( $\sim 95 \%$ decrease) appeared to be more efficiently downregulated than $\mathrm{D}^{\mathrm{k}}$ ( $\sim 50 \%$ decrease) by measuring mean fluorescence intensity (MFI) differences of MHC-I staining of infected and uninfected cells. Similar decreases in class I display were observed when L929 cells were infected with the wild-type K181 strain (not depicted). 
Figure 5. MCMV downregulation of $H-2^{\mathrm{k}}$ and $\mathrm{H}^{\mathrm{b}}{ }^{\mathrm{b}}$ class I proteins on $\mathrm{L929}$ cells and primary (C57L $x$ MA/My)F 1 MEFs. A. Shown is a representative dot plot of $\mathrm{H}-2^{\mathrm{k}}$ class I protein levels on L929 cells by $24 \mathrm{~h}$ after infection with a MCMV- $\Delta \mathrm{m} 157$ reporter virus $(\mathrm{MOI}=10) . \quad$ B. Histograms of $\mathrm{MHC}$ class I protein levels on $(\mathrm{C} 57 \mathrm{~L} \times \mathrm{MA} / \mathrm{My}) \mathrm{F}_{1}$ MEFs (broken line), IFN- $\gamma$-induced (20 U, 24 h) (C57L x MA/My)F 1 MEFs (thin line), and IFN- $\gamma$-induced (C57L x MA/My)F 1 MEFs (bold line) infected with GFP-expressing MCMV $(\mathrm{MOI}=4)$ assessed by use of flow cytometry at $12 \mathrm{~h}$ postinfection are shown. C. Left, $\mathrm{K}^{\mathrm{k}}$ and CD71 cell surface stainings were plotted for IFN- $\gamma$-induced (C57L $\mathrm{x}$ MA/My)F 1 MEFs infected with wild-type K181 (MOI = 4). Right, shown are histograms of CD71 surface staining on gated $\mathrm{K}^{\mathrm{k}}$ high (thin line) and $\mathrm{K}^{\mathrm{k}}$ low (broken line) from the left plot. Control Ig staining (thin dotted line) is also shown. 
A.

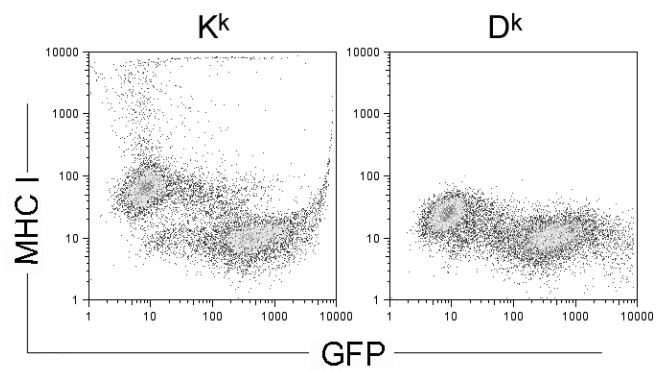

B.
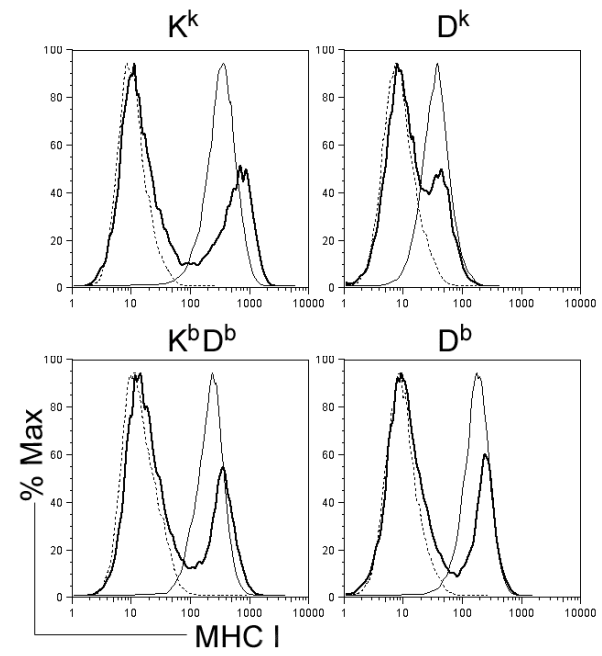

C.

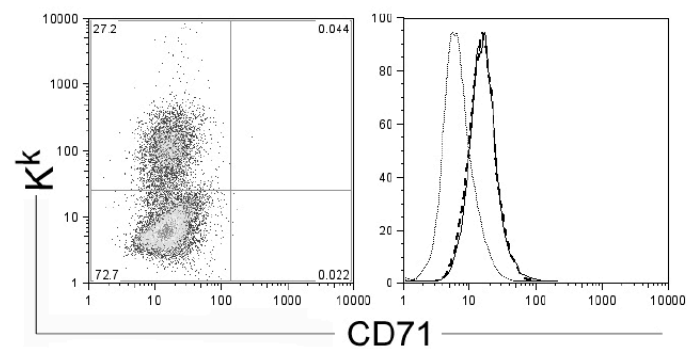


Fine differences in downregulation of $\mathrm{K}^{\mathrm{k}}$ or $\mathrm{D}^{\mathrm{k}}$ proteins on MCMV-infected L929 prompted us to further investigate potential gene- or allele-specific viral regulation of MHC class I expression. We measured class I expression on primary $(\mathrm{C} 57 \mathrm{~L} \times \mathrm{MA} / \mathrm{My}) \mathrm{F}_{1}$ MEFs as an independent means to establish that the diminishment of class I proteins of either haplotype is a general feature of MCMV infection. Due to low constitutive class I levels on the MEFs, IFN- $\gamma$ induction was utilized to boost expression before MCMV infection. By comparing the MFI of MHC-I staining on gated GFP+ and GFP- cells, we found that MCMV downregulated $\mathrm{K}^{\mathrm{k}}, \mathrm{D}^{\mathrm{k}}$, and $\mathrm{H}-2^{\mathrm{b}}$ class I molecules by $\sim 90 \%$ on $\mathrm{F}_{1}$ MEFs (Fig. 5B and data not shown). MCMV control of class I expression is specific, since CD71, a common surface protein, was not affected (Fig. 5C). We obtained similar results using Smith strain MCMV (data not shown). $\mathrm{H}-2^{\mathrm{b}}$ and $\mathrm{H}-2^{\mathrm{k}}$ class I proteins are therefore efficiently and specifically decreased by MCMV on cells expressing alleles of either haplotype.

Because type I interferons are indispensable in innate immunity and MCMV resistance, we also studied class I downregulation by MCMV on IFN- $\beta$-stimulated $\mathrm{F}_{1}$ MEFs. Though IFN- $\beta$ directly affected the percentage of cells infected in a dose-dependent manner, presumably through direct inhibition of viral gene expression (100), MCMV again efficiently decreased $\mathrm{H}-2^{\mathrm{k}}$ and $\mathrm{H}-2^{\mathrm{b}}$ class I proteins on $\mathrm{F}_{1}$ MEFs (Fig. 6A). Additionally, though uninfected $F_{1}$ MEFs have similar levels of $\mathrm{K}^{\mathrm{k}}$ and $\mathrm{D}^{\mathrm{k}}$ display, the amount of $\mathrm{D}^{\mathrm{k}}$ class I proteins was consistently less than half that of $\mathrm{K}^{\mathrm{k}}$ proteins on infected cells. Similar results were obtained over a large range of IFN- $\beta$ doses (Fig. 6B). Furthermore, $\mathrm{D}^{\mathrm{k}}$ MFI decreased sharply, whereas $\mathrm{K}^{\mathrm{k}}$ MFI levels remained fairly constant throughout the study, indicating that MCMV infection under certain conditions may selectively 
Figure 6. Efficient class $I D^{k}$ protein downregulation in IFN- $\beta$-induced primary L/MF 1 MEFs. A. Histograms of class I proteins on L/MF 1 MEFs (broken line), IFN- $\beta$ induced (50-1,000 Units, $30 \mathrm{~h}$ ) L/MF 1 MEFs (thin line) and IFN- $\beta$-induced and MCMVinfected $(\mathrm{MOI}=4) \mathrm{L} / \mathrm{MF}_{1} \mathrm{MEFs}$ (bold line) are shown. B. IFN- $\beta$-treated L/MF $1 \mathrm{MEFs}$ were infected with MCMV-EGFP as in $\mathrm{A} . \mathrm{K}^{\mathrm{k}}$ and $\mathrm{D}^{\mathrm{k}}$ protein levels are compared on gated GFP+ MCMV-infected cells at $12 \mathrm{~h}$ post-infection. cntrl, uninfected control. 
A.
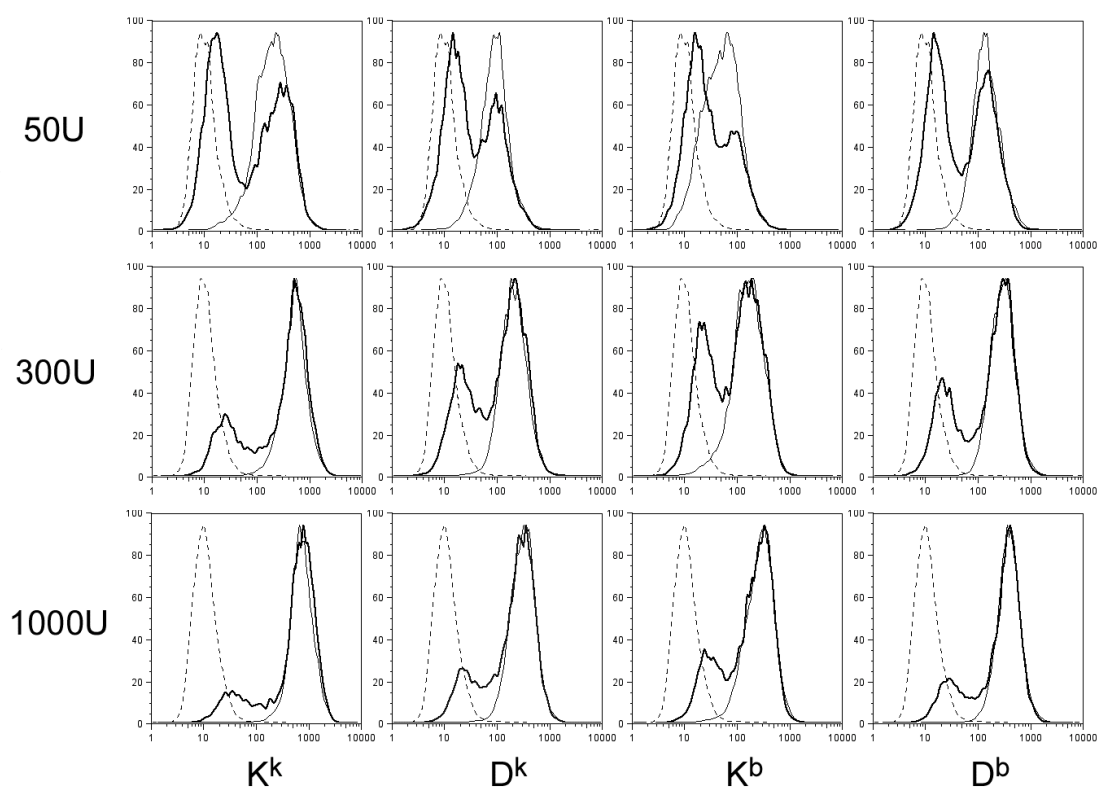

B.

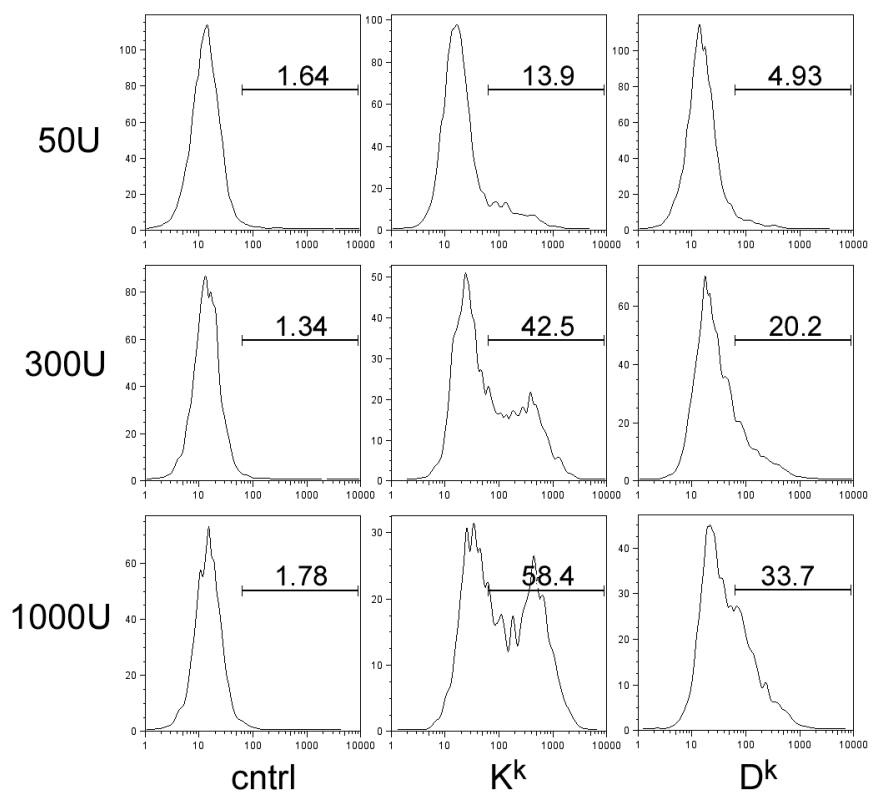


regulate MHC class I proteins in a gene-specific manner. 


\section{Discussion}

An $\mathrm{H}-2^{\mathrm{k}}$ association with host survival following MCMV infection was long ago recognized, though a mechanistic understanding is still elusive. We show that dominant innate virus resistance was converted to profound susceptibility in MA/My.L- $H 2^{b}$ congenic mice, since infectious MCMV freely replicates to very high levels in M.L-H2 ${ }^{b}$ spleens within days after infection. Thus, MA/My H-2 ${ }^{\mathrm{k}}$-linked loci are indeed necessary components of innate viral immunity. This difference cannot be explained by H-2controlled differences in infectivity or replication, as we observe similar MCMV growth kinetics in MEFs derived from embryos from resistant or susceptible strains. Another intriguing and unexpected finding in the current report is seen in Fig. 1, since H- $2^{\mathrm{k}}$-linked resistance is fully competent in $\mathrm{H}-2$ heterozygous or homozygous mice on the C57L background, whereas a single $\mathrm{H}-2^{\mathrm{k}}$ haplotype in $\mathrm{H}-2$ heterozygous mice on the MA/My background did not result in full resistance. An additional polymorphic genetic factor(s) in $\mathrm{C} 57 \mathrm{~L}$ therefore further limits MCMV spread and replication when $\mathrm{H}-2^{\mathrm{k}}$ is available, perhaps through augmentation of NK sensing, but this factor by itself is not sufficient in innate virus resistance because C57L NK cells fail to thwart a comparable MCMV infection. We further show that proximal $\mathrm{H}-2 \mathrm{~K}^{\mathrm{k}}$ class I and class II genes do not explain the observed genetic variation, since our novel H-2 recombinant strain is fully competent to limit virus replication in the spleen at early times after infection. Thus, a genetic locus distal to the MHC class II gene region and overlapping with $\mathrm{D}^{\mathrm{k}}$ class Ia and more-distal nonclassical class Ib genes should contain the responsible gene(s) required in $\mathrm{H}-2^{\mathrm{k}}$-linked innate MCMV resistance through NK cells. Because multiple H-2 loci were previously implicated in the control of MCMV-induced mortality (51), we were also prompted to 
study mortality in the novel strains. Recent preliminary studies with sublethal or lethal doses of MCMV have so far indicated similar mortality rates for our $\mathrm{H}-2^{\mathrm{k}}$ recombinant strain and littermate control tested as shown in Fig. 2E (X. Xie and M. G. Brown, unpublished data). Thus, $\mathrm{H}-2 \mathrm{~K}^{\mathrm{k}} / \mathrm{I}-\mathrm{A}$ subregion seems not important for either spleen virus control or survival in this genetic system.

To further examine the role of NK cells in innate $\mathrm{H}-2^{\mathrm{k}}$ control, IFN- $\gamma$ was quantified for comparison in $\mathrm{H}-2^{\mathrm{k}}$ and $\mathrm{H}-2^{\mathrm{b}}$ strains over a $3.5-\mathrm{d}$ time course following infection. Deficient NK control in C57L and M.L-H2 ${ }^{b}$ is not due to an intrinsic defect in virus sensing, since active viral replication alerted their NK cells to enhance IFN- $\gamma$ production to levels similar to those for NK cells in MA/My or L.M- $H 2^{k}$ shortly after infection. Similar diminished responses in all strains were also noted by later time points and did not directly correlate with innate virus immunity. Whether this response is due to virus sensing through innate receptors (i.e., TLR3 and TLR9) leading to enhanced cytokine stimulation of NK function $(42,101)$ or due to direct NK recognition of virus-infected targets is an important question. Recent reports indicate that NK IFN- $\gamma$ release is severely impaired in mice without TLR9 or MyD88 and that dendritic cell-derived IL-18 is also important $(102,103)$. Here we show similar numbers of NK cells producing IFN- $\gamma$ and comparable induction levels after MCMV infection; thus, these data suggest that an $\mathrm{MCMV} \rightarrow \mathrm{TLR} 9 \rightarrow \mathrm{MyD} 88 \rightarrow$ IL-18 axis in dendritic cells and an IL-18 $\rightarrow$ IFN- $\gamma$ axis in NK cells during the nonspecific phase of NK activation are fully competent in the strains tested in Fig. 4. Nevertheless, $\mathrm{H}-2^{\mathrm{b}}$-linked gene expression fails to support NK control of viral replication on the C57L or MA/My genetic backgrounds. 
While both MCMV and HCMV convergently acquired key gene products to manipulate MHC class I display (37), genetic variance in NK control may not be altogether surprising, since these cells readily respond to MHC-compatible targets with deficient class I expression. Because Wagner et al. noted before that class I $\mathrm{K}^{\mathrm{b}}$ molecules are somewhat refractory to MCMV control (91), we reasoned that class I gene- or allelespecific regulation by MCMV might explain $\mathrm{H}-2^{\mathrm{k}}$ protection, at least in part. However, minor variations in class I display might best be observed only under certain circumstances, since $\mathrm{K}^{\mathrm{k}}$ (decreased by $\sim 95 \%$ ) and $\mathrm{D}^{\mathrm{k}}$ (decreased by $\sim 50 \%$ ) proteins were differently downregulated on MCMV-infected L929 cells. $\mathrm{D}^{\mathrm{k}}$ display, on the other hand, was affected more than $\mathrm{K}^{\mathrm{k}}$ by MCMV in IFN- $\beta$-induced $\mathrm{F}_{1}$ MEFs, since a substantially greater number of infected $\left(\mathrm{GFP}^{+}\right)$cells continued to display $\mathrm{K}^{\mathrm{k}}$ proteins even after $\mathrm{D}^{\mathrm{k}}$ had seemingly been lost from the cell surface. IFN- $\beta$ may conceivably have an impact on $\mathrm{K}^{\mathrm{k}}$ induction greater than that of other class I proteins. Alternately, MCMV proteins known to bind and downregulate class I display may more avidly bind $\mathrm{D}^{\mathrm{k}}$ when class I synthesis is strongly induced by type I interferons. Taken together, our findings suggest that only very minimal levels of $\mathrm{D}^{\mathrm{k}}$ ligands that could potentially stimulate Ly49P receptors on NK cells in the course of MCMV infection should be available on infected host cells and that even fewer might be expected to hold a particular relevant virus peptide, as suggested recently (60).

Alternately, MCMV might stabilize some cell surface class I displays, including that of $\mathrm{D}^{\mathrm{k}}$ proteins, while at the same time interfering with cytotoxic T-lymphocyte recognition. MCMV gp34 is notable in this regard, since it binds endoplasmic reticulum-resident class I proteins destined for expression at the cell surface. Interestingly, $\mathrm{D}^{\mathrm{k}}$ but not $\mathrm{K}^{\mathrm{k}}$ surface 
expression is selectively affected by gp34 in infected L929 cells (Xie and Brown, unpublished data). An intriguing possibility is that $\mathrm{Ly}_{49 \mathrm{P}^{+}} \mathrm{NK}$ cells might specifically recognize gp34-associated $\mathrm{D}^{\mathrm{k}}$ proteins. However, innate $\mathrm{H}-2^{\mathrm{k}}$ resistance is likely more complex, since significant protection has been observed even on the BALB/c background, where Ly49P receptors are not expressed (55). Finally, it is possible that NK recognition and control become fully competent only in mice that express $\mathrm{H}-2^{\mathrm{k}}$ class I ligands during development. While NK cells in C57L and M.L-H2 $2^{b}$ mice do recognize viral intrusion and IFN- $\gamma$ expression is stimulated shortly afterward, these cells could be hyporesponsive (28) or unlicensed (27) in terms of their capacity to attack infected cells. NK receptors in $\mathrm{H}-2^{\mathrm{k}}$ mice, on the other hand, might recognize viral signatures more efficiently than those in other $\mathrm{H}-2$ haplotypes, in addition to undergoing potential stimulation through Ly49P/D $\mathrm{D}^{\mathrm{k}}$ interactions during NK encounters with MCMV-infected cells. While inhibitory $\mathrm{KIR} / \mathrm{MHC}$ interactions also insure functional competency in human NK cells (25) and can regulate antiviral immune responses in infected individuals $(104,105)$, this model should enhance our understanding of the role of NK cells in the early detection and control of viral pathogens. 


\section{Chapter III}

MHC class I $D^{k}$ locus and Ly49G2+ NK cells confer $H-2^{k}$ resistance to murine cytomegalovirus $^{2}$

\footnotetext{
${ }^{2}$ Journal of Immunology (2009) Volume 182 / No. 11, June 1: Amended here with permission from American Association of Immunologists, Copyright (c) 2009.
} 


\begin{abstract}
Essential NK cell-mediated MCMV resistance is under histocompatibility- $2^{\mathrm{k}}\left(\mathrm{H}-2^{\mathrm{k}}\right)$ control in MA/My mice. We generated a panel of intra-H-2 ${ }^{\mathrm{k}}$ recombinant strains from congenic C57L.M-H2 $2^{k / b}$ (MCMV-resistant, $C m v^{r}$ ) mice for precise genetic mapping of the critical interval. Recombination breakpoint sites were precisely mapped and MCMV resistance/susceptibility traits were determined for each of the new lines to identify the MHC locus. Strains C57L.M-H2 $2^{k}(\mathrm{R} 7)\left(\mathrm{Cm}^{r}\right)$ and C57L.M-H2 ${ }^{k}(\mathrm{R} 2)$ (MCMVsusceptible, $C m v^{s}$ ) are especially informative; we found that allelic variation in a 0.3 megabase $(\mathrm{Mb})$ interval in the class I D locus confers substantial difference in MCMV control phenotypes. When NK cell subsets responding to MCMV were examined, we found that Ly49G2+ NK cells rapidly expand and selectively acquire an enhanced capacity for cytolytic functions only in C57L.M-H2 ${ }^{k}(\mathrm{R} 7)$. We further show that depletion of Ly49G2+ NK cells before infection abrogated MCMV resistance in C57L.M-H2 ${ }^{k}(\mathrm{R} 7)$. We conclude that the MHC class I D locus prompts expansion and activation of Ly49G2+ NK cells that are needed in $\mathrm{H}-2^{\mathrm{k}}$ MCMV resistance.
\end{abstract}




\section{Introduction}

During virus infection, NK cells are needed in the body to provide early immune defense. Their activity is regulated by MHC class I-binding cell surface inhibitory and stimulatory receptors that include mouse Ly49, human $\mathrm{KIR}$ and NKG2/CD94 receptors $(8,12,106)$. NK cell-mediated virus control is subject to genetic factors that can influence viral replication and host mortality (107). For instance, the Ly49H activation receptor displayed on the surface of NK cells in C57BL/6 mice binds MCMV m157 ligands at the surface of infected cells to impart MCMV resistance $(15,16)$. In NZW, MA/My and PWK strains, MCMV resistance also requires NK-mediated virus control, but Ly49Hindependent defense mechanisms are key $(55-57,60,61)$. It remains unclear what genetic factors are at work and how such factors mediate virus resistance through NK cells.

Attempts have been made to identify genetic factors which underlie MCMV resistance/susceptibility traits in offspring of genetic crosses between MA/My $\left(\mathrm{Cmv}^{r}\right)$ and strains which display greater MCMV susceptibility $\left(\mathrm{Cmv}^{\mathrm{s}}\right)$. So far, major MCMV control loci have been mapped to the $\mathrm{MHC}$ and $\mathrm{NK}$ gene complex (NKC) on chromosomes 17 and 6 , respectively $(60,61)$. We have further shown that MHC polymorphism is responsible for genetic variation in NK-mediated virus resistance in C57L.M-H2 $2^{k}$ and MA/My.L- $H 2^{b}$ congenic mice $(61,108)$.

To pin down an MCMV control $\left(\mathrm{Cmv}^{\mathrm{r}}\right)$ locus within the $\mathrm{MHC}$, we generated a genetic mapping panel of $13 \mathrm{H}-2^{\mathrm{k}}$ recombinant congenic lines on the $\mathrm{C} 57 \mathrm{~L}\left(\mathrm{Cmv}^{\mathrm{s}}\right)$ genetic background. Recombination breakpoints were definitively mapped and MCMV 
resistance/susceptibility traits determined for each of the new lines so that the MHC Cmv ${ }^{r}$ locus could be identified. Interestingly, virus infection clearly distinguished MCMV control in two of the novel lines, C57L.M-H2 $2^{k}(\mathrm{R} 2)\left(\mathrm{Cm} v^{s}\right)$ and C57L.M-H2 ${ }^{k}(\mathrm{R} 7)\left(\mathrm{Cm} v^{r}\right)$ which only differ by about $0.3-\mathrm{Mb}$ DNA within the MHC. We further examined the role of $\mathrm{NK}$ subsets in $\mathrm{MHC} \mathrm{H}-2^{\mathrm{k}}$ resistance to MCMV infection. We propose that the novel recombinant strains represent a powerful new model for investigating MHC regulation of NK-mediated virus immunity. 


\section{Results}

H-2 ${ }^{\mathrm{k}}$ MCMV resistance mapped to the class I D subregion. To identify a critical MCMV resistance interval between SSLP markers D17Mit16 and D17Mit10 (108), we generated a mapping panel of recombinant congenic strains (see Materials and Methods) on C57L $\left(C m v^{s}\right)$ and MA/My $\left(C m v^{r}\right)$ backgrounds. We screened for recombinant animals using a panel of SSLP genetic markers that distinguish MA/My and C57L alleles (Table II and Fig. 7A). In total, seventeen recombinant lines were isolated (Table III); seven lines have been depicted in Figure 7 with recombinant chromosome cross-over intervals in each of the lines mapped. For example, C57L.M- $H 2^{k}(\mathrm{R} 2)$ (hereafter referred to as R2) mice retained MA/My-derived alleles in the D17Mit16-17Uva12 interval, and only C57L-derived alleles for 17Uva01 and markers distal to it (Table III and Fig. 7A). Thus, the R2 crossover was bounded by $17 U v a 12$ and $17 U v a 01$. Likewise, C57L.M-H2 ${ }^{k}(\mathrm{R} 7)$ (R7 hereafter) mice retained MA/My-derived alleles in the D17Mit16-H2D interval and C57L-derived alleles for $17 U v a 03$ and markers distal to it. Thus, the R7 crossover occurred between H-2D and 17Uva03. A similar strategy was used to locate crossovers for each of the recombinant lines; together the lines established a valuable genetic mapping resource.

We next separately backcrossed each new mouse line with C57L to generate heterozygous offspring. About half of the offspring received a recombinant chromosome haplotype, and the other half received a non-recombinant C57L.M-H2 $2^{k}$-derived haplotype. We compared the recombinant offspring and their non-recombinant littermates for MCMV control traits by assessing spleen and liver (not shown) virus genome levels 
Table II. SSLP markers used for genetic mapping.

\begin{tabular}{|c|c|c|c|c|c|}
\hline \multirow[b]{2}{*}{ Marker } & \multirow[b]{2}{*}{ Chr. 17 Locus $^{a}$ (bp) } & \multirow[b]{2}{*}{ Primers (5'-3') } & \multicolumn{3}{|c|}{ Allele Size ${ }^{b}(b p)$} \\
\hline & & & C57BL/6 & MA/My & C57L \\
\hline 17Uva12 & $34547552-34547799$ & $\begin{array}{l}\text { ACCAGCAAGCCCTATGTCAC } \\
\text { TATGTCTACTGGTCAGGTTG }\end{array}$ & 248 & 250 & 245 \\
\hline 17Uva18 & $34707366-34707702$ & $\begin{array}{l}\text { GTTCAGGGATACGGTGCTCC } \\
\text { ССTTCTCTGATAAGACGGTC }\end{array}$ & 337 & ND & ND \\
\hline 17Uva19 & $35099356-35099606$ & $\begin{array}{l}\text { GCGTTGTGACCCCTGGAGGC } \\
\text { GAATGCCTGTCTCAGCACGG }\end{array}$ & 251 & ND & ND \\
\hline 17Uva20 & $35143895-35144160$ & $\begin{array}{l}\text { GGGTGTTGGATGCTCCTGGA } \\
\text { TACTGCCGAACCACTTCTCC }\end{array}$ & 266 & 271 & 266 \\
\hline 17Uva15 & $35341805-35342016$ & $\begin{array}{l}\text { AGACAATGGCTAACAGAGGC } \\
\text { TTCTATACAACCTGCCTGGA }\end{array}$ & 212 & 225 & 208 \\
\hline $17 U v a 01$ & $35375912-35376112$ & $\begin{array}{l}\text { GCAGCACTCTGTCTCTTTCC } \\
\text { ATAGTAAGTCTCTGTCTCTC }\end{array}$ & 198 & 182 & 198 \\
\hline 17Uva16 & $35406718-35406802$ & $\begin{array}{l}\text { CCTCCCATATTGGCTCTTCC } \\
\text { GCAGTTGGACCTTTGACAGA }\end{array}$ & 85 & 126 & 81 \\
\hline 17 Uva17 & $35424300-35424711$ & $\begin{array}{l}\text { AGCGACTGAATATGGGTGAC } \\
\text { GCAGGACTAACTGGATTGTC }\end{array}$ & 412 & 427 & 414 \\
\hline 17Uva03 & $35451303-35451610$ & $\begin{array}{l}\text { TGCATGGGAAATACTCGTCC } \\
\text { GGAGCTGACTCATCTCATTG }\end{array}$ & 308 & 291 & 311 \\
\hline 17 Uva14 & $36458241-36458469$ & $\begin{array}{l}\text { CCAAGGGCACTGTATTCCTG } \\
\text { GACAAGTACCAAGTGCTCCT }\end{array}$ & 229 & 189 & 199 \\
\hline 17Uva06 & $38389926-38390222$ & $\begin{array}{l}\text { AGGTGTTTATCAGCTGTAGG } \\
\text { CAAGCCAACATTCAACATCA }\end{array}$ & 297 & 304 & 294 \\
\hline 17Uva09 & $43168363-43168537$ & $\begin{array}{l}\text { AGCCCTGTCTCAAGTCAACG } \\
\text { TCTGTGCCATTGACGTTAGC }\end{array}$ & 175 & 179 & 155 \\
\hline
\end{tabular}

${ }^{a}$ Chromosome locations for forward primers are based on C57BL/6 genomic sequence (Build 37, Ensembl Release 52). 
${ }^{\mathrm{b}}$ Allele sizes based on electrophoretic mobility in POP7-filled capillaries run on a Genetic Analzyer 3130xl. 17UVA18 and 17UVA19 allele differences are based on electrophoresis in $4.0 \%$ agarose gel (data not shown) but exact sizes are not determined (ND). 
Figure 7. Genetic mapping of $\mathrm{H}-2^{\mathrm{k}}$-linked MCMV resistance in chromosome 17 recombinant congenic strains. A panel of seventeen recombinant congenic mouse lines (Table III) was generated and genotyped with genetic markers (Table II) to pinpoint chromosome 17 crossover sites. A. A chromosome 17 physical map between D17Mit16 and D17Mit10 (based on C57BL/6 genome, Build 37) is shown with a reference scale in megabases $(\mathrm{Mb})$ included below. Also depicted are seven informative recombinant chromosome haplotypes with C57L- (open) or MA/My- (filled) derived intervals based on the genetic analysis of the new mouse lines. B. A refined haplotype map for the critical genetic region based on genotype analysis of the four most informative intra-H-2 recombinant lines. SNP $(\Delta)$ and $\operatorname{SSLP}(\boldsymbol{\Delta})$ genetic marker positions are indicated. 
A.

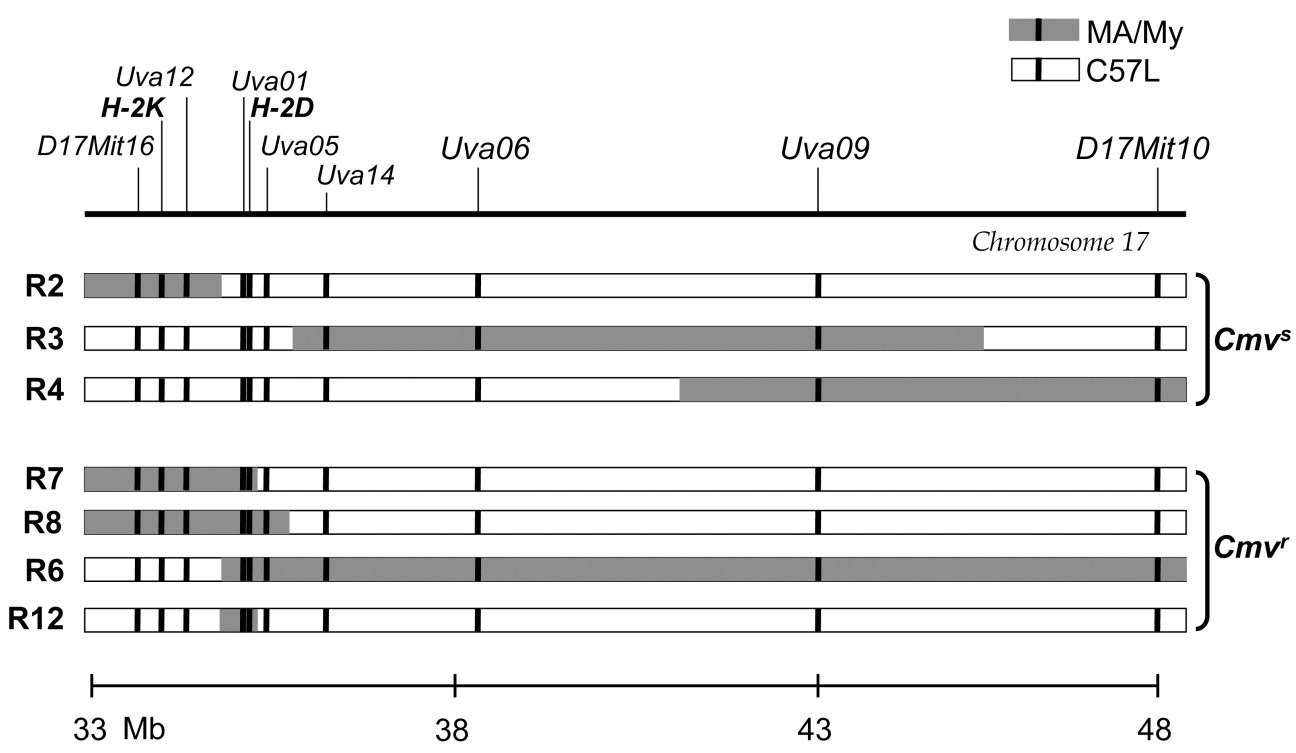

B.
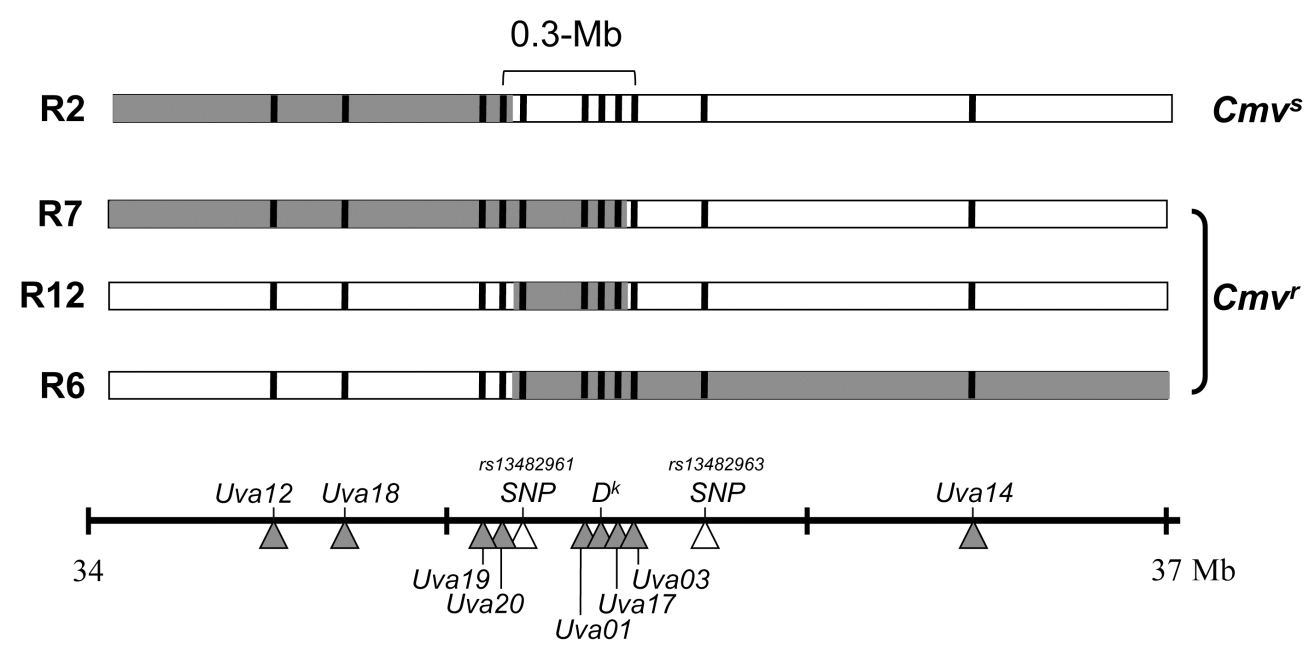
Table III. Genetic analysis of chromosome 17 recombinant lines.

\begin{tabular}{|c|c|c|c|c|c|c|c|c|c|c|c|c|c|c|c|c|c|}
\hline \multirow[t]{3}{*}{ Locus $^{a}$} & \multicolumn{17}{|c|}{ Recombinant lines $^{\mathrm{b}}$} \\
\hline & \multicolumn{13}{|c|}{ C57L.M-H2 ${ }^{k}$} & \multicolumn{4}{|c|}{ MA/My.L-H2 ${ }^{b}$} \\
\hline & R1 & R2 & R3 & R4 & R5 & R6 & R7 & R8 & R9 & R10 & R11 & R12 & R13 & $\begin{array}{c}\text { MR } \\
1\end{array}$ & $\begin{array}{c}\text { MR } \\
2\end{array}$ & $\begin{array}{c}\text { MR } \\
3\end{array}$ & $\begin{array}{c}\text { MR } \\
4\end{array}$ \\
\hline D17Mit16 & $M$ & $\mathrm{M}$ & $\mathrm{L}$ & $\mathrm{L}$ & $\mathrm{L}$ & $\mathrm{L}$ & $M$ & $M$ & $M$ & $M$ & $M$ & $\mathrm{~L}$ & $\mathrm{~L}$ & $\bar{L}$ & $M$ & $M$ & $\bar{L}$ \\
\hline$H-2 K$ & $\mathrm{M}$ & $\mathrm{M}$ & $\mathrm{L}$ & $\mathrm{L}$ & $\mathrm{L}$ & L & $\mathrm{M}$ & $\mathrm{M}$ & $\mathrm{M}$ & $M$ & ND & $\mathrm{L}$ & $\mathrm{L}$ & $\mathrm{L}$ & M & M & L \\
\hline $17 U v a 12$ & $\mathrm{M}$ & $M$ & $\mathrm{~L}$ & $\mathrm{~L}$ & $M$ & L & $M$ & $M$ & $\mathrm{M}$ & M & L & L & L & $\mathrm{L}$ & M & M & $\mathrm{L}$ \\
\hline $17 U v a 01$ & $\mathrm{M}$ & $\mathrm{L}$ & $\mathrm{L}$ & L & $\mathrm{M}$ & $\mathrm{M}$ & $M$ & $M$ & $M$ & $M$ & L & M & $M$ & M & M & $M$ & M \\
\hline$H-2 D$ & $\mathrm{M}$ & $\mathrm{L}$ & $\mathrm{L}$ & $\mathrm{L}$ & $\mathrm{M}$ & $\mathrm{M}$ & $\mathrm{M}$ & $M$ & ND & M & L & M & M & M & M & M & $M$ \\
\hline 17Uva03 & $\mathrm{M}$ & $\mathrm{L}$ & $\mathrm{L}$ & $\mathrm{L}$ & $\mathrm{M}$ & $\mathrm{M}$ & $\mathrm{L}$ & $\mathrm{M}$ & $\mathrm{L}$ & $M$ & L & L & L & M & M & $M$ & $M$ \\
\hline 17Uva06 & $\mathrm{M}$ & L & $M$ & L & $\mathrm{M}$ & $\mathrm{M}$ & $\mathrm{L}$ & $\mathrm{L}$ & $\mathrm{L}$ & L & $\mathrm{L}$ & L & L & M & M & L & $M$ \\
\hline 17Uva09 & $\mathrm{M}$ & $\mathrm{L}$ & $M$ & $M$ & $M$ & $\mathrm{M}$ & $\mathrm{L}$ & $\mathrm{L}$ & $\mathrm{L}$ & L & $\mathrm{L}$ & $\mathrm{L}$ & $\mathrm{L}$ & $M$ & M & $\mathrm{L}$ & $M$ \\
\hline D17Mit10 & $\mathrm{L}$ & L & $\mathrm{L}$ & $M$ & $M$ & $\mathrm{M}$ & $\mathrm{L}$ & $\mathrm{L}$ & $\mathrm{L}$ & L & L & L & $\mathrm{L}$ & $M$ & L & $\mathrm{L}$ & $M$ \\
\hline
\end{tabular}

${ }^{\text {a }}$ Chromosome 17 locus markers (see Table II) used to determine MA/My (M) or C57L (L) alleles for the recombinant chromosome in each line are shown. Some alleles are not determined (ND).

${ }^{\mathrm{b}}$ Recombinant lines were generated on C57L (denoted as R) or MA/My (denoted as MR) backgrounds. 
Figure 8. MHC H-2 ${ }^{\mathrm{k}}$ MCMV resistance maps to the class I D locus. The recombinant congenic mouse lines in Table II (heterozygous for chromosome 17 haplotypes) were backcrossed to C57L. Offspring with a recombinant chromosome and several littermate controls (denoted LM for the indicated line) without a recombinant chromosome were infected with MCMV. After 90 h, spleen and liver (not shown) MCMV genome levels were determined. Interquartile range and the median values are shown, with whisker extensions to extreme values. Open and grey boxes indicate infections with 3.1 .05 or 8.3.07 SGV stocks, respectively. The numbers of mice used in each group are indicated at the bottom. The box plots were created with Minitab 15. Data are representative of at least two independent experiments. 


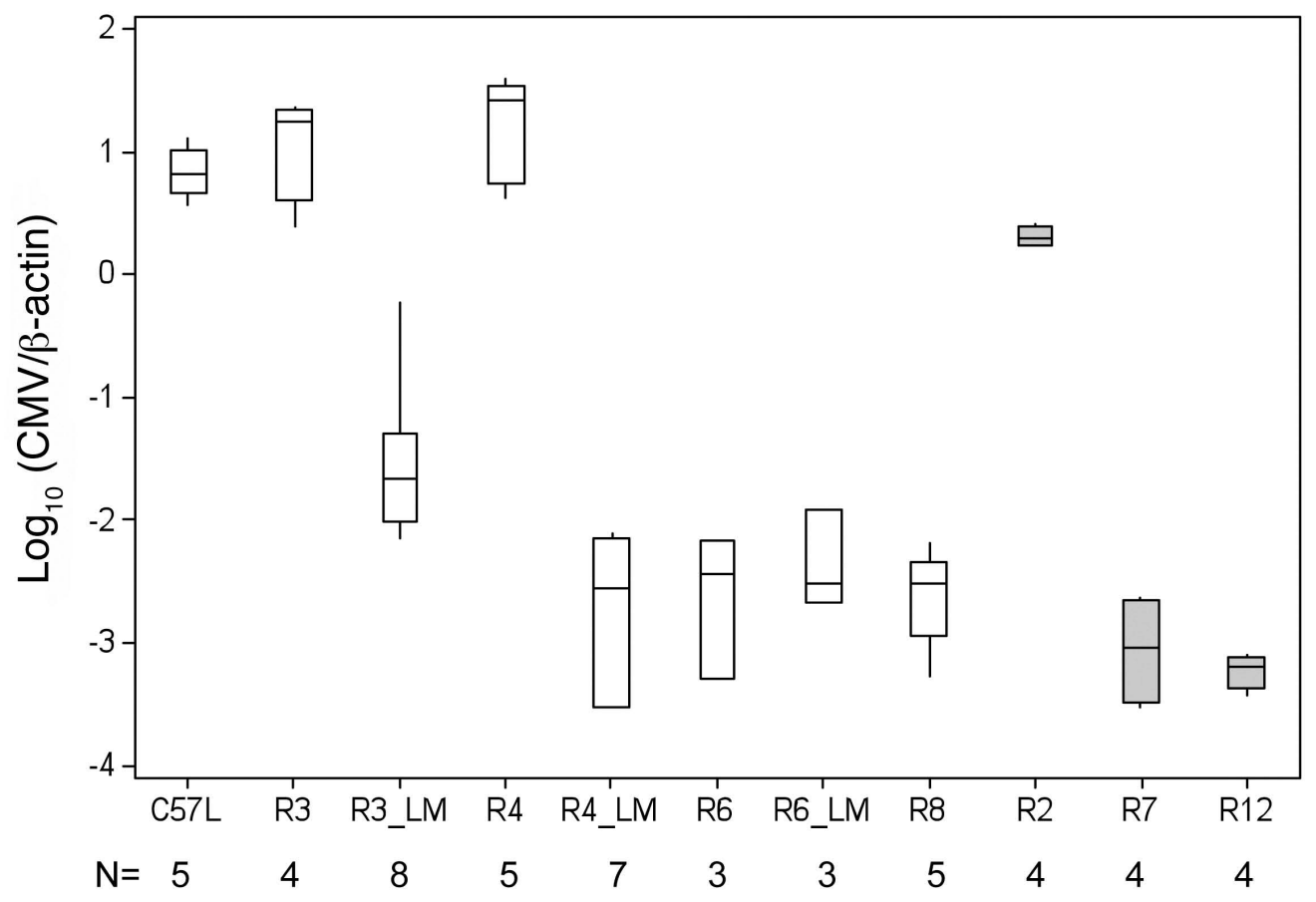


3.5 days after infection. As shown in Figure 8, only low MCMV titers were observed in R6, R7, R8 and R12 spleens, similar to R6-LM littermate control spleen. Thus, an MCMV-resistance $\left(\mathrm{Cmv}^{r}\right)$ locus should reside in the region of overlap. In contrast, MCMV was substantially higher in R2, R3 and R4 spleens than in R3-LM and R4-LM littermates, indicating that their retained MA/My-derived haplotypes are insufficient in MCMV-resistance. Altogether, the data in Figure 7 pointed toward a critical interval bounded by R2 and R7 cross-overs. An $\mathrm{H}-2^{\mathrm{k}} C m v^{r}$ locus was first placed in the H-2 S-D region flanked by markers $17 U v a 12$ and $17 U v a 03$.

To refine the locus, R2, R7 and R12 were genotyped with additional allele-specific markers located near the H-2 class I D gene (Table IV and Fig. 7B). By this strategy, the R2 and R7 cross-overs were mapped between 17Uva20 and SNP rs13482961 and 17 val7 and $17 U v a 03$, respectively. Thus, an $\mathrm{H}-2^{\mathrm{k}} C m v^{r}$ locus must be flanked by markers $17 U v a 20$ and $17 U v a 03$, an $\sim 0.3-\mathrm{Mb}$ interval that spans 30 genes including the class I D gene (Fig. 9). In accord with this, R12, which arose spontaneously from the R7 line, also displays the resistance phenotype (Fig. 8).

NK cells are required in $\mathrm{H}_{-2}^{\mathrm{k}}$ MCMV resistance. To assess their role in resistance, we depleted NK cells from R7 $\left(\mathrm{Cmv}^{\mathrm{r}}\right)$ mice before $\mathrm{MCMV}$ infection. Our previous work had shown that the anti-NK1.1 mAb PK136 does not efficiently deplete NK cells from mice on the C57L (NK1.1 ${ }^{\mathrm{c} 571}$ ) background (61). Consequently, when C57L.M-H2 $2^{k / b}$ $N K C^{\text {het }}$ mice with an NK1.1 ${ }^{\text {c571 }}$ allele were given PK136 treatment before MCMV infection, only a partial loss of splenic MCMV resistance was observed (61). Residual MCMV control was likely due to ineffective depletion of NK cells from 
Table IV. Refined genetic mapping of informative $\mathrm{H}-2$ recombinant lines.

\begin{tabular}{|c|c|c|c|c|}
\hline \multirow[t]{2}{*}{ Locus $^{a}$} & \multicolumn{4}{|c|}{ C57L.M-H2 ${ }^{k}$ recombinant lines } \\
\hline & R2 & $\mathbf{R} 12$ & R7 & $\mathbf{R 6}$ \\
\hline 17Uva12 & $\mathrm{M}$ & $\mathrm{L}$ & $\mathrm{M}$ & $\mathrm{L}$ \\
\hline 17Uva18 & M & L & $\mathrm{M}$ & $\mathrm{L}$ \\
\hline 17Uva19 & M & L & $\mathrm{M}$ & $\mathrm{L}$ \\
\hline $17 U v a 20$ & M & L & M & $\mathrm{L}$ \\
\hline$r s 13482961^{b}$ & $\mathrm{~L}$ & M & M & $\mathrm{M}$ \\
\hline 17Uva15 & $\mathrm{L}$ & M & M & M \\
\hline 17Uva01 & $\mathrm{L}$ & M & $M$ & $M$ \\
\hline$H-2 D$ & $\mathrm{~L}$ & M & M & M \\
\hline 17Uva16 & $\mathrm{L}$ & M & $\mathrm{M}$ & $\mathrm{M}$ \\
\hline 17Uva17 & $\mathrm{L}$ & $\mathrm{M}$ & M & M \\
\hline 17Uva03 & $\mathrm{L}$ & L & $\mathrm{L}$ & M \\
\hline$r s 13482963^{b}$ & $L$ & L & $\mathrm{L}$ & $\mathrm{M}$ \\
\hline $17 U v a 14$ & $\mathrm{~L}$ & L & $\mathrm{L}$ & $\mathrm{M}$ \\
\hline 17Uva06 & $\mathrm{L}$ & L & $\mathrm{L}$ & $\mathrm{M}$ \\
\hline
\end{tabular}

${ }^{\mathrm{a}} \mathrm{H}-2$ locus markers (see Table I) used to determine MA/My (M) or C57L (L) alleles for the critical locus are shown. 
Figure 9. List of potential candidate genes in the mapped H-2D region of chromosome 17. The black bars to the left of the map are segments of the H-2D interval with scale indicating positions in megabases $(\mathrm{Mb})$. Mouse gene names and symbols as well as the corresponding human gene symbols from syntenic human chromosome $6 \mathrm{p} 21.3$ are listed on the right side. The H-2D region was annotated according to the Ensembl Genome database (http://www.ensembl.org). 


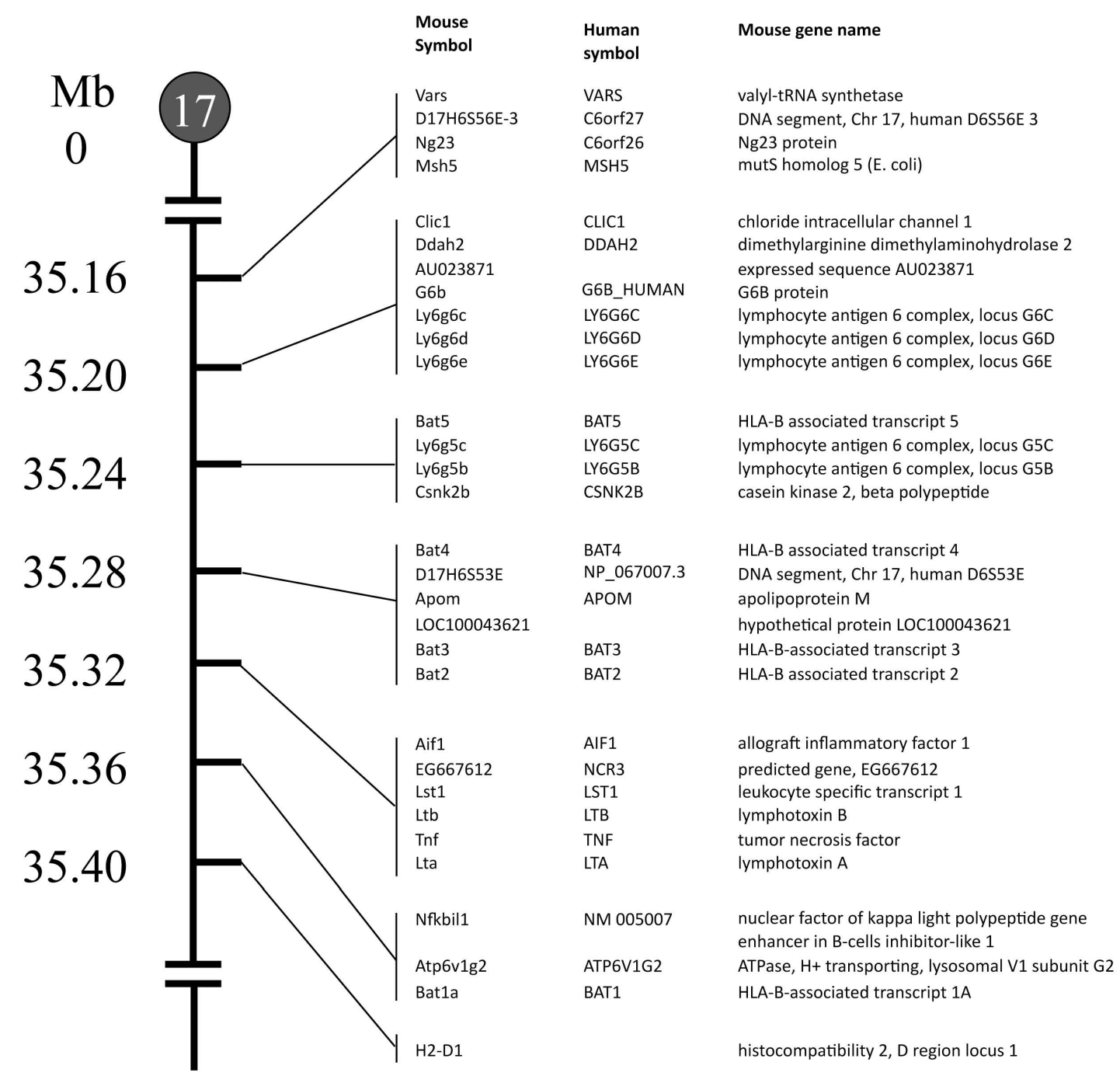


NK1.1 ${ }^{\text {c571 }}$ mice (data not shown).

To achieve efficient NK depletion, the $\mathrm{NKC}^{\text {mamy }}$ haplotype was crossed onto the $\mathrm{R7}$ genetic background and homozygous R7-NKC ${ }^{\text {mamy }}$ animals were generated. As shown in Figure 10A, PK136 treatment efficiently depleted $\sim 78 \%$ and $>93 \%$ of splenic NKp46+ NK cells from $\mathrm{R} 7-\mathrm{NKC}^{\text {het }}$ and $\mathrm{R} 7-\mathrm{NKC}^{\text {mamy }}$ mice, respectively. Similar results were obtained by staining for residual NK cells with anti-CD49b (DX5) or anti-NKG2D mAb (data not shown). In accord with NK depletion from C57L.M-H2k/b $N K C^{\text {het }}$ mice (61), MCMV control in $\mathrm{R} 7-\mathrm{NKC}^{\text {het }}$ mice was consistently more dramatically altered in the liver than in the spleen (Fig. 10B). Nonetheless, PK136 depletion of R7-NKC ${ }^{\text {mamy }} \mathrm{NK}$ cells fully abrogated spleen and liver MCMV control (Fig. 10B). We conclude that NK cells are essential to MHC H-2 ${ }^{\mathrm{k}}$ MCMV resistance. Strains R2 and R7 establish an excellent model system to investigate NK-mediated virus immunity under MHC genetic control.

To address a potential role for other lymphocyte subsets, we also assessed resistance in mice after depletion of CD4 and CD8 T cells, as the importance of both subsets has been established $(39,109)$. Further, recent work has shown that in BALB.Klra8 congenic mice with Ly49H resistance, MCMV-specific activated CD8 $\mathrm{T}$ cells in the spleen can be detected by day 4 post-infection (110). T cell depletions were confirmed by flow cytometry using anti-CD4 and anti-CD8 mAb clones other than those used as depleting Abs (data not shown). As shown in Fig. 10C, T cell depletions failed to alter MCMV replication in the spleens or livers of infected mice and thus these cells have no measurable impact in early $\mathrm{MHC} \mathrm{H}-2^{\mathrm{k}} \mathrm{MCMV}$ resistance. 
Figure 10. A requirement for NK cells in $M H C H-2^{k}$ MCMV resistance. A. Splenocytes from R7-NKC ${ }^{\text {het }}$ and R7-NKC ${ }^{\text {mamy }}\left(\mathrm{Cmv}^{r}\right)$ mice given PBS, anti-NK1.1 mAb PK136, or PK136 followed by MCMV infection were stained for CD3 and NKp46. Numbers indicate the percentage of splenocytes within the NKp46+CD3- lymphocyte gate. B. R2 $\left(C m v^{s}\right), \mathrm{R} 7\left(C m v^{r}\right), \mathrm{C} 57 \mathrm{~L}$ and PK136 treated mice were infected with MCMV. Shown are spleen (open) and liver (filled) MCMV genome levels for individual animals $90 \mathrm{~h}$ after infection. C. R7, C57L and T-cell-depleted (anti-CD4/CD8; see Materials and Methods) mice were infected with MCMV. Shown are spleen (open) and liver (filled) MCMV genome levels for individual animals $90 \mathrm{~h}$ after infection. Data included 3-5 mice per group. 


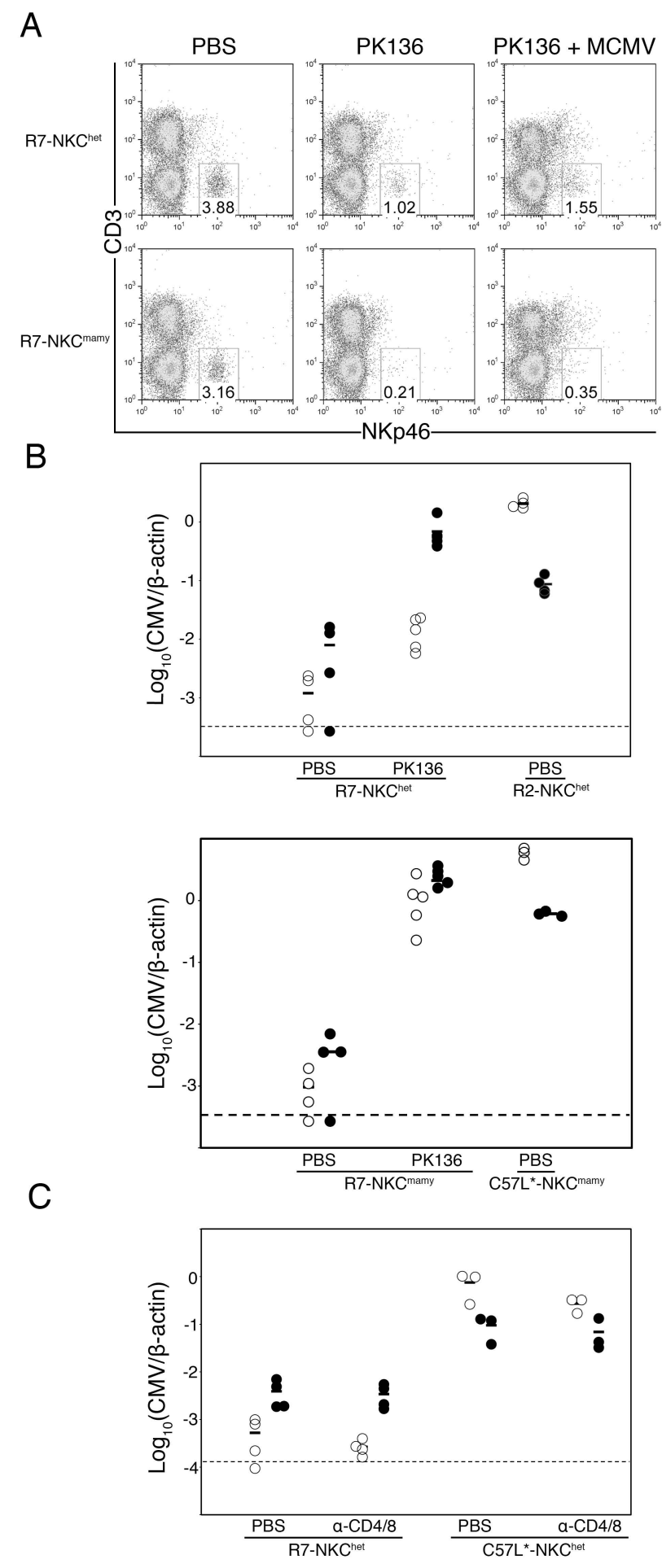




\section{Selective activation and expansion of Ly49G2+ NK cells confers ${\mathrm{H}-2^{\mathrm{k}}}^{\mathrm{MCMV}}$} resistance. The activating $\mathrm{Ly} 49 \mathrm{H}$ receptor mediates NK dependent MCMV control in B6 mice $(58,59,82)$. In accord, Ly49H+ NK cells specifically expand and proliferate to counter MCMV (83). We hypothesized therefore that some NK cells might undergo selective expansion and/or activation in $\mathrm{R} 7\left(\mathrm{Cmv}^{\mathrm{r}}\right)$ mice during infection. Ly49G2 is an especially interesting inhibitory NK cell receptor because Ly49G2 $2^{129}$ can bind MHC class I $\mathrm{D}^{\mathrm{k}}$ as a ligand $(18,111)$. In addition, we found that only one amino acid difference distinguishes Ly49G2 $2^{\text {mamy }}$ from Ly49G2 $2^{\mathrm{c} 571}$ and Ly49G2 $2^{129}$ alleles (unpublished data). Thus, NK cell subset responses were examined in R2 and R7 mice at discrete times after MCMV infection.

To examine Ly49+ NK subsets responding to MCMV, we stained splenic NK cells using anti-Ly49 mAbs 14B11 (specific for Ly49C/I/F/H) and 4D11 (Ly49G2-specific) before and after infection in $\mathrm{R} 2\left(\mathrm{Cmv}^{\mathrm{s}}\right)$ and $\mathrm{R} 7\left(\mathrm{Cmv}^{\mathrm{r}}\right)$ congenic strains. As expected, splenic MCMV was substantially higher in R2 than R7 after $90 \mathrm{~h}$ (Fig. 11A). We found that 45$50 \%$ of NK cells in C57L and MA/My spleens can be stained with mAb 14B11 (data not shown). On the other hand, different subsets of NK cells in C57L ( $\sim 50 \%)$ or MA/My ( $\sim 30 \%$ ) express Ly49G2 on the cell surface (data not shown). In R2 and R7 (both on the C57L genetic background) mice, 50-60\% of NK cells display Ly49G2 on the cell surface before infection (Fig. 11B).

Comparison of 14B11+ and 14B11- NK cells in R2 and R7 mice revealed little, if any, change in either percentage or cell numbers after infection (data not shown). In contrast, a slight increase in the percentage of Ly49G2+ NK1.1+ CD3- NK cells was observed in 
Figure 11. Ly49G2+ NK cells respond selectively to MCMV infection. R2 and R7 mice were infected with $10^{5}$ PFU MCMV (A-C) or with the indicated dose in the range $10^{4}$ to $5 \times 10^{5}$ PFU (D-F). A. Average MCMV genome levels for R2 (open) and R7 (filled) spleens are shown. B. R2 (open) and R7 (filled) splenocytes were stained for NK1.1, CD3 and Ly49G2 (4D11). Numbers indicate the mean percentage of NK cells expressing Ly49G2+ at the cell surface at the indicated times after MCMV infection. C. As in $\mathrm{B}$, but values represent total numbers of $\mathrm{G} 2+$ and $\mathrm{G} 2-\mathrm{NK}$ cells in R2 and R7 spleens after infection. R2 NK cells in spleen, regardless of G2 expression, decreased significantly at $90 \mathrm{~h}$ after infection $(\mathrm{P}<0.005)$. In $\mathrm{R} 7$ spleen, $\mathrm{G} 2-\mathrm{NK}$ cells decreased by $39 \mathrm{~h}$ after infection and were still significantly lower than in control spleen at $90 \mathrm{~h}$ after infection $(\mathrm{P}<0.005)$. On the other hand, only R7 G2+ NK cells increased significantly between 39-90 $\mathrm{h}$ after infection until they were also significantly higher than in uninfected R7 spleen $(\mathrm{P}<0.05)$. D. Groups of $\mathrm{R} 7$ mice were infected with the indicated dose of MCMV. Shown are average MCMV genome levels for spleen (open) and liver (filled) at $90 \mathrm{~h}$ after infection. The limit of MCMV detection (dashed line) is indicated. E. and F. Splenocytes from R7 mice in (D) were stained for NK1.1, Ly49G2 (4D11) and cell surface CD69 (E) or intracellular perforin (F). Plots show MCMV genome levels and mean fluorescence intensity (MFI) values for G2- (open) and G2+ (filled) NK cell subsets for individual animals. The correlation exponential trend lines with $\mathrm{R}^{2}$ values are shown. Data are representative of at least two independent experiments. Error bars indicate standard deviation. 

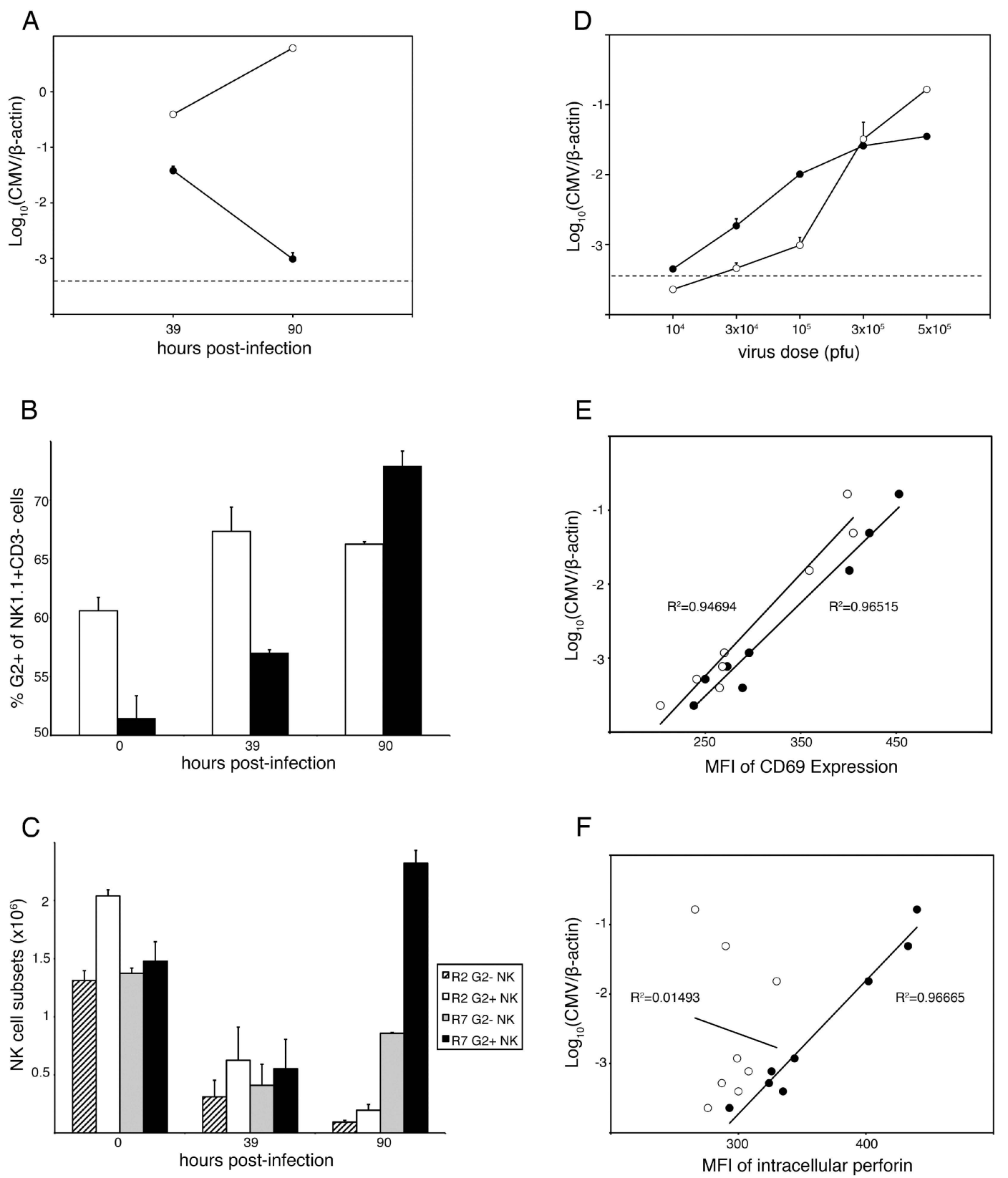
$\mathrm{R} 2$ spleen by $39 \mathrm{~h}$ after infection, and the percentage of Ly49G2+ NK1.1+ CD3- NK cells rose steadily through $90 \mathrm{~h}$ after infection in R7 spleen (Fig. 11B). Even so, splenic NK cells showed an overall decline in number in both strains by $39 \mathrm{~h}$ after infection (Fig. 11C), consistent with splenic NK cells responding to MCMV in B6 mice $(82,83,112)$. After 39 h however, G2+ NK cells increased substantially in R7 mice to a level that exceeded steady state levels in uninfected controls (Fig. 11C). This was not the case for G2- NK cells in R7 mice, or either subset in R2 mice (Fig. 11C). We have observed similar expansion of G2+ NK cells in infected MA/My mice (data not shown). These data are congruent with the finding of Welsh and colleagues showing a proportional increase in Ly49G2+ NK cells after MCMV infection in B6 mice $(82,112)$. More remarkable here however, the absolute number of Ly49G2+ NK cells and the proportion of NK cells is significantly augmented under $\mathrm{H}-2^{\mathrm{k}}$ control. These data therefore indicate that splenic Ly49G2+ NK cells are selectively expanded in response to MCMV infection in R7 mice with highly efficient $\mathrm{H}-2^{\mathrm{k}} \mathrm{NK}$-mediated virus control.

We have previously shown that the peak and extent of NK intracellular IFN- $\gamma$ in response to MCMV is similar in MA/My and C57L mice (108). Thus, we examined R2 and R7 NK cells for cell surface CD69 and intracellular perforin (prfl) expression in response to MCMV. We delivered MCMV to mice in a dose range that yielded different spleen ( $\sim 1,000$-fold variation) and liver ( $\sim 100$-fold variation) MCMV levels by $90 \mathrm{~h}$ after infection (Fig. 11D). In accord with previous NK IFN- $\gamma$ data (108), CD69 activation in R2 and R7 NK cells correlated well with splenic MCMV (data not shown). In addition, G2+ and G2- NK cells in R7 had enhanced CD69 expression that corresponded with spleen MCMV (Fig. 11E). 
We next examined perforin in NK cells responding to MCMV. Similar to CD69 expression, R7 G2+ NK cells expressed perforin levels that corresponded directly to splenic MCMV over a wide range (Fig. 11F). In contrast, perforin levels in R7 G2- NK cells did not correlate with spleen MCMV loads in the inoculation range of $10^{4}-5 \times 10^{5}$ PFU (Fig. 11F). We further observed peak expansion of total NK cells and a maximal $\mathrm{G} 2+/ \mathrm{G} 2-\mathrm{NK}$ cell ratio in $\mathrm{R} 7$ mice given $10^{5} \mathrm{pfu}$ MCMV at $90 \mathrm{~h}$ after infection (Fig. 12A). In contrast, G2+ NK cells in R2 mice declined by 3-fold even at the lowest MCMV dose tested (Fig. 12B). Hence, MCMV provoked potent induction of perforin and acquisition of cytolytic effector status by G2+ NK cells in R7 mice. We conclude that R7 G2+ NK cells preferentially expand and become activated during MCMV infection due to the MHC class $\mathrm{I}^{\mathrm{k}}$ subregion.

To discern their involvement in virus resistance, Ly49G2+ NK cells were depleted from R7 $\left(\mathrm{Cmv}^{\mathrm{r}}\right)$ mice using mAb 4D11 given before infection. In spleens of 4D11 treated R7 mice, we found a selective loss of about 35\% of NKp46+CD3-CD19- splenocytes and residual NK cells (includes 14B11+ and 14B11-) in these animals were refractory to staining with 4D11 or AT8 (also Ly49G2-specific) (Fig. 13A). Intriguingly, 4D11 treatment also significantly diminished resistance such that virus replication was enhanced in spleen and liver after low or high dose MCMV infection (Fig. 13B and C). In comparison, PK136 depletion of most NK1.1+ cells gave an effect comparable in magnitude. Inasmuch as Ly49G2 NK subset depletion from C57BL/6 mice using 4D11 or 4LO439 mAbs given before infection has no effect on resistance in the spleen or liver $(112,113)$, our data indicate that Ly49G2+ NK-mediated resistance is selective and that 
Figure 12. Specific expansion of R7 Ly49G2+ NK cells. Congenic mice R7 (A) and $\mathrm{R} 2$ (B) with at least one $\mathrm{NKC}^{\text {mamy }}$ haplotype were infected with a range of MCMV doses as indicated and splenocytes were analyzed by flow cytometry at $90 \mathrm{~h}$ post-infection. $\mathbf{A}$. Percentages (upper graph) and numbers (lower graph) of G2+ (black) or G2- (grey) NK cells (gated NK1.1+ CD3-) from uninfected or infected $\mathrm{R} 7$ mice are shown. ${ }^{*} \mathrm{P}<0.05, * *$ $\mathrm{P}<0.01$. NS, not significant. Statistical analysis was performed with Student's T-test. B. Percentages (upper graph) and numbers (lower graph) of Ly49G2+ NK cells (gated NK1.1+ CD3-) from uninfected or infected R2 mice are shown. 
A
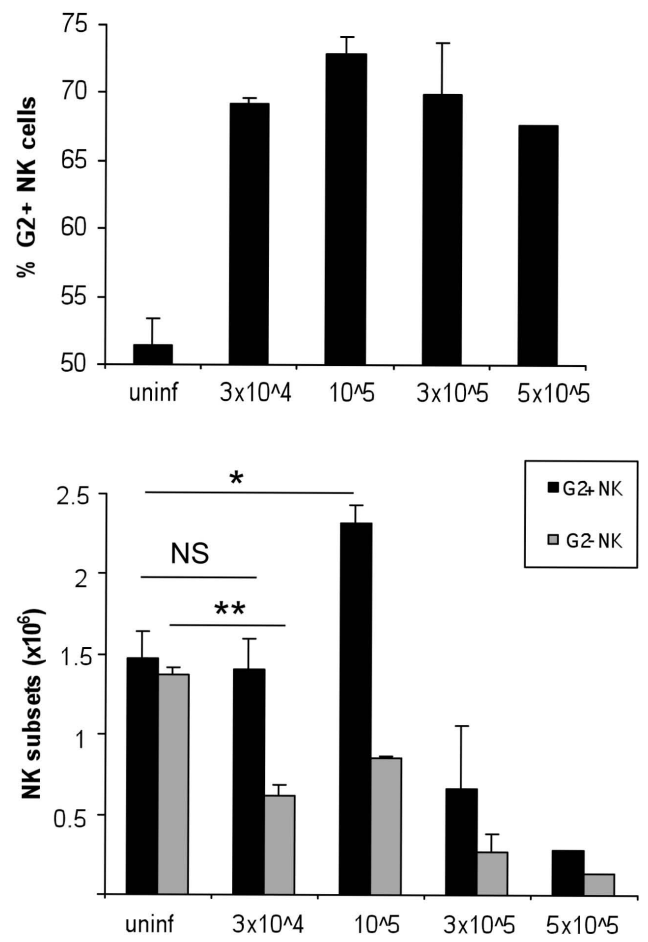

B
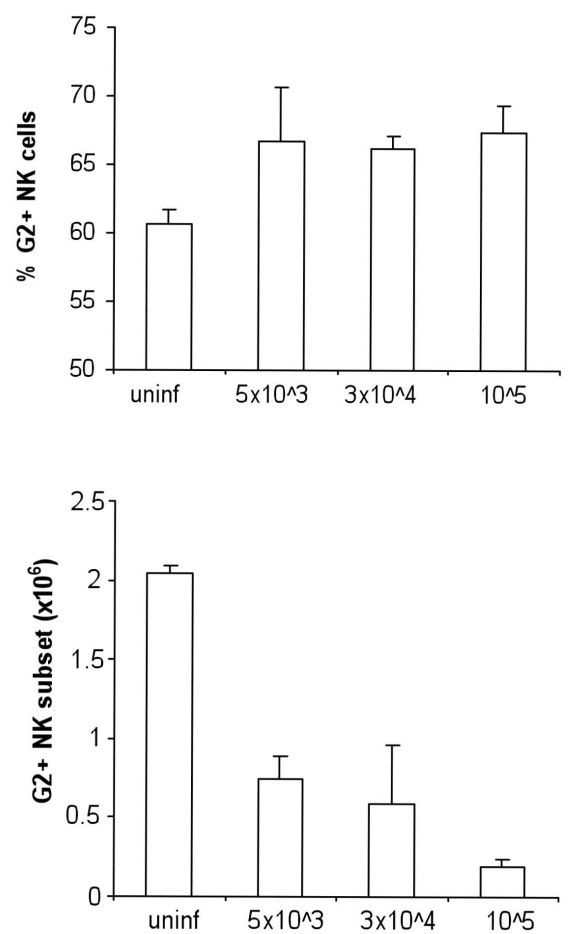
Figure 13. Ly49G2+ NK cells required in MCMV resistance. A. Splenocytes from rat IgG or 4D11 treated $\mathrm{R} 7\left(\mathrm{Cmv}^{\mathrm{r}}\right)$ mice with $\mathrm{MCMV}$ infection were stained for $\mathrm{CD} 3$, NKp46, AT8 and 4D11. At top, numbers indicate the percentage of splenocytes within the NKp46+CD3- lymphocyte gate. Shown below, plots are gated on NKp46+CD3lymphocytes. Left plots show splenocytes from rat IgG treated mice. Right plots show splenocytes from mAb 4D11 treated mice. B. Spleen (open) and liver (filled) MCMV genome levels for IgG, 4D11 or PK136 treated R7 mice infected with $10^{3}$ (top) or $10^{4}$ (bottom) PFU MCMV are shown. For both virus doses, 4D11-treated spleen virus levels were significantly higher than that of rat IgG-treated animals $(\mathrm{P}<0.005)$, though not significantly different than PK136-treated animals. At the lower dose, 4D11-treated liver virus levels were significantly higher than rat $\operatorname{IgG}$ treated $(\mathrm{P}<0.05)$, but significantly lower than PK136 treated animals $(\mathrm{P}<0.05)$. Statistical analysis was performed using a Mann-Whitney/Wilcoxon test. Data included 3-9 mice per group. 
A
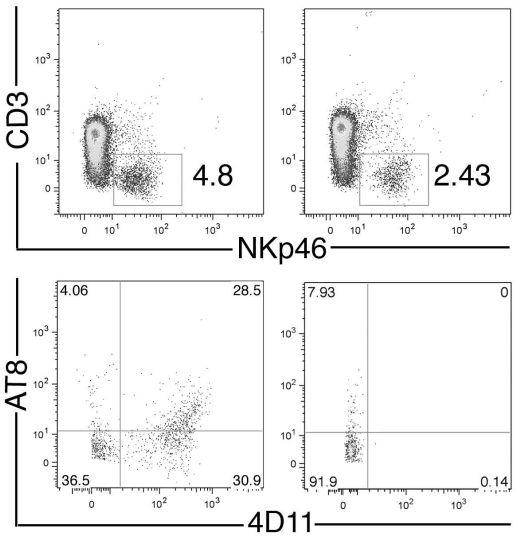

B
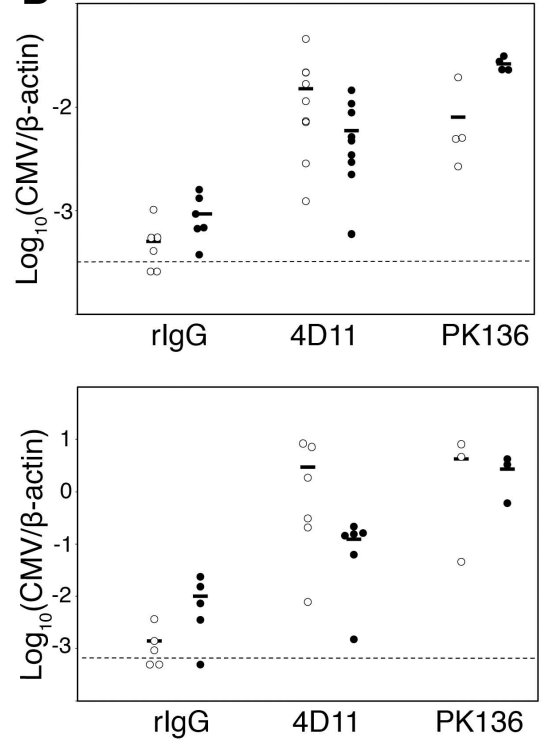
residual NK subsets are ineffective in this genetic setting. We conclude that the $\mathrm{H}-2^{\mathrm{k}}$ class I D locus confers MCMV resistance through Ly49G2+ NK cells in R7 mice. 


\section{Discussion}

$\mathrm{H}-2^{\mathrm{k}}$ genetic resistance to lethal MCMV infection was previously mapped to MHC K/I-A and D intervals using MHC recombinant congenic mice (51). Later, a key role for NKmediated MCMV resistance in MA/My mice was shown (55). Only recently however, has it come to light that MA/My resistance is largely affected by a dominant $\mathrm{H}-2^{\mathrm{k}}$ locus which can contribute MCMV control through epistatic (60) or additive ((61) and M.S. and M.G.B., unpublished data) interaction with an NKC locus on chromosome 6. Although we did not observe a K/I-A-associated resistance effect in this study, distinct background gene or allele effects in $\mathrm{C} 3 \mathrm{H}, \mathrm{B} 10$ and BALB.K strains could have influenced $\mathrm{H}-2^{\mathrm{k}}$ resistance to MCMV mortality in the former study (51). Nevertheless, here we extended precise genetic mapping for an $\mathrm{H}-2^{\mathrm{k}} \mathrm{Cm} v^{r}$ locus to a narrow class I D interval spanning $0.3-\mathrm{Mb}$ DNA with roughly 30 genes.

Though multiple genes at this locus encode proteins with at least some immune function, EG667612, lymphotoxin, tumor necrosis factor and class I D genes are especially interesting in consideration of a possible role in virus resistance. EG667612 sequence includes an $N c r 3$ pseudogene for mouse NKp30 and it is not expressed in a variety of different mouse strains (114) including MA/My (X.X. and M.G.B., unpublished data). Lymphotoxin and TNF cytokines contribute important immune functions with potential to influence innate resistance to viruses, including MCMV (115-117). The class I D

molecule is also an excellent positional candidate for $\mathrm{H}-2^{\mathrm{k}} C m v^{r}$. NK cell receptors have as their ligands MHC class I molecules, which therefore can influence NK self-tolerance and effector functions. Because MHC-I is targeted by MCMV proteins for down- 
regulation after infection (118), including $\mathrm{D}^{\mathrm{k}}$ cell surface expression which is rapidly diminished (108), NK cells with self-MHC inhibitory receptors should in principle readily respond to MCMV infection.

Only Ly49H has so far been coupled with virus recognition and resistance due to specific binding to its 157 ligand displayed by MCMV infected cells $(15,16)$. Also implicated in MCMV recognition and resistance, Ly49P+ reporter cells can respond specifically to $\mathrm{D}^{\mathrm{k}}$-expressing MCMV infected cells (60). In support of a potential in vivo role, a panspecific anti-Ly49 mAb YE1/48 with reactivity for Ly49A/P/V/T given before infection can interfere with MCMV resistance in MA/My mice (60). Genetic map analysis in the current work establishes a critical involvement for the MHC-I $D^{\mathrm{k}}$ locus in vivo. We found unexpectedly that Ly49G2+ NK cells selectively respond during MCMV infection with expansion and activation when $\mathrm{H}-2^{\mathrm{k}}$ protection (i.e. in the $\mathrm{R} 7$ genetic setting) is available. Similar features were not observed for G2+ NK cells in R2 $\left(\mathrm{Cmv}^{s}\right)$ mice, or for G2- or 14B11+ NK subsets in either strain after infection. Others have already noted that the frequency of Ly49G2+ NK cells increases in the spleens, peritoneal cavities, and livers of B6 mice by day 3 after MCMV infection as well as during the course of other viral infections, including mouse hepatitis virus, vaccinia virus, and lymphocytic choriomeningitis virus infections $(82,112)$. Ly49G2 is therefore not a bona fide marker for NK cells providing protection from MCMV infection in B6 animals. In stark contrast with MCMV resistance manifest in the B6 strain, we found herein that Ly49G2-depleted R7 animals with about $65 \%$ of NKp $46+$ NK cells intact were severely deficient for MCMV resistance. Other NK cell subsets were therefore unable to effectively deliver MCMV resistance in this system. Altogether, these data substantiate a likely critical role, 
one influenced by MHC genetic variation, for Ly49G2+ NK cells in MCMV resistance in the R7 strain. MAb 4D11 likely specifically binds the inhibitory Ly49G2 ${ }^{\text {c571 }}$ receptors expressed by R7 NK cells for several reasons: 1) We found that the C57L and 129 NKCLy49 haplotypes are highly related, if not identical (90); 2) Sequence analysis of Ly49G2 $2^{\text {c571 }}$ revealed that it is identical to Ly49G2 ${ }^{129}$; Ly49G2 ${ }^{\text {mamy }}$ differs by one amino acid (unpublished data); 3) 4D11 was shown specific for Ly49G2 receptors on C57BL/6, BALB/c, C3H and 129 NK cells $(119,120)$; and 4) another Ly49G2 allele-specific mAb AT8 (120) similarly co-stained IL-2 activated 4D11+ NK cells from 129, R2-NKC ${ }^{\text {mamy }}$ and R7-NKC ${ }^{\text {mamy }}$ mice (Fig. 14). Primary 4D11+ NK cells from uninfected and MCMV infected R7-NKC ${ }^{\text {mamy }}$ mice were also co-stained with mAb AT8 (data not shown). Collectively, these data substantiate mAb 4D11 specific recognition of Ly49G2 $2^{\text {c571 }}$ and Ly49G2 ${ }^{\text {mamy }}$ NK receptors.

It has been shown that $\mathrm{Ly} 49 \mathrm{H}+$ splenic NK cells, which are needed for MCMV control in B6 mice, preferentially expand by day 6 after infection (83). More intriguing in this system, G2+ NK cells rapidly expanded in MCMV infected R7 spleens by $90 \mathrm{~h}$ after infection. The 14B11+ NK subset was not similarly affected (data not shown). Further, we found that R2 and R7 NK cells displayed classical signs of early activation (CD69+) after infection (Fig. 11F and data not shown), but R7 G2+ NK cells acquired high perforin expression with enhanced cytotoxic potential. We speculate that selective expansion and activation of G2+ NK cells was due to $\mathrm{D}^{\mathrm{k}}$ expression in $\mathrm{R} 7$ mice. While cytokine stimulation (e.g. IL-2 or IL-15) is important for perforin activation (10), this finding further suggests that G2+ NK cells may have better access to cytokine stimulation than other NK subsets in R7, or any NK subsets in R2. This feature further distinguishes 
Figure 14. Confirmation of the Ly49G2 receptor with specific mAbs 4D11 and AT8. Splenocytes were harvested from uninfected 129 and congenic mice R2 and R7 with the homozygous $\mathrm{NKC}^{\text {mamy }}$ haplotype and cultured in IL-2 media for 5 days. Adherent cells (lymphokine activated killer cells) were stained and analyzed by flow cytometry. Purity of NK cells was 70-95\% as determined by gating (DX5+CD3-CD19- for 129 mice and NK1.1+CD3-CD19- for NKC ${ }^{\text {mamy }}$ mice). Representative dot plots are shown. 


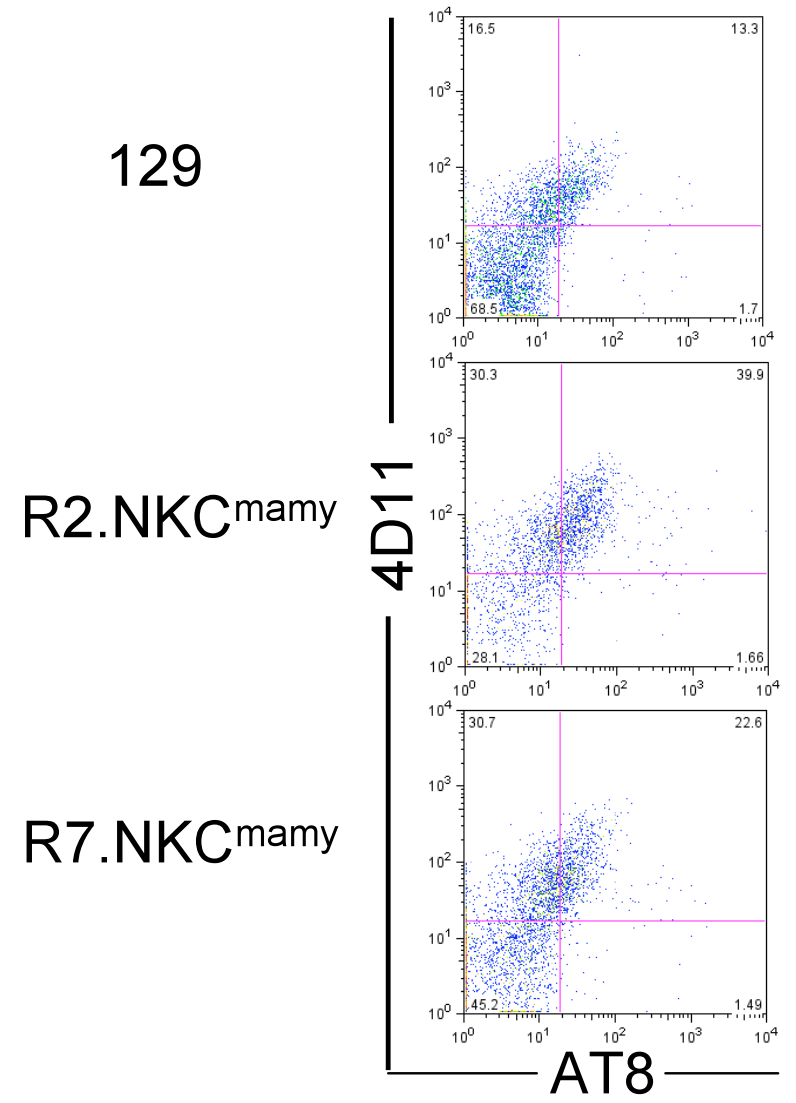


H-2 ${ }^{\mathrm{k}}$ and Ly49H MCMV control since both Ly49H+ and Ly49H- NK cells have enhanced perforin expression after infection in B6 mice (10).

Because Ly49P has been shown to recognize MCMV-experienced $\mathrm{D}^{\mathrm{k}}$ molecules on infected cells (60), its coexpression with Ly49G2 on NK cells could help to explain selective expansion during MCMV infection. So far, we have been unable to directly address this possibility since anti-Ly49 mAbs, YE1/32 and YE1/48 poorly recognize primary Ly49P+ NK cells from 129 (119) and C57L and MA/My spleens (data not shown). Nonetheless, G2+ and G2- NK cells should have similar variegated Ly49P expression (106) before and $48 \mathrm{~h}$ after MCMV infection when both NK subsets were comparable in $\mathrm{R} 2\left(\mathrm{Cmv}^{\mathrm{s}}\right)$ and $\mathrm{R} 7\left(\mathrm{Cmv}^{\mathrm{r}}\right)$ mice (Fig. 11C). One may expect $\mathrm{G} 2+\mathrm{P}+$ and $\mathrm{G} 2-\mathrm{P}+\mathrm{NK}$ cells to have expanded in a similar fashion after early Ly49P recognition of MCMV-D $\mathrm{D}^{\mathrm{k}}$ on infected cells. Instead, only G2+ NK cells selectively expanded and became activated for cytolytic function in R7 spleen. Thus, although the actual role of Ly49G2 in NK activation must still be determined, the G2+ NK subset may have been more effectively licensed (27) or armed (28) for effector function and/or responsive to cellular alterations in self-MHC class I expression, perhaps due to viral down-regulation of H-2 $\mathrm{D}^{\mathrm{k}}$ cell surface expression (108). Consistent with this possibility, inhibitory Ly49G2 $2^{\text {balb }}$ and Ly49G2 $2^{129}$ receptors can specifically bind MHC-I $D^{\mathrm{k}}(18,111)$ and Ly49G2 ${ }^{\text {c571 }}$ is identical to Ly49G2 ${ }^{129}$ (unpublished data).

Though mouse Ly49 and human KIR receptors are structurally unrelated, they have several features in common, including sequence polymorphism, MHC-I recognition and signaling through ITAM (on co-receptors) or ITIM domains for stimulating or inhibiting 
NK effector functions, respectively. Recent genetic studies have revealed that certain KIR / HLA combined genotypes associate with resistance or susceptibility to some human diseases (121), but the mechanistic details have not been elucidated. We propose that further study of NK-mediated virus immunity under MHC genetic control will provide an important model to begin to examine a role for NK cell receptors, as they can be influenced by MHC alleles, in virus immunity. 


\title{
Chapter IV
}

\section{Transgenic expression of $H-2 D^{k}$ gene in highly susceptible $H-2^{b}$ mice confers innate MCMV resistance}

\begin{abstract}
NK cell-mediated MCMV resistance is under $\mathrm{H}-2^{\mathrm{k}}\left(\mathrm{Cm}^{r}\right)$ genetic control in MA/My mice, but the underlying gene(s) is unclear. Previous genetic studies have precisely mapped the $\mathrm{H}-2^{\mathrm{k}} \mathrm{Cm} v^{r}$ locus to a $0.3-\mathrm{Mb}$ critical interval containing the class $\mathrm{I}^{\mathrm{k}}$ gene. Because Ly49 NK cell receptors are licensed by and responsive to MHC class I molecules, $\mathrm{D}^{\mathrm{k}}$ is a positional gene candidate. Thus, a $10-\mathrm{kb} \mathrm{D}^{\mathrm{k}}$ genomic DNA was isolated and cloned for transgenesis. A transgenic founder $\left(\mathrm{Tg} 3-\mathrm{D}^{\mathrm{k}}\right)$ mouse was produced on the MCMV-susceptible $\left(C m v^{s}\right)\left(\mathrm{MA} / \mathrm{My} \cdot \mathrm{L}-H 2^{b}\right.$ x C57L) $\mathrm{F}_{1}$ background. Germline transmission and surface expression of $\mathrm{D}^{\mathrm{k}}$ transgene were confirmed and the role of $\mathrm{D}^{\mathrm{k}}$ was evaluated in the transgenic offspring. We found that the $\mathrm{D}^{\mathrm{k}}$ transgene fully rescued innate MCMV immunity when expressed in $C m v^{s}$ mice; $\operatorname{Tg} 3-\mathrm{D}^{\mathrm{k}}$ mouse spleens had $\sim 1000$-fold lower MCMV at $90 \mathrm{~h}$ after infection than non-transgenic littermate controls. Importantly, MCMV resistance in this system requires Ly49G2+ NK cells. In support, the Ly49G2 subset preferentially expanded during MCMV infection in $\mathrm{Tg} 3-\mathrm{D}^{\mathrm{k}}$ mice. We conclude that Ly49G2 NK cells are responsible for $\mathrm{D}^{\mathrm{k}}$-dependent MCMV resistance.
\end{abstract}




\section{Introduction}

MCMV infection of inbred mice provides a useful model to study genetic regulation of host immune responses to viral infections. Inbred mouse strains display great variation in their susceptibility to MCMV infection in both virus replication and mortality. Their resistance to lethal MCMV inoculation is genetically controlled by $\mathrm{H}-2$ and non- $\mathrm{H}-2$ genes (51). In the B6 strain, $C m v 1$ was mapped to the $\mathrm{NKC} \mathrm{(52)} \mathrm{and} \mathrm{later} \mathrm{identified} \mathrm{as} \mathrm{a}$ single Ly49 receptor gene, Ly49H $(58,59)$. Further, different groups demonstrated that B6 NK cells mediate early MCMV control through Ly49H recognition of m157, a MHC class I like MCMV glycoprotein expressed on infected cells $(15,16)$. In addition to Cmv1-dependent MCMV control, $\mathrm{H}-2^{\mathrm{k}}$ linked genes were associated with survival resistance upon lethal MCMV infection $(50,51)$. However, the responsible H-2 gene(s) remain unidentified. Although there was controversy on greater inherent resistance of $\mathrm{H}-$ $2^{\mathrm{k}}$ cells to MCMV infection $(50,51,98,122)$, effective MCMV control in $\mathrm{H}-2^{\mathrm{k}}$ mice appeared to be associated with augmented NK activation (88) and dependent on NK cells (89). Therefore, further studies are needed to uncover the immunogenetic control mechanisms in $\mathrm{H}-2^{\mathrm{k}}$ linked MCMV resistance.

Consistent with previous mortality studies, $\mathrm{H}-2^{\mathrm{k}}$ was recently reported to be associated with low viral replication in the resistant MA/My $\left(\mathrm{H}-2^{\mathrm{k}}\right)$ mice by two different genetic mapping systems using offspring from crosses between MA/My and susceptible C57L (61) or $\mathrm{BALB} / \mathrm{c}(60)$. We confirmed that $\mathrm{H}-2^{\mathrm{k}}$ linked genes are essential for innate MCMV resistance in MA/My and C57L congenic strains $(61,108)$. In MA/My, NK cells mediate effective early MCMV control (55), but do not involve the Ly49H receptor (61). 
Instead, it was proposed that an epistatic interaction between the activating receptor Ly49P and $\mathrm{D}^{\mathrm{k}}$ on infected cells accounts for NK cell mediated MCMV control in $\mathrm{F}_{2}$ offspring of MA/My and BALB/c mice (60). However, relevant genetic confirmation of Ly49P or $\mathrm{D}^{\mathrm{k}}$ in $\mathrm{NK}$ control of MCMV infection is lacking. Recently, we initiated positional cloning to isolate the $\mathrm{H}-2^{\mathrm{k}}$ linked $C m v^{r}$ (MCMV-resistant) locus by producing a panel of intra-H-2 recombinant congenic strains and precisely mapped a $C m v^{r}$ locus to a 0.3-Mb interval in the $\mathrm{H}-2 \mathrm{D}$ region (Chapter III). Within the narrow region, MHC-I $\mathrm{D}^{\mathrm{k}}$ appears to be the only class I related protein that can interact with NK Ly49 receptors. Moreover, we have shown that the NK cells expressing Ly49G2 ${ }^{\text {mamy }}$ receptors, which might also recognize $\mathrm{D}^{\mathrm{k}}$ similar to $\mathrm{Ly} 49 \mathrm{G} 2^{\mathrm{balb} / \mathrm{c}}$ receptors, are required for $\mathrm{D}^{\mathrm{k}}$ locus dependent MCMV control in MCMV-resistant R7 mice (Chapter III). Thus, $\mathrm{D}^{\mathrm{k}}$ is an interesting candidate for $\mathrm{H}-2^{\mathrm{k}}$ linked MCMV resistance.

Although published data suggest that $\mathrm{D}^{\mathrm{k}}$ may be involved in NK cell dependent MCMV control in MA/My, it is necessary to directly assess the role of $\mathrm{D}^{\mathrm{k}}$ in $\mathrm{H}-2^{\mathrm{k}}$ linked MCMV resistance and to determine whether expression of $\mathrm{D}^{\mathrm{k}}$ regulates anti-MCMV immunity of NK cells. Here we used a cloned genomic fragment with the $\mathrm{D}^{\mathrm{k}}$ gene intact to generate $\mathrm{D}^{\mathrm{k}}$ transgenic mice on a $C m v^{s}\left(\mathrm{M} . \mathrm{L}-H 2^{b}\right.$ x C57L) $\mathrm{F}_{1}$ background. A Tg3- $\mathrm{D}^{\mathrm{k}}$ founder male was identified and germ-line transgene transmission has been confirmed. The $\mathrm{Tg} 3-\mathrm{D}^{\mathrm{k}}$ transgene was then backcrossed separately to MA/My.L-H2 ${ }^{b}$ and C57L genetic backgrounds to examine MHC-I $\mathrm{D}^{\mathrm{k}}$ gene expression, virus control and $\mathrm{NK}$ cell involvement. 


\section{Results}

Isolation of genomic $D^{k}$ gene for transgenesis. In order to faithfully express $D^{k}$, we sought to construct $\mathrm{D}^{\mathrm{k}}$ transgene with the endogenous promoter. It was previously reported that $a D^{b}$ transgenic mouse was generated with a $10-\mathrm{kb}$ HindIII digestion fragment of genomic DNA carrying the entire $\mathrm{H}-2 \mathrm{D}^{\mathrm{b}}$ gene (123). We hypothesized that the $\mathrm{D}^{\mathrm{k}}$ gene could be isolated from a $\mathrm{H}-2^{\mathrm{k}}$ DNA fragment (e.g. a BAC clone) as long as HindIII digestion sites are conserved in the H-2 D subregion. In accordance, the published $\mathrm{C} 3 \mathrm{H} / \mathrm{HeN} \mathrm{D}^{\mathrm{k}}$ gene does not contain any HindIII digestion sites (124). To isolate the $\mathrm{D}^{\mathrm{k}}$ gene from genomic DNA, we took advantage of $\mathrm{H}-2^{\mathrm{k}} \mathrm{BAC}$ clones derived from the $\mathrm{C} 3 \mathrm{H} / \mathrm{HeJ}$ BAC library (see Methods and Materials). Interestingly, a $\mathrm{H}-2^{\mathrm{k}}$ BAC clone, 121F5 covers part of the class I D subregion, with a complete $\mathrm{D}^{\mathrm{k}}$ gene at the distal end as characterized with SSLP markers including 17UVA15, 17UVA01, 17UVA16, $17 U V A 17$ and a primer pair specific for the NCR3 gene (Fig. 15A) as well as the primer sets covering all the exons of the $\mathrm{D}^{\mathrm{k}}$ gene (data not shown). BAC $121 \mathrm{~F} 5$ 's size $(\sim 200 \mathrm{~kb})$ is based on PFGE sizing analysis after NotI or XhoI digestion (Fig. 15B). A 10-kb HindIII $\mathrm{D}^{\mathrm{k}}$ fragment was isolated from out of two $\sim 20-\mathrm{kb}$ XhoI bands after HindIII digestion and subsequently cloned (see materials and methods, Fig. 15B). The cloned HindIII fragment was then used for transgenesis. Since $\mathrm{D}^{\mathrm{k}}$ contains a NotI site, digestion of this $10-\mathrm{kb}$ band by NotI supports the presence of a $\mathrm{D}^{\mathrm{k}}$ fragment (Fig. 15B). Further verified by $\mathrm{D}^{\mathrm{k}}$-specific PCR amplification (data not shown), this $10-\mathrm{kb}$ HindIII restriction fragment contains a single but entire functional $D^{\mathrm{k}}$ gene (eight exons), $\sim 4 \mathrm{~kb}$ of the $5^{\prime}$ flanking $\mathrm{D}^{\mathrm{k}}$ promoter UTR $(123,125,126)$ and $\sim 1 \mathrm{~kb}$ downstream of 3'-UTR (Fig. 15A). The eight exons of $\mathrm{D}^{\mathrm{k}}$ transgene were sequenced and found identical to the MA/My $\mathrm{D}^{\mathrm{k}}$ 
Figure 15. Isolation of $D^{k}$ fragment for transgenesis. A. A schematic map of $H-2^{k}$ BAC clone $121 \mathrm{~F} 5$ and the $\mathrm{D}^{\mathrm{k}}$ transgene. Markers and genes located in this BAC DNA fragment are listed above. The 10-kb HindIII fragment isolated from 121F5 includes the complete $\mathrm{D}^{\mathrm{k}}$ gene, its promoter and downstream DNA. B. Left, 1\% PFGE gel of 121F5 DNA digested with indicated restriction enzymes (lane 2 and 3) or without enzyme treatment (lane 4) is shown. Lower right, two XhoI bands $(\sim 20 \mathrm{~kb})$ purified from the left gel were further subjected with enzyme digestion (lane 6 and 7) and fractionized in 1\% agarose gel. The $10-\mathrm{kb} \mathrm{D}^{\mathrm{k}}$ band cloned for transgenesis is indicated. 
A.

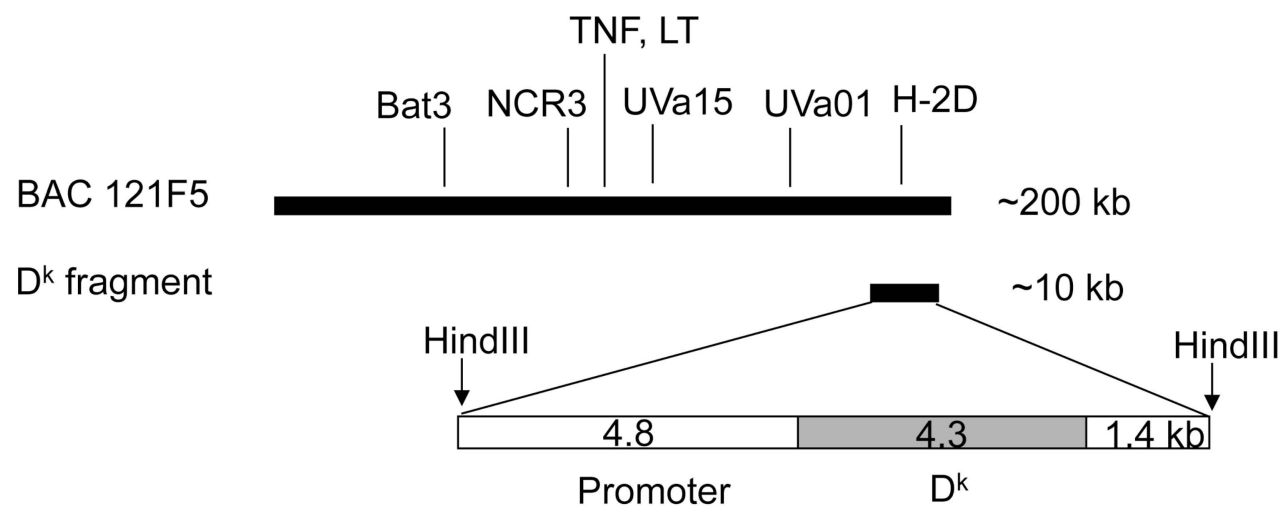

B.

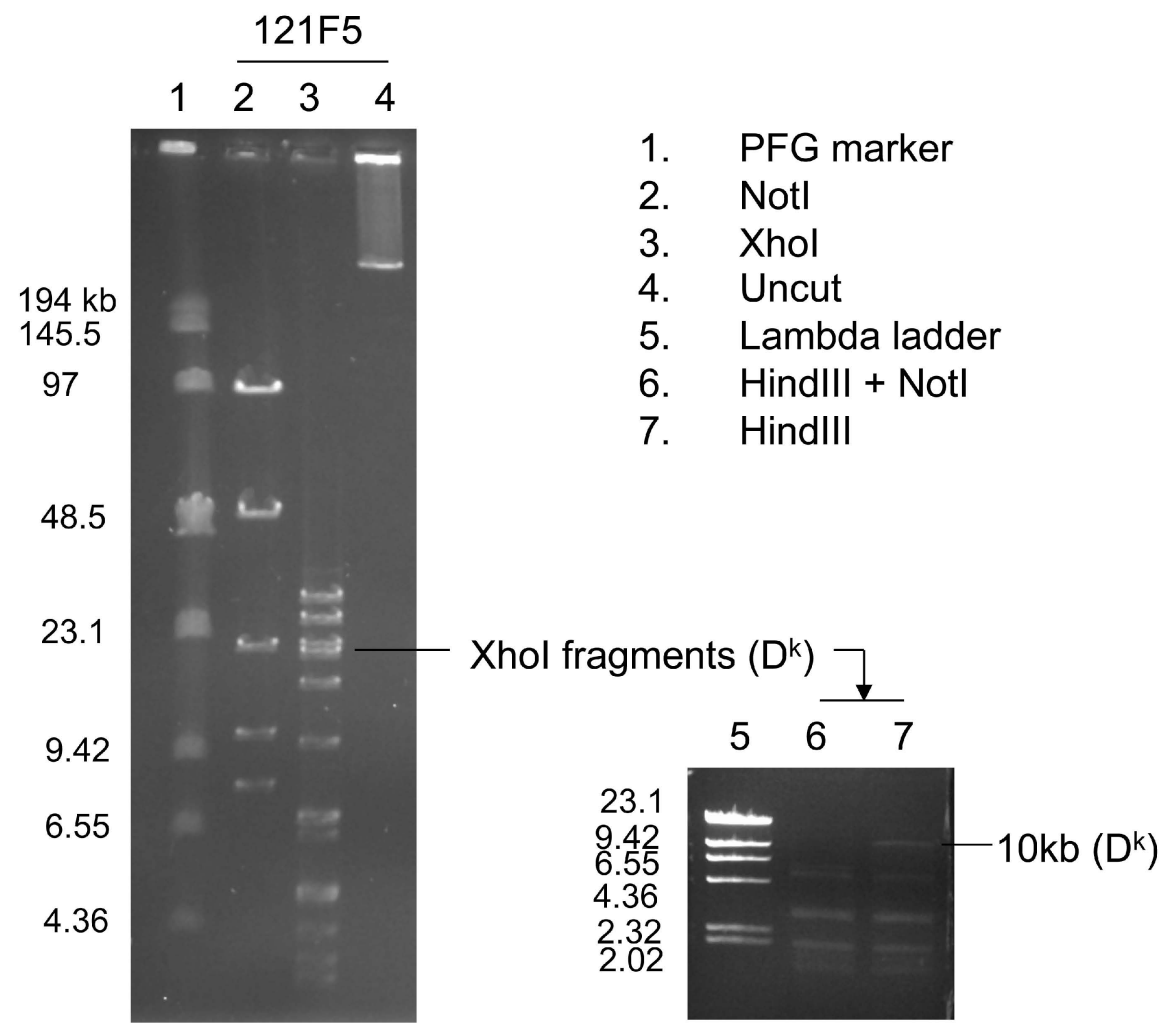


cDNA sequence, whereas one SNP in the promoter region distinguishes MA/My and $\mathrm{C} 3 \mathrm{H} / \mathrm{HeJ}$ alleles (Fig. 16 and data not shown). Thus, the 10-kb HindIII fragment was isolated and justified for $\mathrm{D}^{\mathrm{k}}$ transgenesis.

Generation and analysis of $\mathbf{D}^{\mathrm{k}}$ transgenic mice. $\mathrm{H}-2^{\mathrm{k}}$ confers dominant resistance in (C57L x MA/My) $F_{1}$ mice (61), whereas (C57L x M.L-H2 $\left.2^{\mathrm{b}}\right) \mathrm{F}_{1}\left(\mathrm{~F} 1 . \mathrm{H} 2^{\mathrm{b}}\right)$ mice are fully susceptible (Fig. 17). Thus, if the $\mathrm{D}^{\mathrm{k}}$ transgene contributes to MCMV control, introduction of $\mathrm{D}^{\mathrm{k}}$ to the $\mathrm{F} 1 . \mathrm{H} 2^{\mathrm{b}}$ mice should at least in part rescue their anti-MCMV immunity. A transgenic founder, $\mathrm{F} 1 . \mathrm{H} 2^{\mathrm{b}}-\mathrm{Tg} 3\left(\mathrm{D}^{\mathrm{k}}\right)$ was identified after screening with a SSLP marker located inside the intron 3 of H-2 D gene and confirmed with a pair of $\mathrm{D}^{\mathrm{k}}$ specific primers (amplifies exons 2-3) but negative for $\mathrm{H}-2^{\mathrm{k}}$ alleles of 17UVA15, 17UVA01, 17UVA16 and 17UVA17 by PCR, whereas R12 strain only carrying the critical 0.3-Mb interval is positive for all the markers (Fig. 18A). To maintain the Tg3- $\mathrm{D}^{\mathrm{k}}$ line, the founder mouse was separately backcrossed to C57L or M.L-H2 ${ }^{b}$ with selection for $\mathrm{D}^{\mathrm{k}}$ PCR positive offspring. Surface expression of the transgene was examined in PBMCs and splenocytes from $\operatorname{Tg} 3-\mathrm{D}^{\mathrm{k}}$ transgenic mice with the $\mathrm{D}^{\mathrm{k}}$-specific monoclonal antibody, 15-5-5. In confirmation, leukocytes from all the transgenic mice express $\mathrm{D}^{\mathrm{k}}$, while no staining was observed for cells from nontransgenic littermate controls (Fig. 18B and data not shown). Importantly, the surface $\mathrm{D}^{\mathrm{k}}$ levels were comparable to the $\mathrm{H}-2^{\mathrm{k}}$ mice expressing a single copy of $\mathrm{D}^{\mathrm{k}}$ allele (Fig. 18B). Moreover, transgenic expression of $\mathrm{D}^{\mathrm{k}}$ did not significantly change the proportions of NK cells ( $3.385 \pm 0.54$ v.s. $2.53 \pm 0.68 \%$ ), CD4 (22.15 \pm 2.33 v.s. $25.4 \pm 2.12 \%)$ and CD8 $(14.35 \pm 0.35$ v.s. $12.85 \pm 1.20 \%)$ T cells in the spleen as compared to the transgene negative littermates (Fig. 18C). 
Figure 16. Sequence verified for the $D^{\mathbf{k}}$ transgene. This is a diagrammatic representation of $\mathrm{D}^{\mathrm{k}}$ sequences from $\mathrm{C} 3 \mathrm{H} / \mathrm{HeN}$ [ $\lambda$ phage clones, Ref (124)], C3H/HeJ BAC clone 121F5 and MA/My DNA. Eight exons (open box) of the BAC $\mathrm{D}^{\mathrm{k}}$ and MA/My $D^{k}$ cDNA were PCR amplified and sequenced. Similarly, the promoter region (filled box) was sequenced with nested PCR products amplified from 121F5 and MA/My genomic DNA. The promoter region and exons, but not introns (lines connecting exons), are depicted to the scale. Single nucleotide polymorphisms (SNPs) are labeled; a single nucleotide deletion is indicated with black bars on the promoter region. Amino acid changes caused by asynonymous nucleotide substitutions are listed above the exons. Intronic SNPs observed for $121 \mathrm{~F} 5$ and $\mathrm{C} 3 \mathrm{H} / \mathrm{HeN}$ are not depicted here. 


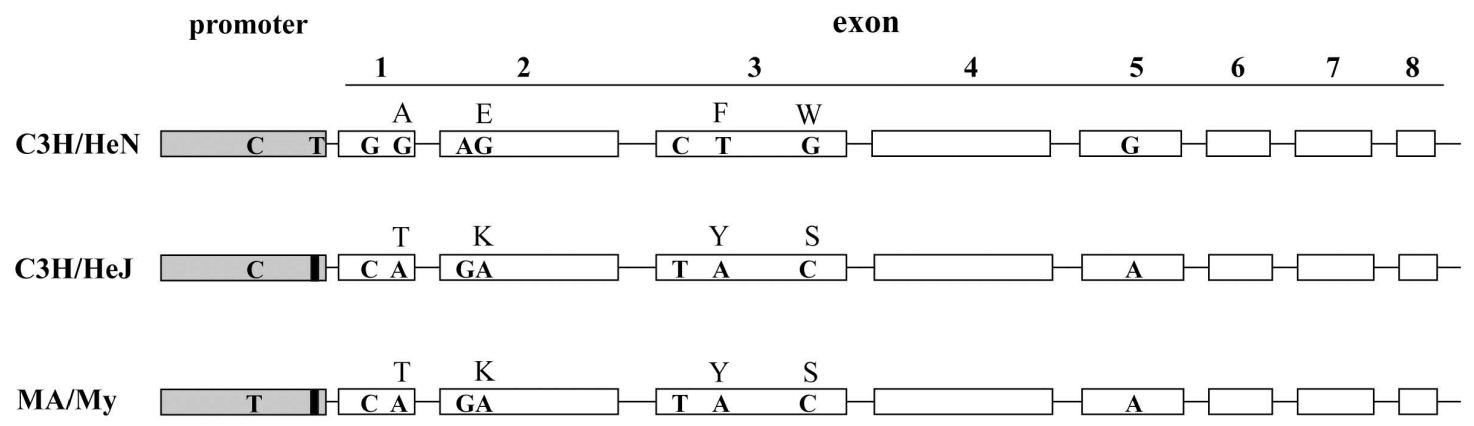


Figure 17. Full MCMV susceptibility observed in (M.L-H2 ${ }^{b}$ x C57L) F $_{1}$ mice. Individual mice were infected with $10^{5}$ PFU SGV and spleen MCMV levels at 3.5 dpi are shown. Five to eight mice of the indicated strains were studied per group. The dashed line indicates the detection limit. 


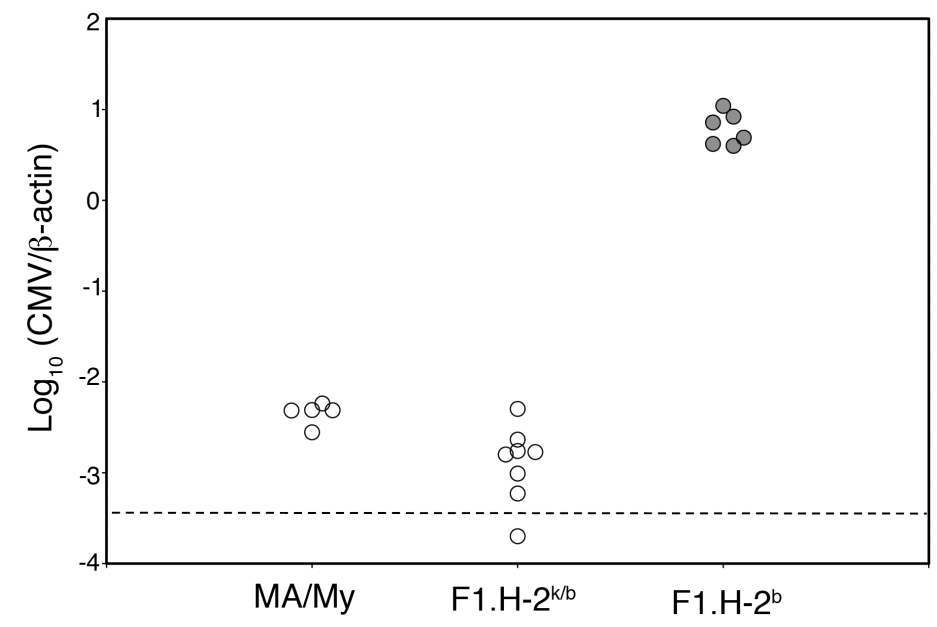


Figure 18. Characterization of Tg3-D ${ }^{k}$ transgenic mice. A. An interval map of the H2D subregion is shown with locations of SSLP markers as well as a primer set spanning $\mathrm{D}^{\mathrm{k}}$ exon 2-3. The box indicates the $\mathrm{D}^{\mathrm{k}}$ gene. Markers located inside the transgene were used for screening and PCR identification of transgenic founders; PCR amplification for $D^{k}$ flanking markers confirmed that only a $D^{k}$ transgene could explain the result. Positive results for each marker are labeled with $(+)$. B. PBMCs were prepared from the Tg3-D ${ }^{k}$ founder (thick line), a nontransgenic littermate (grey thin line) and a positive control (M.L-H2 ${ }^{\mathrm{k} / \mathrm{b}}$, long dashed line) for $\mathrm{D}^{\mathrm{k}}$ staining. Histograms show $\mathrm{D}^{\mathrm{k}}$ expression on gated lymphocyte (upper plot) and monocyte (lower plot) populations. C. The proportions of different spleen cell subsets, NK cells (NK1.1+ CD3-), CD4 T and CD8 T cells are compared between Tg3MN2 and their nontransgenic littermates (LM). Error bars indicate standard deviation. 
A.

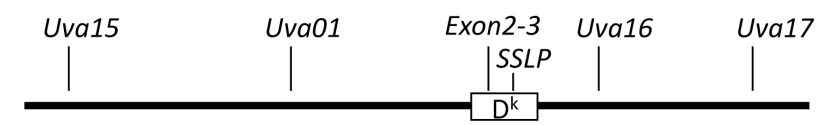

\section{Strain}

Tg3 founder -

R12

B.

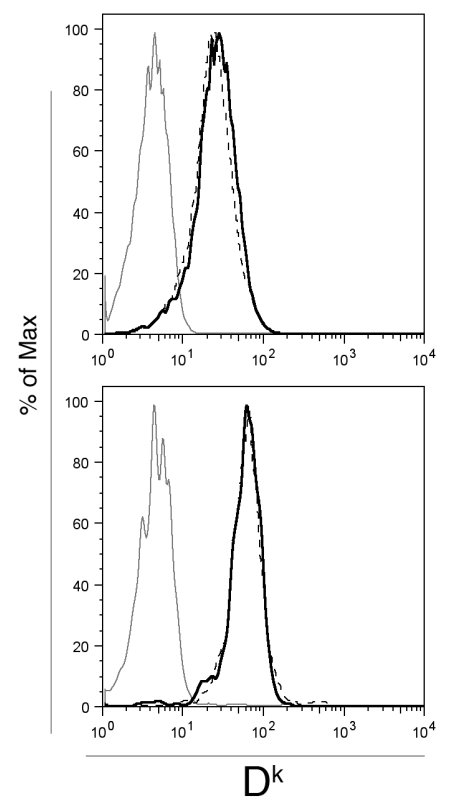

C.

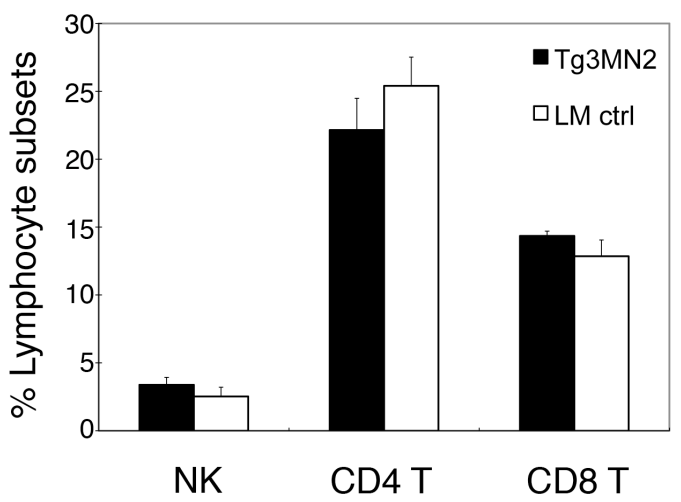


in the backcross offspring $\mathrm{F} 1 . H 2^{b}-\mathrm{Tg} 3\left(\mathrm{D}^{\mathrm{k}}\right) \times \mathrm{M} \cdot \mathrm{L}-H 2^{b}$ (hereafter referred as Tg3MN2) and $\mathrm{F} 1 . H 2^{b}-\mathrm{Tg} 3\left(\mathrm{D}^{\mathrm{k}}\right) \times \mathrm{C} 57 \mathrm{~L}(\mathrm{Tg} 3 \mathrm{LN} 2$ hereafter) as well as their nontransgenic siblings. As shown in Figure 19, viral loads were $\sim 3 \log _{10}$ lower in transgenic mice than their littermates regardless of the backcross direction. The difference between transgenic and nontransgenic mice is comparable to that observed in $\mathrm{R} 7 \mathrm{vs.} \mathrm{C57L}$ as well as MA/My vs. M.L-H2 $2^{b}$ (Fig. 19). Thus, $\mathrm{D}^{\mathrm{k}}$ gene expression is sufficient to fully rescue innate MCMV susceptibility in $\mathrm{H}-2^{\mathrm{b}}$ mice.

NK cells mediate $D^{k}$ dependent MCMV resistance. To assess the role of NK cells in $\mathrm{D}^{\mathrm{k}}$ transgenic mice, NK cells were immunodepleted as previously described (61). As expected, MA/My mice were unable to efficiently control MCMV without NK cells (Fig. 20B). Intriguingly, NK depletion completely abrogated MCMV resistance and virus replication in the transgenic spleens reached the levels of susceptible littermate controls (Fig. 20B). Prior results provide evidence that innate MCMV resistance exerted by the $\mathrm{H}-$ 2 D subregion requires the Ly49G2+ NK subset (Chapter III). To examine whether the Ly49G2+ subset is also critical in a $\mathrm{D}^{\mathrm{k}}$ dependent manner, we studied the role of Ly49G2 subset by removing them from the transgenic mice with a Ly49G2-specific mAb, 4D11. The Ly49G2 subset consists of only $\sim 30 \%$ of the NK cells in uninfected transgenic Tg3MN2 mice (Fig. 20A). However, the remaining 70\% NK cells (G2-) could not efficiently limit virus replication; depletion of G2+ subset substantially changed the phenotype by more than $2 \log _{10}$ (Fig. 20B), which is consistent with our previous data.

Since the Ly49G2 receptor is responsible for innate MCMV resistance conferred by a $\mathrm{D}^{\mathrm{k}}$ transgene, G2+ NK cells should display selective expansion in response to MCMV 
Figure 19. $D^{k}$ expression confers innate MCMV resistance. Tg3 backcross offspring with M.L-H2 $2^{b}(\mathrm{Tg} 3 \mathrm{MN} 2)$ or C57L (Tg3LN2), nontransgenic littermates (LM) as well as other control strains were infected with $10^{5} \mathrm{pfu} \mathrm{SGV} /$ mouse. Shown are spleen virus levels of at $90 \mathrm{hr}$ post-infection. Closed circles represent individual mice expressing $\mathrm{D}^{\mathrm{k}}$, while open circles represent $\mathrm{H}-2^{\mathrm{b}}$ mice without $\mathrm{D}^{\mathrm{k}}$ expression. The bars indicate average viral titers. 


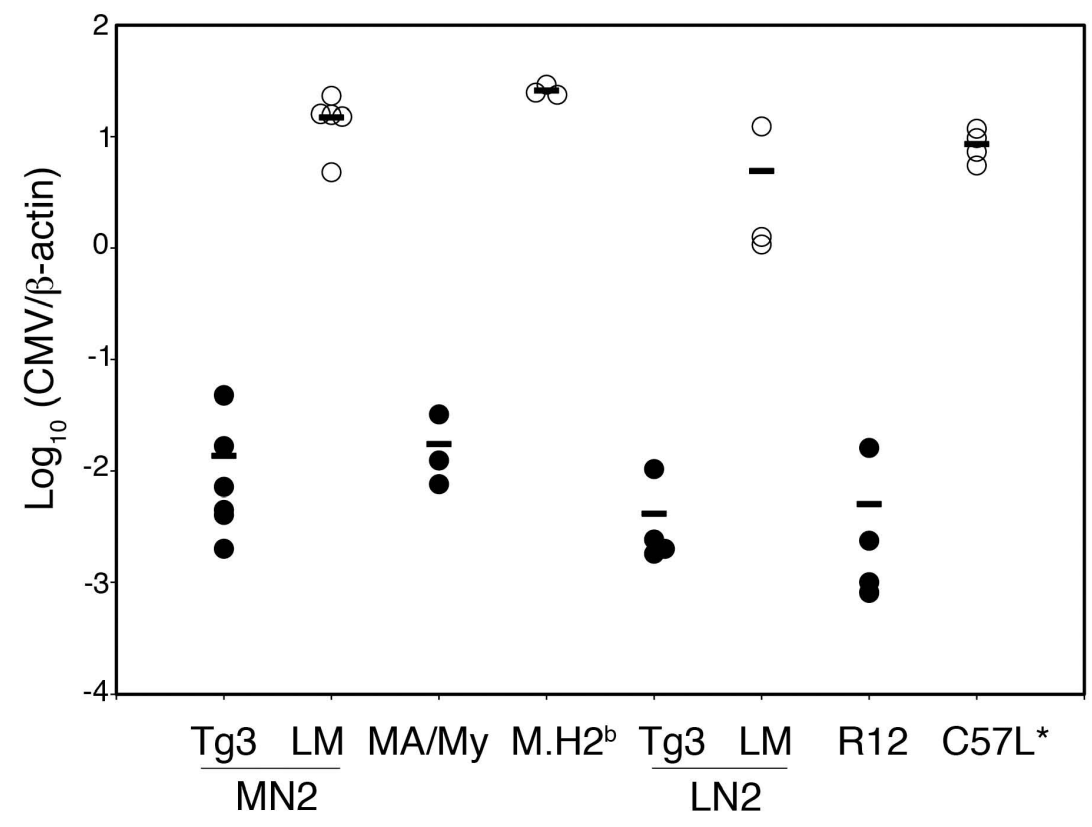


Figure 20. Ly49G2 expressing NK cells mediate effective MCMV control in Tg3-D ${ }^{\mathrm{k}}$ mice. A. Splenocytes from an uninfected Tg3MN2 mouse were stained for CD3, NK1.1 and Ly49G2. Left, numbers indicate the percentage of splenocytes within the NK1.1+ CD3- lymphocyte gate. Shown right, the plot is gated on NK1.1+ CD3- lymphocytes. The plots are a representative of several transgenic mice. B. PBS, 4D11 or PK136 treated Tg3MN2, MA/My mice or untreated nontransgenic littermates (Tg3-LM) were infected with $10^{5}$ PFU MCMV. Spleen MCMV genome levels at $90 \mathrm{hr}$ post-infection are shown. 
A.

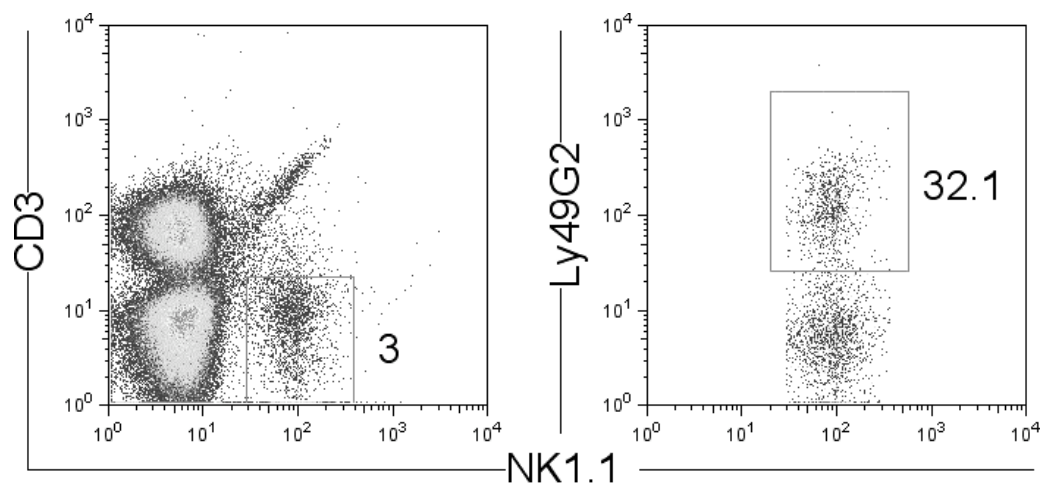

B.

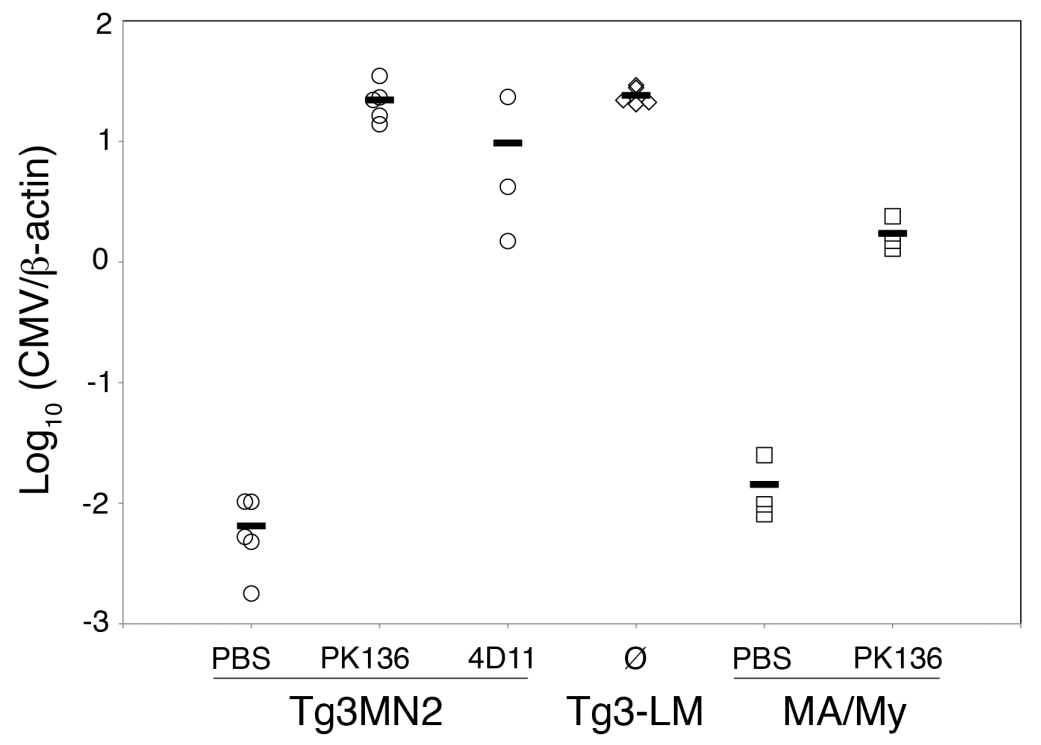


infection in $\mathrm{D}^{\mathrm{k}}$ transgenic mice as we previously reported in $\mathrm{R} 7$ mice (Chapter III). In accord, the numbers of Ly49G2+ NK subset doubled in the spleen of Tg3MN2 transgenic mice at $90 \mathrm{hr}$ after infection compared to uninfected mice, whereas Ly49G2- cell numbers dropped in the same mice (Fig. 21A). It is worth noting that the G2+/G2- ratio increased from 1:2 to $2.5: 2$ after infection (Fig. 21A), further highlighting the specific response of G2+ NK cells. In contrast, 14B11+ (pan-specific Ly49 mAb) NK cells with multiple Ly49 receptors displayed remained the same before and after infection (Fig. 21B). On the other hand, both G2+ and G2- NK cells decreased by more than 10 fold in nontransgenic littermates (data not shown). Taken together, we conclude that selective expansion of $\mathrm{G} 2+\mathrm{NK}$ cells is promoted by $\mathrm{D}^{\mathrm{k}}$ expression during MCMV infection. 
Figure 21. Specific expansion of Ly49G2+ NK cells in $D^{k}$ transgenic mice. Splenocytes were isolated from infected Tg3MN2 mice and stained for NK1.1, CD3 and 4D11+ Ly49G2 (A) or 14B11+ Ly49C/I/F/H (B). A. Shown are average total numbers of G2+ (filled) and G2- (open) NK cells at the indicated times after MCMV infection. G2+ NK cells increased significantly between $39-90 \mathrm{~h}$ after infection until they were also significantly higher than in uninfected spleen $(\mathrm{P}<0.05)$. B. As in $\mathrm{A}$, but values represent total numbers of 14B11+ (filled) and 14B11- (open) NK cells in Tg3MN2 spleens after infection. 14B11+ NK cells, on the other hand, decreased by $39 \mathrm{~h}$ after infection but did not significantly change at $90 \mathrm{~h}$ after infection compared to that of control spleen $(\mathrm{P}>$ $0.5)$. 
A

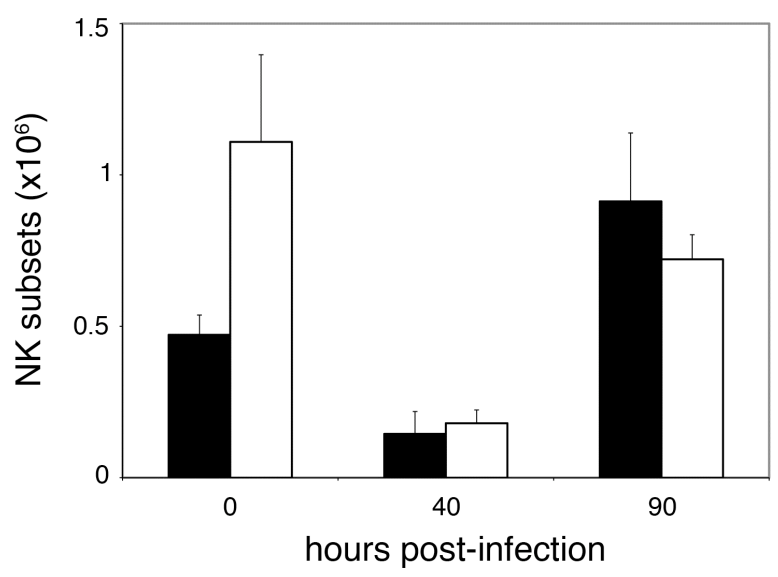

B

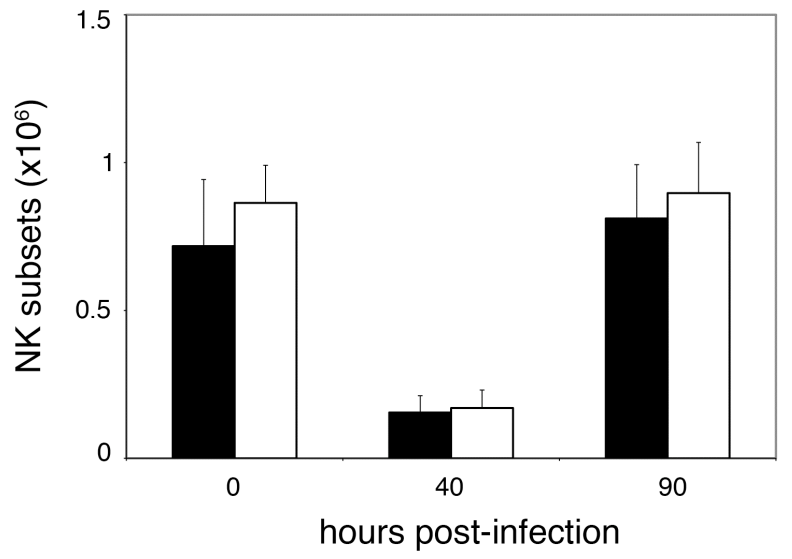




\section{Discussion}

$\mathrm{D}^{\mathrm{k}}$ serves as a strong candidate for the $\mathrm{H}-2^{\mathrm{k}} \mathrm{Cmv}{ }^{\mathrm{r}}$ locus for the following reasons: 1) it locates within the minimized 0.3-Mb H-2 ${ }^{\mathrm{k}} \mathrm{Cmv}^{\mathrm{r}}$ interval (Chapter III); 2) MA/My NK

cells mediate $\mathrm{H}-2^{\mathrm{k}}$ dependent $\mathrm{MCMV}$ control; 3 ) it is specifically recognized by the activating NK Ly49P receptor in the context of MCMV infection; 4) an NK subset expressing the inhibitory Ly49G2 receptor, which ligates $\mathrm{D}^{\mathrm{k}}$, is required for $\mathrm{H}-2^{\mathrm{k}}$ linked MCMV resistance (Chapter III); 5) Ly49G2 should be released from $\mathrm{D}^{\mathrm{k}}$ engagement upon MCMV downregulation of $\mathrm{D}^{\mathrm{k}}$. Although the actual control mechanisms of NK cells still remain elusive, these findings justify a further study to directly assess genetic contribution of $\mathrm{D}^{\mathrm{k}}$ to $\mathrm{MHC}$ associated MCMV resistance. Here we demonstrated that $\mathrm{D}^{\mathrm{k}}$ gene alone is sufficient to convert MCMV susceptibility in $\mathrm{H}-2^{\mathrm{b}}$ mice through $\mathrm{D}^{\mathrm{k}}$ transgenic expression.

The transgene utilized is a $\sim 10-\mathrm{kb}$ genomic fragment isolated from a $\mathrm{C} 3 \mathrm{H} \mathrm{BAC}$ clone, which assures that $\mathrm{D}^{\mathrm{k}}$ expression is controlled by the endogenous promoter and regulatory elements. Probably due to this endogenous regulation, we did not observe an overexpression of the $\mathrm{D}^{\mathrm{k}}$ transgene based on surface staining with a specific $\mathrm{mAb}$ for $\mathrm{D}^{\mathrm{k}}$; the expression levels of $\mathrm{D}^{\mathrm{k}}$ in transgenic mice were the same as the mice bearing only one copy of $\mathrm{H}-2^{\mathrm{k}}$ alleles (Fig. 17B). Although our $\mathrm{D}^{\mathrm{k}}$ transgene was obtained from $\mathrm{C} 3 \mathrm{H} / \mathrm{HeJ}$, its coding sequence is identical to the $\mathrm{MA} / \mathrm{My}^{\mathrm{k}}$ gene, indicating the transgenic $\mathrm{D}^{\mathrm{k}}$ protein if faithfully expressed will deliver the same effects as that of MA/My. Indeed, the same resistant trait linked to $\mathrm{H}-2^{\mathrm{k}}$ is manifested in $\mathrm{D}^{\mathrm{k}}$ transgenic mice, indicating that $\mathrm{D}^{\mathrm{k}}$ corresponds to the $\mathrm{H}-2^{\mathrm{k}} \mathrm{Cm} v^{r}$ locus. 
Consistent with NK cell mediated MCMV control in $\mathrm{H}-2^{\mathrm{k}}$ MA/My and R7 mice, we found that MCMV resistance in $\mathrm{D}^{\mathrm{k}}$ transgenic mice is fully dependent on NK cells. Thus, the $\mathrm{D}^{\mathrm{k}}$ gene appears to have the same ability to regulate NK antiviral immunity as a H-2 $C m v^{r}$ locus, further supporting $\mathrm{D}^{\mathrm{k}}$ as the critical genetic factor. Importantly, Ly49G2+ NK cells are also required for effective MCMV control in the transgenic mice, the same phenomenon that is observed in the resistant R7 mice. Although the mechanistic roles of the inhibitory Ly49G2 receptor in $\mathrm{D}^{\mathrm{k}}$ dependent MCMV resistance have not yet been elucidated, several possibilities may be considered: 1) MCMV efficiently downregulates MHC-I $D^{k}$, which could be detected by the Ly49G2 receptor; 2) Since $D^{k}$ complexes with gp34 on the cell surface (see Chapter V), Ly49G2 binding of $\mathrm{D}^{\mathrm{k}}$ may be affected by gp34, leading to further release of inhibitory signals.

The activating Ly49P receptor was proposed to mediate MCMV control in MA/My, because it specifically recognizes $\mathrm{D}^{\mathrm{k}}$ expressed on MCMV infected cells (60). It is possible that Ly49P is co-expressed on some Ly49G2+ NK cells. Thus, NK cells may be activated by integration of positive signals delivered by Ly49G2 and Ly49P receptors responding to MCMV infection. Further study of this control mechanism will help to delineate the interactions between NK receptors and host MHC class I. 


\section{Chapter V}

\section{Conclusions}

\section{H-2 class I D locus responsible for innate MCMV resistance in MA/My}

The outcomes of virus infection are influenced by host genetic factors. In the mouse model of MCMV infection, $\mathrm{H}-2^{\mathrm{k}}$ linked genes not only regulate virus replication levels but also host survival. Previous studies confirmed that innate MCMV resistance is associated with H-2 in MA/My $(60,61)$. However, the H-2 linked $C m v^{r}$ locus has not been defined and the responsible gene(s) remains unknown. In this dissertation, $\mathrm{H}-2^{\mathrm{k}}$ $C m v^{r}$ is precisely mapped to a $0.3-\mathrm{Mb}$ interval with only 30 genes in the $\mathrm{H}-2 \mathrm{D}$ subregion by assessing innate MCMV immunity in a panel of recombinant congenic strains generated in the lab. The positional gene candidate $H-2 D^{k}$ is identified as responsible to regulate innate $\mathrm{MCMV}$ immunity. Since $\mathrm{NK}$ cells are required for $\mathrm{H}-2$ dependent MCMV resistance in MA/My, this system provides a useful tool to study innate virus immunity regulated by host MHC genes.

\section{H-2 $D^{k}$ enhances NK cell response to MCMV infection}

\section{NK cells are functional in MCMV infected $\mathrm{H}-2^{\mathrm{k}}\left(\mathrm{Cmv}^{\mathrm{r}}\right)$ and $\mathrm{H}-2^{\mathrm{b}}\left(\mathrm{Cmv}^{\mathrm{s}}\right)$ congenic strains}

NK cells are able to effectively control MCMV infection in MCMV-resistant MA/My and congenic C57L.M-H2 $2^{k}$ strains, but not in MCMV-susceptible C57L and congenic MA/My.L-H2 $2^{b}$ strains. This difference is not due to the presence of dysfunctional NK 
cells in $\mathrm{Cmv}^{\mathrm{s}}$ strains because $\mathrm{NK}$ cells from both $\mathrm{Cmv}^{\mathrm{r}}$ and $\mathrm{Cmv}^{\mathrm{s}}$ mice are equally competent to respond to cytokines induced by MCMV infection and activated to produce IFN- $\gamma$ as well as the cytotoxic protein, perforin (data not shown). In other words, nonspecific activation of NK cells in the inflammatory environment is intact in infected $\mathrm{Cmv}^{\mathrm{s}}$ mice. Rather, deficient NK control of MCMV infection in $\mathrm{Cmv}^{\mathrm{s}}$ mice should be explained by the inability of NK cells to specifically recognize viral signatures on infected cells. Strikingly, the ability of NK cells to recognize and eliminate infection is dictated by $\mathrm{D}^{\mathrm{k}}$ expression.

\section{NK-mediated $H-2^{k}$ MCMV resistance may involve $D^{k}$ ligand recognition by inhibitory and stimulatory receptors}

In this dissertation, we uncovered an important role for Ly49G2 receptors in $\mathrm{D}^{\mathrm{k}}$ dependent NK mediated MCMV control, because depletion of Ly49G2+ subset led to loss of MCMV control in $\mathrm{Cmv}^{\mathrm{r}}\left(\mathrm{R} 7\right.$ and $\left.\mathrm{Tg} 3-\mathrm{D}^{\mathrm{k}}\right)$ mice. Moreover, specific expansion and selective activation of Ly49G2+ NK cells correlates with efficient MCMV control. Given

that the critical role of Ly49G2 in virus control requires $\mathrm{D}^{\mathrm{k}}$ expression, we hypothesize that Ly49G2 sensing of altered $\mathrm{D}^{\mathrm{k}}$ expression during infection contributes to NK recognition of infected targets. This hypothesis is supported by: 1) the evidence that $\mathrm{D}^{\mathrm{k}}$ is a specific ligand for Ly49G2 $[(18,111)$ and our unpublished results]; 2$)$ the finding that MCMV infection efficiently and quickly downregulates $\mathrm{D}^{\mathrm{k}}$ surface expression; 3 ) the fact that important role of inhibitory Ly49 receptors has long been established in NK recognition of MHC class I deficient targets.

MCMV glycoprotein gp34 associates with MHC class I on the cell surface (45) and thus 
may interfere with class I interaction with Ly49 receptors. It was noticed that gp34 couples with certain class I alleles $\left(\mathrm{K}^{\mathrm{b}}, \mathrm{D}^{\mathrm{d}}\right.$ and $\left.\mathrm{L}^{\mathrm{d}}\right)$ more efficiently than others $\left(\mathrm{K}^{\mathrm{d}}\right.$ and $\left.\mathrm{D}^{\mathrm{b}}\right)(45,46)$. These findings prompted us to carefully examine whether gp34 has a potential gene- or allele- specific effect on $\mathrm{D}^{\mathrm{k}}$ using a mutant virus lacking m04/gp34. Since the other two MCMV immunoevasins, m06 and m152, compete with m04 to target MHC-I molecules $(47,91), \Delta \mathrm{m} 06$ and $\Delta \mathrm{m} 152$ were also included for this study. At $24 \mathrm{hr}$ post-infection, $50-60 \%$ of L929 cells were positive for anti-MCMV mouse serum in each virus infection (Fig. 22A), indicating all the infections achieved comparable levels. Interestingly, WT had an equal capacity to downregulate $\mathrm{K}^{\mathrm{k}}$ as $\Delta \mathrm{m} 04$, while $\mathrm{D}^{\mathrm{k}}$ was more efficiently downregulated by $\Delta \mathrm{m} 04$ than WT (Fig. 22B). In other words, m04 positively regulates $\mathrm{D}^{\mathrm{k}}$ surface expression but exerts no measurable effect on the $\mathrm{K}^{\mathrm{k}}$, indicating that m04/gp34 only allows $\mathrm{D}^{\mathrm{k}}$ surface expression even in the presence of m06 and m152 in WT infected cells. In support, a significant increase of $\mathrm{D}^{\mathrm{k}}$ but not $\mathrm{K}^{\mathrm{k}}$ is observed in $\Delta \mathrm{m} 06$ infected cells ( $\Delta \mathrm{m} 06$ vs. uninfected) probably due to the positive gp34 effect (Fig. 22B). On the other hand, m152 seems to cooperate with $\mathrm{m} 06$ to more efficiently downregulate $\mathrm{D}^{\mathrm{k}}$ because its absence led to a higher $\mathrm{D}^{\mathrm{k}}$ but not $\mathrm{K}^{\mathrm{k}}$ surface expression $(\Delta \mathrm{m} 152 \mathrm{vs.} \mathrm{WT}$, Fig. 22B). Taken together, m04/gp34 selectively allows $D^{k}$ surface expression by competing with $\mathrm{m} 06$ and $\mathrm{m} 152$ during infection.

The selective impact of gp34 on $\mathrm{D}^{\mathrm{k}}$ expression led us to study a physical association of gp34 with the $\mathrm{D}^{\mathrm{k}}$ class I molecule. A surface biotinylation approach was used to focus on association of class I proteins with gp34 on the cell surface. Biotinylated surface proteins, including $\mathrm{H}-2^{\mathrm{k}}$ class I and gp34 molecules, were immunoprecipitated with anti- $\mathrm{D}^{\mathrm{k}}$ or $-\mathrm{K}^{\mathrm{k}}$ mAbs and blotted with streptavidin-HRP. Surprisingly, we found that a band of $\sim 34 \mathrm{kDa}$ 
Figure 22. Regulation of $\mathrm{H}-2^{\mathrm{k}}$ class I molecules by MCMV immunoevasins in L929 cells. L929 cells were infected with WT Smith strain or MCMV mutants lacking m04/gp34 $(\Delta \mathrm{m} 04), \mathrm{m06} / \mathrm{gp} 48(\Delta \mathrm{m} 06)$ or m152/gp40 $(\Delta \mathrm{m} 152)$ at an MOI of 10 . A. At 24 hr post-infection, cells were harvested and stained with anti-MCMV serum generated in BALB/c. The percentages of serum-positive infected cells were indicated for each virus infection. B. As in A, surface class I proteins on uninfected L929 cells or cells after different infections were stained with anti- $\mathrm{K}^{\mathrm{k}}$ or $-\mathrm{D}^{\mathrm{k}}$ specific $\mathrm{mAbs}$ and assessed by flow cytometry. 
A.
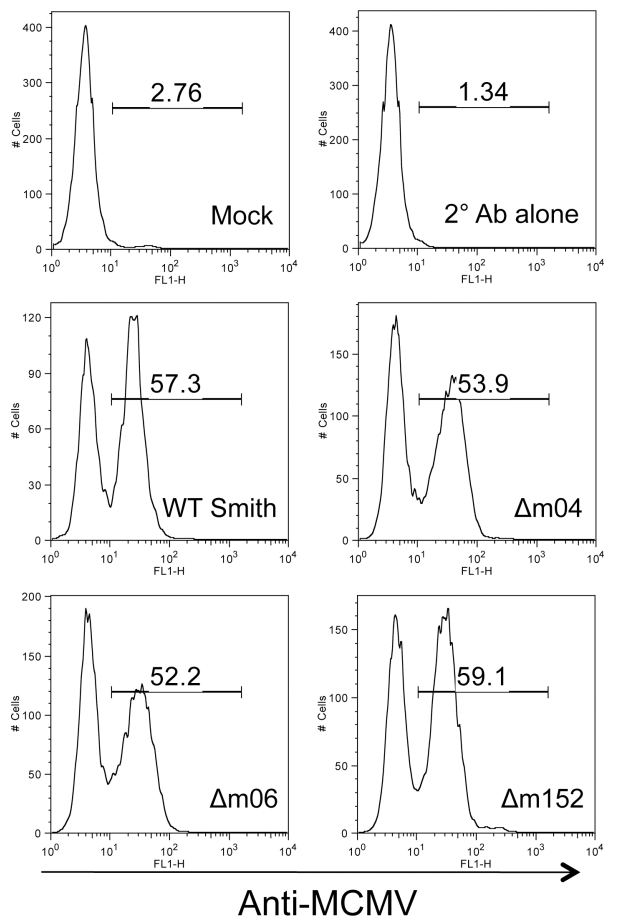

B.
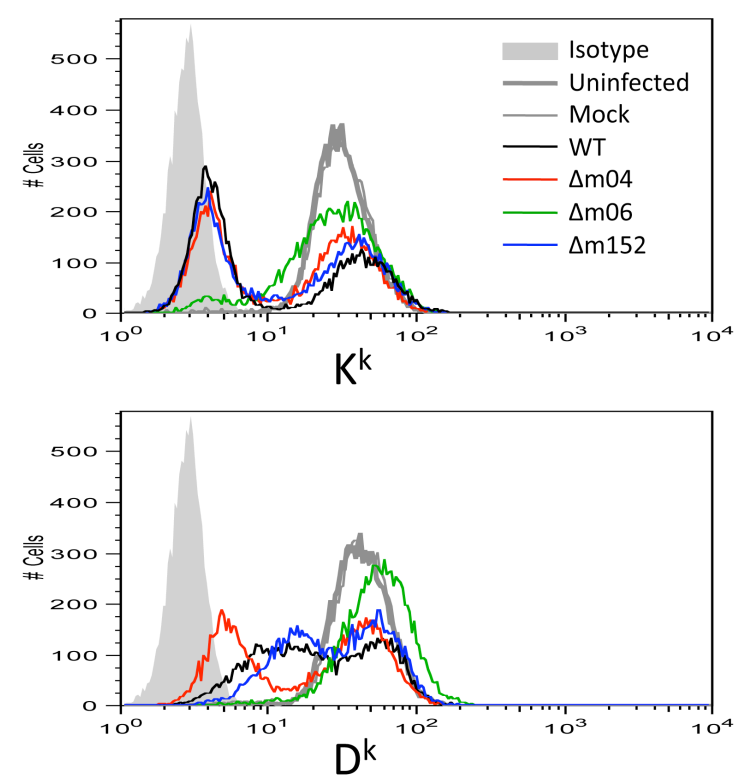
co-precipitated with $\mathrm{D}^{\mathrm{k}}$, but not with $\mathrm{K}^{\mathrm{k}}$, from $\mathrm{WT}, \Delta \mathrm{m} 06$ and $\Delta \mathrm{m} 152$ infected cell extracts (Fig. 23A). The band for the WT sample was detected but faint probably due to a lower MOI used for the WT infection (data not shown). This 34-kDa protein is absent in uninfected or $\Delta \mathrm{m} 04$ infected cell lysates, indicating it is the viral protein gp34 (Fig. 23A). The presence of surface gp34 associated with $\mathrm{D}^{\mathrm{k}}$ was confirmed with anti-gp34 rabbit serum (8142) (Fig. 23B). Since $\mathrm{D}^{\mathrm{k}}$ associated with gp34 could be immunoprecipitated by the anti- $D^{k} \mathrm{mAb}$, this rules out the possibility that downregulation of $\mathrm{D}^{\mathrm{k}}$ surface expression detected by the same $\mathrm{mAb}$ is due to a physical blocking of antibody access to $\mathrm{D}^{\mathrm{k}}$ molecules by gp34. We conclude that gp34 preferentially associates only with $\mathrm{D}^{\mathrm{k}}$ on the surface of MCMV infected $\mathrm{H}-2^{\mathrm{k}}$ cells.

Formation of surface $\mathrm{D}^{\mathrm{k}}$-gp34 complexes during infection may affect Ly49 receptor binding. Here I propose a refined model for NK cell recognition of MCMV infection (Fig. 24). During in vivo infection, $\mathrm{D}^{\mathrm{k}}$ expression is slightly upregulated by type I IFNs in uninfected cells but efficiently downregulated in infected cells. When NK cells encounter infected cells, the inhibitory Ly49G2 receptor senses MCMV downregulation of $\mathrm{D}^{\mathrm{k}}$; gp34 may interfere with Ly49G2- $\mathrm{D}^{\mathrm{k}}$ recognition and further minimizes the inhibitory signal. Consequently, Ly49G2+ NK cells recognize 'missing self' (absence of $\mathrm{D}^{\mathrm{k}}$ ligands) and are activated to lyse infected targets. Recent data demonstrate that gp34 is necessary, but not sufficient, for the activating Ly49P receptor to recognize $\mathrm{D}^{\mathrm{k}}$ in vitro (127). Thus, NK recognition of infected cells may also involve Ly49P. In this scenario, $\mathrm{D}^{\mathrm{k}}$-gp34 complexes recognized by Ly49P receptors may simultaneously prevent interaction with Ly49G2 receptors, thereby releasing inhibitory signals to further activate MCMV control. 
Figure 23. Selective association of $D^{\mathbf{k}}$ with gp34 on the cell surface. A. L929 cells were infected with WT smith strain, $\Delta \mathrm{m} 04, \Delta \mathrm{m} 06$ or $\Delta \mathrm{m} 152.20 \mathrm{hr}$ p.i., cell surface proteins were biotinylated and cell lysate extracts were subjected to immunoprecipitation (IP) with anti-D $\mathrm{D}^{\mathrm{k}}$ or anti-K $\mathrm{K}^{\mathrm{k}} \mathrm{mAbs}$. B. After IP as described in A, the immune complexes associated with class I were released by boiling in $1 \%$ SDS for $10 \mathrm{~min}$ and then subjected to $2^{\text {nd }}$ round IP using anti-gp34 serum. Western blot was performed using streptavidinHRP. The size position of rainbow markers is also indicated. 
A

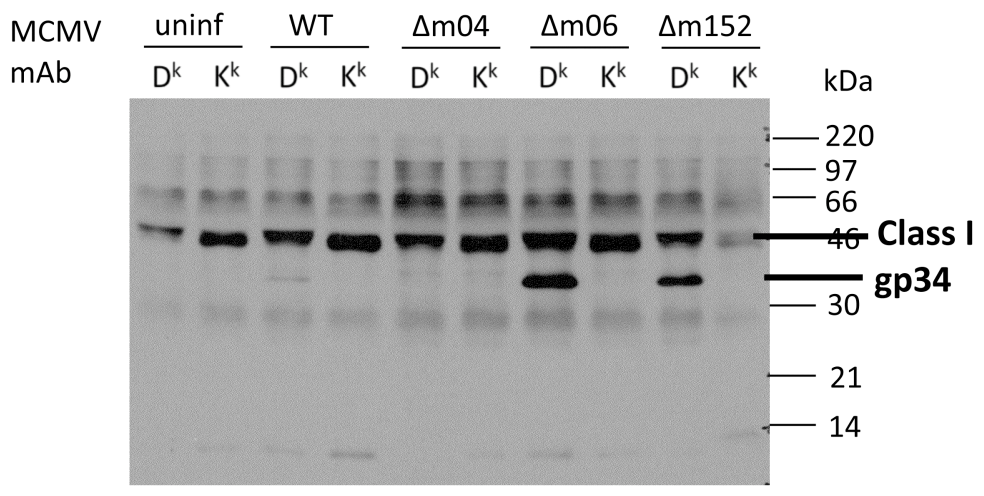

B

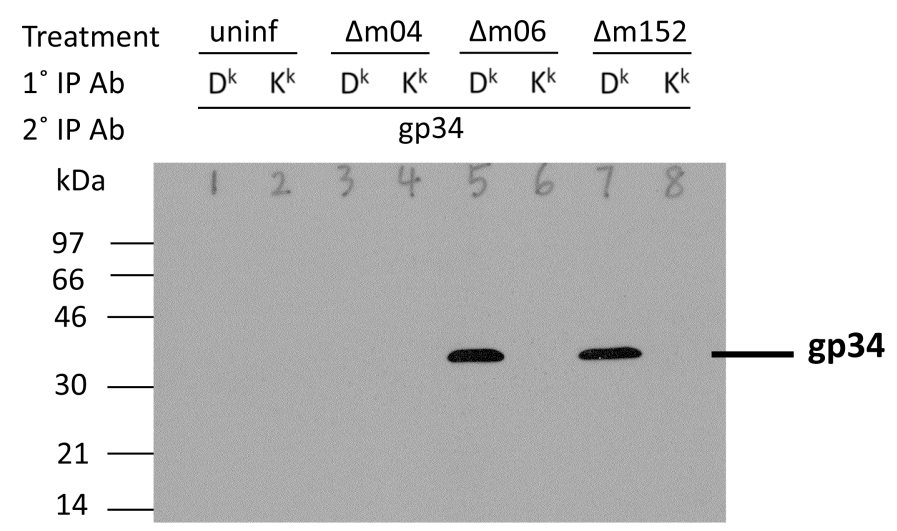




\section{Figure 24. Schematic representation of Ly49G2 receptor-bearing NK cells from} MA/My mice in recognition of MCMV infection. A. In the inflammatory environment of infected mice, uninfected cells display normal or upregulated $\mathrm{D}^{\mathrm{k}}$ (induced by type I IFNs) and are protected from NK killing through interaction with inhibitory Ly49 receptors, such as Ly49G2. B. In MCMV-infected cells, most of $\mathrm{D}^{\mathrm{k}}$ proteins are either retained in the ER-Golgic compartment by gp40 or degraded in the lysosomes with gp48. Only a small proportion of $\mathrm{D}^{\mathrm{k}}$ associated with gp34 is transported to the cell surface. Due to diminished $\mathrm{D}^{\mathrm{k}}$ expression and gp34 association with $\mathrm{D}^{\mathrm{k}}$, the Ly49G2 receptor is no longer engaged, which leads to activation of NK cells. On the other hand, the activating Ly49P receptor may deliver additional stimulatory signal through interaction with $\mathrm{D}^{\mathrm{k}} / \mathrm{gp} 34$. Upon activation, NK cells synthesize and release cytotoxic proteins (perforin and granzymes) and lyse infected cells. 

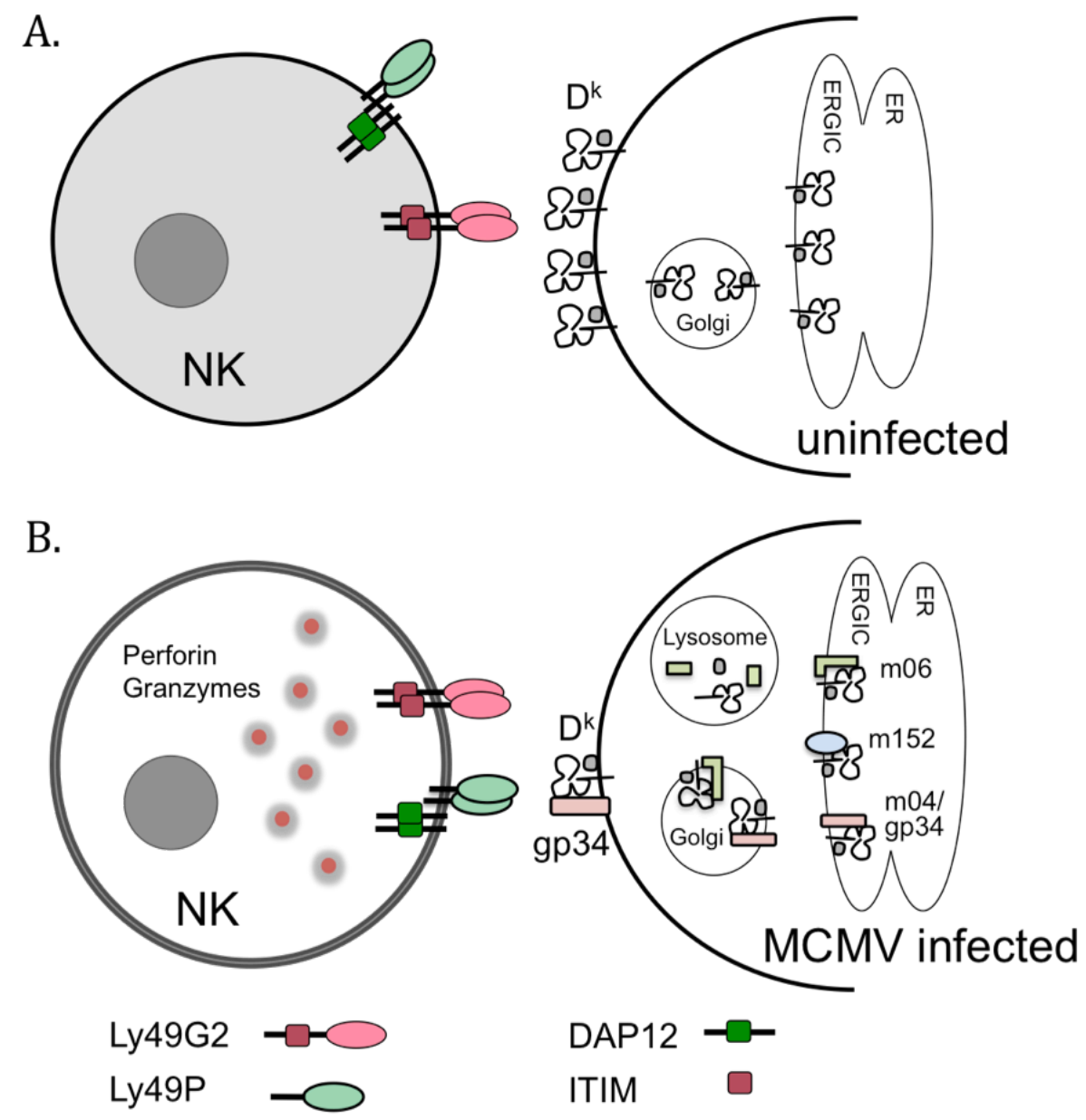

DAP12 $\square$

ITIM

ITAM 
Theoretically, other Ly49 inhibitory receptors for $\mathrm{D}^{\mathrm{k}}$, if there are any, may also play a role in virus recognition. However, the likelihood for indispensible roles for Ly49P and other Ly49 receptors is low because the residual $65-70 \%$ NK cells which should express Ly49P and/or other Ly49 receptors for $\mathrm{D}^{\mathrm{k}}$, are unable to control virus infection after depletion of the Ly49G2 subset. It is unlikely a quantitative issue, since depletion of irrelevant Ly49 subset(s) did not affect the residual Ly49H+ NK cells to control MCMV infection in B6 mice (112). Although further investigations are needed to understand the mechanisms involving Ly49G2 and $\mathrm{D}^{\mathrm{k}}$, here this research established a definitive role for an inhibitory receptor and a class I allele in innate virus control.

\section{MHC $\mathrm{H}^{\mathrm{k}}{ }^{\mathrm{k}}$ MCMV resistance through NK cells as a novel model for human NK cell immunity to viruses}

In human, recent genetic studies have revealed that certain combinations of KIR and HLA class I alleles greatly impact the disease outcomes of some virus infections. For instance, a combined genotype for KIR2DL3 / HLA-C1 was seen to be protective in HCV infected patients (105); KIR3DS1 / HLA-Bw4 and KIR3DL1 and given HLA-B alleles were associated with protection in HIV infected patients (128-131). However, not all KIR/HLA combinations were associated with protection. Rather, some combinations were clearly associated with greater susceptibility to autoimmune diseases or certain cancers (121). Thus, although the genetic associations strongly implicate NK receptors and their HLA ligands with human disease control, the mechanisms are still not clear. This thesis study of NK-mediated virus immunity under MHC genetic control has 
established a novel model to begin to examine the role for NK cell receptors, as they can be influenced by MHC alleles, in virus immunity.

In both human and mouse, NK cells are licensed or educated by MHC class I molecules through their inhibitory KIR or Ly49 receptors in order to achieve self-tolerance after maturation $(25,27,28)$. In other words, NK cells that express inhibitory receptors for self MHC class I are fully competent, whereas those that lack any inhibitory MHC I receptor are hyporesponsive. Although the positive role of inhibitory receptors in NK cell education by MHC class I is widely accepted $(132,133)$, the underlying mechanisms are not well understood. Therefore, further study of MHC regulated NK cell immunity may shed light on NK cell education. On the other hand, the consequence of NK cell education by KIR/Ly49-MHC I may also help to explain the association between KIR/Ly49, MHC and diseases. 


\section{Future Directions}

Although Ly49G2 bearing NK cells are responsible for $\mathrm{D}^{\mathrm{k}}$ dependent MCMV resistance, the identity of the inhibitory Ly49G2 receptor and its functional interaction with $\mathrm{D}^{\mathrm{k}}$ need to be confirmed in vitro. Moreover, blocking Ly49G2 in vivo should also abrogate MCMV control if the Ly49G2 receptor-ligand interaction is important for MCMV recognition. To further substantiate and understand the role of Ly49G2 in NK recognition of MCMV infection, I propose the following studies:

1. Confirm that 4D11 only immunoprecipitates the inhibitory Ly49G2 receptor without an associated co-receptor and that Ly49G2 can be costained with 4D11 and the $\mathrm{D}^{\mathrm{k}}$ tetramer.

2. Clone and express the Ly49G2 $2^{\text {mamy }}$ and Ly49G2 $2^{\mathrm{c} 571}$ receptor in a rat NK cell line, RNK-16, and study whether the G2- $\mathrm{D}^{\mathrm{k}}$ interaction inhibits RNK killing of rat YB2/0 targets expressing $D^{k}$ (111). Since MCMV gp34 can form a complex with $\mathrm{D}^{\mathrm{k}}$ on the cell surface, YB2/0-D $\mathrm{D}^{\mathrm{k}}$ can be cotransfected with gp34 to test whether gp34 blocks $\mathrm{D}^{\mathrm{k}}$ recognition by the Ly49G2 receptor.

3. Test whether blocking of the Ly49G2 receptor in vivo affects MCMV control with the $F^{\prime}(a b)_{2}$ fragments of the Ly49G2-specific 4D11 or AT8 mAbs.

4. For a long-term goal, the role of Ly49G2 can be formally addressed by generating a Ly49G2 transgenic mouse on a Ly49-/- background or a Ly49G2 KO mouse.

Inhibitory Ly49 receptors can be engaged by class I ligands on target cells (in trans) or on the same NK cell (in cis). Recent data demonstrate that cis interaction of inhibitory Ly49A receptor with its ligand $\mathrm{D}^{\mathrm{d}}$ is necessary to educate NK cells (134). To test whether 
$\mathrm{D}^{\mathrm{k}}$ expression on NK cells only (education) or on targets only ('missing-self' recognition) or both is important to rescue MCMV control, we can perform NK cell transfer from $\mathrm{D}^{\mathrm{k}}$ transgenic mice to nontransgenic $\mathrm{H}-2^{\mathrm{b}}$ littermates and vice versa. Since NK cells with the $\mathrm{NKC}^{\mathrm{c} 5 \mathrm{~L}}$ haplotype are refractory to PK136-mediated immunodepletion, recipients bearing $\mathrm{NKC}^{\text {mamy }}$ are NK-depleted with PK136 prior to NK cell transfer from donors with $\mathrm{NKC}^{\mathrm{c} 571}$. By this strategy, most of the donor NK cells will be unaffected and survive to repopulate. Importantly, $\mathrm{T}$ cells from recipients are also removed to prevent rejecting donor cells because the donor and recipient can be mismatched for MHC-I expression (A and C in Fig. 25). The experimental setup for four different NK cell transfers is depicted in Figure 25 and the possible outcomes of each transfer are discussed here.

A: donor NK cells express Ly49G2 but not $\mathrm{D}^{\mathrm{k}}$, while the targets express $\mathrm{D}^{\mathrm{k}}$. Thus, $\mathrm{D}^{\mathrm{k}}$ is available for interaction with Ly49G2 in trans but not in cis. In this scenario, donor Ly49G2 NK cells are not educated by $\mathrm{D}^{\mathrm{k}}$, but they should be able to sense downregulated $\mathrm{D}^{\mathrm{k}}$ on infected target cells.

B: a positive control with $\mathrm{D}^{\mathrm{k}}$ expression on both donor NK cells and the targets in the recipient.

C: donor NK cells express both Ly49G2 and $\mathrm{D}^{\mathrm{k}}$ but the targets do not express $\mathrm{D}^{\mathrm{k}}$. Thus, these NK cells are educated by $\mathrm{D}^{\mathrm{k}}$ but $\mathrm{D}^{\mathrm{k}}$ is not available for Ly49G2 trans recognition.

D: a negative control, neither NK cells nor targets express $\mathrm{D}^{\mathrm{k}}$.

Comparison 1 (A vs. B and D). By comparing A with B and D, if A fully rescues MCMV control comparable to $\mathrm{B}$, it indicates that $\mathrm{D}^{\mathrm{k}}$ on target cells is important for NK 
Figure 25. A diagram for NK transfer setup. Four different transfer experiments were depicted (A-D) with indicated Ly49G2 and $\mathrm{D}^{\mathrm{k}}$ expression on NK or target cells after transfer. Donors are treated with 4D11 or control rIgG to study the role of Ly49G2 bearing NK cells. Recipients are treated with PK136, GK1.5 and 2.43 to deplete NK cells, CD4 $\mathrm{T}$ and CD8 $\mathrm{T}$ cells (NK- T-). Numbers on the right indicate comparison among groups. Comparison 1 is among A, B and D; comparison 2 is among C, B and D. 


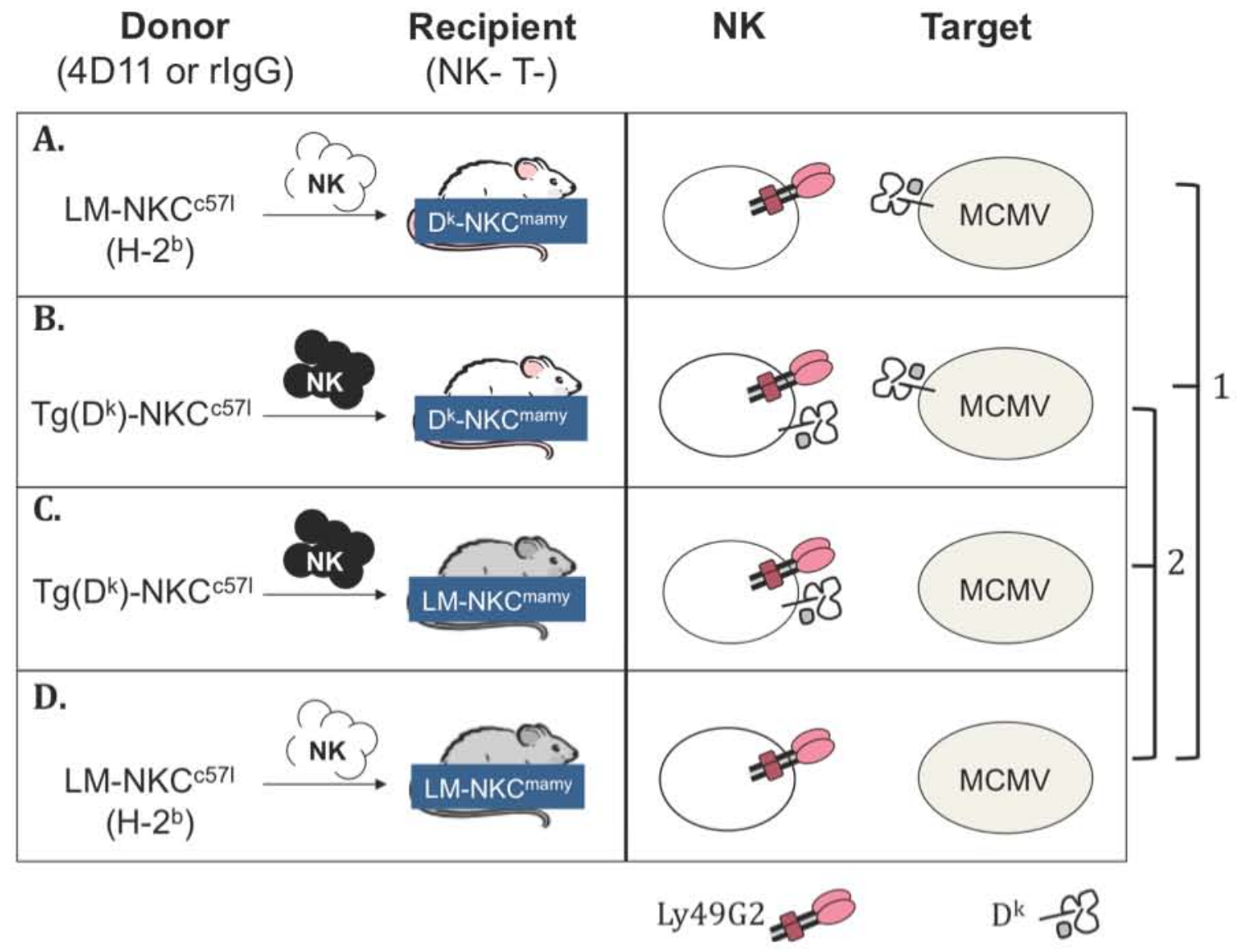


recognition of MCMV infection but NK cell education by $\mathrm{D}^{\mathrm{k}}$ is not critical for virus control; if A partially rescues MCMV control compared to B and D, it implies that both NK education and $\mathrm{D}^{\mathrm{k}}$ recognition on the target contribute to efficient virus control but neither of them is sufficient for the most effective control; if A is not beneficial to the recipient similar to $\mathrm{D}$, it implies that $\mathrm{D}^{\mathrm{k}}$ recognition on the target is not sufficient while NK education is critical.

Comparison 2 (C vs. B and D). By comparing C with B and D, if C fully rescues MCMV control comparable to $\mathrm{B}$, it indicates that $\mathrm{NK}$ cell education by $\mathrm{D}^{\mathrm{k}}$ is sufficient for effective virus control while $\mathrm{D}^{\mathrm{k}}$ expressed on the target is not required; if C partially rescues MCMV control compared to B and D, it implies that both NK recognition of $\mathrm{D}^{\mathrm{k}}$ on the target NK education contribute to efficient virus control but neither of them is sufficient for the most effective control; if C is not beneficial to the recipient similar to D, it implies that NK education by $\mathrm{D}^{\mathrm{k}}$ is not sufficient while NK recognition of $\mathrm{D}^{\mathrm{k}}$ on the target is critical. 


\section{Materials and Methods}

\section{Mice.}

MA/My and C57L breeder pairs were purchased from the Jackson Laboratory (Bar Harbor, ME) and housed in the MR-5 specific-pathogen-free vivarium at the University of Virginia, which is fully accredited by the American Association for Accreditation of Laboratory Animal Care. A simple sequence length polymorphism (SSLP) markerassisted genome selection method was used to produce MA/My.L-H2 ${ }^{\mathrm{b}}$ (M.L-H2 ${ }^{\mathrm{b}}$ ) mice as we have described previously $(61,135)$. Briefly, $(\mathrm{C} 57 \mathrm{~L} \times \mathrm{MA} / \mathrm{My}) \mathrm{F}_{1}$ hybrid mice were first backcrossed to MA/My. Backcross offspring were selected for $\mathrm{H}-2^{\mathrm{b}}$-linked D17Mit16 and D17Mit10 donor alleles on a genetic background enriched for MA/My alleles. Selected backcross mice were then backcrossed to MA/My, and further selective backcrossing followed by brother-sister crossing for $\mathrm{H}-2^{\mathrm{b}}$ homozygosity yielded the M.L$\mathrm{H}^{2}{ }^{\mathrm{b}}\left(\mathrm{N}_{6}\right.$ [sixth backcross generation]) mice tested as shown in Fig. 1. Notably, homozygous M.L-H2 ${ }^{\mathrm{b}}\left(\mathrm{N}_{9}\right)$ mice display comparable MCMV susceptibilities (not shown). (C57L $\times$ MA/My)F 1 hybrids, L.M-H2 ${ }^{\mathrm{k}}\left(\mathrm{N}_{7}\right)$, and MA/My.L-H2 ${ }^{\mathrm{b}} \mathrm{R} 1$ (M.L-H2 ${ }^{\mathrm{b}} \mathrm{R} 1$ $\left[\mathrm{N}_{9}\right]$ ) recombinant congenic mice were bred in the same facility. All recombinant congenic strains generated by and used in the later figures were backcrossed to the progenitor strain $\mathrm{C} 57 \mathrm{~L}$ or MA/My for at least ten generations. All animal studies were approved by and conducted in accordance with Animal Care and Use Committee oversight. 


\section{Recombinant congenic strain generation, genetic markers and genotyping.}

$\left(\mathrm{C} 57 \mathrm{~L} . \mathrm{M}-H 2^{k} \times\right.$ C57L)F $\mathrm{F}_{1}$ or (MA/My.L-H2 $2^{b}$ x MA/My)F $\mathrm{F}_{1}$ were brother $\mathrm{x}$ sister mated and screened for recombination cross-overs within the D17Mit16-D17Uva09 interval using several simple sequence length polymorphism (SSLP) markers to distinguish MA/My and C57L alleles (Table II). SSLP amplified PCR products were resolved in POP7-filled capillaries and analyzed on a Genetic Analyzer 3130xl using Data Collection (v3.0) and Genemapper software (v4.0, Applied Biosystems, Foster City, CA) as described previously (61). Some unlabeled SSLP amplicons were fractionated in 4\% agarose gel electrophoresis and visualized on a UV transilluminator after ethidium bromide staining.

For generation of novel SSLP markers, chromosome 17 sequence data available from the NCBI was manually inspected for microsatellite repeat sequences. Sequence specific primers were designed and tested for specific amplification of microsatellites and capacity for distinguishing SSLPs (Table II). SNP markers rs 13482961 and $r s 13482963$ were amplified on the iCycler iQ Real-Time PCR detection system (Bio-Rad, Hercules, CA) according to the manufacturer's protocol (Taqman SNPs, Applied Biosystems, Foster City, CA).

Mice with intra-region recombinations were confirmed and further backcrossed to the C57L or MA/My genetic background, followed by more extensive genetic analysis to pinpoint chromosome crossovers as we have described previously (136). The novel recombinant lines have been maintained at the University of Virginia in accordance with IACUC guidelines. 


\section{Cell lines and tissue culture.}

NIH 3 T12 (ATCC CCL-164), NIH 3 T3 (ATCC CRL1658), and L929 (ATCC CCL-1, H-

$\left.2^{\mathrm{k}}\right)$ were grown in Dulbecco's modified Eagle medium supplemented with $10 \%$ (vol/vol) newborn calf serum, penicillin-streptomycin $(100 \mathrm{U} / \mathrm{ml}: 100 \mu \mathrm{g} / \mathrm{ml})$, and glutamine $(2.0$ mM). C57L, MA/My, (C57L $\times$ MA/My)F 1 , and C57L.M-H2 ${ }^{\mathrm{k}}$ MEFs were prepared on $\mathrm{d}$ 16 to 18 postcoitus as described previously (137). After expansion in Dulbecco's modified Eagle medium plus 10\% fetal bovine serum in T175 flasks, passage 2 MEFs were stored under liquid nitrogen. Only passage 2 to 5 MEFs were utilized in experiments. For IFN induction of MHC class I cell surface expression, MEFs were incubated in recombinant mouse IFN- $\gamma$ (Research Diagnostics, Inc.) or IFN- $\beta$ (Fitzgerald Industries, Concord, MA) for 24 to $30 \mathrm{~h}$ before virus infection.

\section{Antibodies and flow cytometry.}

Anti-mouse CD49b (DX5) phycoerythrin (PE), H-2D ${ }^{b}$ (28-14-8) PE, control immunoglobulin G2a (IgG2a) (eBM2a), and rat anti-mouse CD71 and IgG2a, CD4 (RM4-4) FITC, NK1.1 (PK136) PE-Cy7, Ly49C/I/F/H (14B11) biotin, NKG2D (CX5) PE, Ly49G (AT8) biotin, streptavidin-APC-Cy7 and perforin (prf1, eBioOMAK-D) APC were purchased from eBioscience. Anti-mouse CD3 (145-2C11) PerCP and APC, NK1.1 (PK136) PE, CD49b (DX5) PE, Ly49G2 (4D11) FITC, CD8a (53-6.7) PE, IFN- $\gamma$ fluorescein isothiocyanate, $\mathrm{H}-2 \mathrm{~K}^{\mathrm{k}}$ (36-7-5) PE or unlabled, $\mathrm{H}-2 \mathrm{D}^{\mathrm{k}}$ (15-5-5) biotinylated, $\mathrm{H}-2 \mathrm{~K}^{\mathrm{b}}$ (AF6-88.5) PE, and streptavidin-PerCP were purchased from BD Pharmingen. Anti-mouse H-2D ${ }^{\mathrm{k}}(15-5-5)$ PE, purified anti-D $\mathrm{D}^{\mathrm{k}}(15-5-5)$ and CD69 (H1.2F3) APC was purchased from BioLegend. Anti-mouse NKp46 (goat IgG) PE was purchased from 
R\&D Systems. Dr. Wayne Yokoyama kindly provided the PK136 hybridoma. The rat LGL-1 hybridoma 4D11 was purchased from ATCC. Purified PK136 and 4D11 mAbs were obtained from hybridoma supernatants at the University of Virginia Lymphocyte Culture Center. Anti-H-2-K $-\mathrm{D}^{\mathrm{b}}$ (20-8-4S; kindly provided by V. Engelhard, University of Virginia, Charlottesville, VA) antibodies were purified from spent hybridoma supernatant by use of a HiTrap Protein G Hp column (Amersham Pharmacia Biotech, Sweden) and subsequently biotinylated using EZ-Link sulfo- $N$-hydroxysuccinimide- LCbiotin, 2-(4'-hydroxyazobenzene) benzoic acid (HABA), and avidin (Pierce). AntiMCMV serum was generated by immunization of male BALB/c mice with SGV MCMV.

All antibody staining was performed on ice. For analysis of spleen leukocytes, in vitro cultured cell lines or MEFs, cells were first blocked with mAb 2.4G2 $(5 \mu \mathrm{g} / \mathrm{ml})$ on ice for 20-30 min before primary antibody staining. For intracellular IFN- $\gamma$ staining, cells were incubated for $2 \mathrm{~h}$ at $37^{\circ} \mathrm{C}$ in media containing either monensin $(2.5 \mu \mathrm{M})$ or brefeldin $\mathrm{A}(5$ $\mu \mathrm{g} / \mathrm{ml})$. Afterwards, cells were first stained for cell surface markers and then fixed and permeabilized using a CytoFix/CytoPerm kit (BD Pharmingen). Intracellular perforin staining is similar as IFN- $\gamma$ but without prior incubation with monensin or brefeldin A. To study peripheral blood mononuclear cells (PBMCs), blood leukocytes were prepared from tail blood of the $\mathrm{Tg}+$ founder mice or $\mathrm{Tg}$ - littermate control after RBC lysis (Tris$\mathrm{NH}_{4} \mathrm{Cl}$ lysis buffer, $\mathrm{pH}$ 7.2). Ab-labeled cells were analyzed by flow cytometry on a FACScan instrument (BD Biosciences), and data were subsequently analyzed using FlowJo (TreeStar, version 4.3.1 or 8.0). 


\section{Virus assays.}

MCMV (Smith strain, ATCC VR 194) salivary gland stock virus (SGV) was prepared after serial passage in BALB/c as described previously $(61,138)$. Experimental mice (8 to 12 weeks of age) were intraperitoneally (i.p.) infected with SGV stocks $\left(1 \times 10^{5} \mathrm{PFU}\right)$. On day 3.5 post-infection ( 84 to $90 \mathrm{~h}$ ), spleen and liver virus levels were quantified using quantitative real-time PCR (QPCR) as described previously $(61,138)$. All sample measurements were performed in triplicate. For some experiments, spleen homogenate infectious MCMV PFU were also measured on NIH 3T3 monolayers essentially as described previously $(58,138)$, but with a slight modification. Briefly, serially 10 -folddiluted tissue homogenates $(100 \mu \mathrm{l})$ were plated on NIH $3 \mathrm{~T} 3$ cell monolayers (70 to 90\% confluent) in duplicate in 24 -well tissue culture plates for $1 \mathrm{~h}$ at $37^{\circ} \mathrm{C}$ with frequent rocking. Afterwards, MCMV-infected cell monolayers were fully resuspended in D10 medium $(1 \mathrm{ml})$. Virus plaques were counted microscopically on day 3 . In confirmation, infectious virus particles can be efficiently and reliably distributed through limiting dilution based on viral titers determined using this strategy. In particular, when NIH 3T3 monolayers are infected with 0.67 PFU per well (10 wells of a 24-well plate), 20 to $70 \%$ of wells contain at least one plaque by day 3 after cellular infection. Most wells without viral plaques on day 3 after infection remain plaque free through day 7 after infection.

For in vitro MCMV infectivity and replication studies, MEFs growing in 24-well plates were infected with MCMV (multiplicity of infection $[\mathrm{MOI}]=0.08$ ). Supernatants were collected daily through d 8 and subsequently titered on 3 T12 cells. DNA was also isolated from the remaining cell monolayers by use of a Puregene DNA isolation kit as 
described previously (138). Recombinant green fluorescent protein (GFP)-expressing Am157-MCMV (61), wild-type K181, and Smith strain MCMV viruses were utilized after passage and thorough titer determinations with NIH $3 \mathrm{~T} 3$ cells. Cell lines or primary MEFs were infected with a range of MCMV PFU (MOI, 0.01 to 10). L929 cells were infected with T.C.P. virus stocks Smith strain WT, $\Delta \mathrm{m} 04, \Delta \mathrm{m} 06, \Delta \mathrm{m} 152$ or heat inactivated (HI) WT with a MOI $=10$ and trypsinized $20 \mathrm{hr}$ post-infection for immunoprecipitation assays. MEFs infected with T.C.P. virus stocks $(\mathrm{MOI}=4)$ were harvested with trypsin $12 \mathrm{hr}$ post-infection for FACS analysis.

To study the role of NK cells during MCMV infection, mice were i.p. injected with 200 $\mu \mathrm{g}$ anti-NK1.1 mAb PK136 $48 \mathrm{~h}$ before and where noted immediately prior to MCMV infection. Ly49G2+ NK cells were similarly depleted using $200 \mu \mathrm{g}$ anti-Ly49G2 mAb 4D11 given $48 \mathrm{~h}$ before MCMV infection. NK cell depletions from spleen were confirmed by flow cytometry using anti-NKp46, anti-CD49b and anti-Ly49G2 AT8. For T cell depletions, mice were i.p. injected daily with $200 \mu \mathrm{g}$ each of GK1.5 (anti-CD4) and 2.43 (anti-CD8) mAbs for three consecutive days (day $-5,-4,-3$ ) and one more dose three days later immediately before MCMV infection (day 0 ). $\mathrm{T}$ cell depletions were confirmed by flow cytometry using anti-CD4 and anti-CD8 mAb clones other than those used as depleting Abs (data not shown). Spleens and livers were collected from euthanized mice at $3.5 \mathrm{~d}$ post-infection for virus quantitation using QPCR as described previously $(61,138)$. 


\section{Generation of $\mathbf{H}-2 D^{\mathrm{k}}$ transgenic mice.}

$\mathrm{H}-2^{\mathrm{k}}$ BAC clone $121 \mathrm{~F} 5$ was obtained by screening CHORI-34 Mouse C3H/HeJ (Mus musculus) BAC Library, which was originated from genomic DNA of the MCMVresistant $\mathrm{H}-2^{\mathrm{k}}$ strain $\mathrm{C} 3 \mathrm{H} / \mathrm{HeJ}$ (BACPAC Resource Center). A 40-bp probe (TACATCTCTGTCGGCTATGTGGACAACAAGGAGTTCGTGC) designed specifically for $\mathrm{H}-2 \mathrm{D}$ sequence was used for screening the $\mathrm{C} 3 \mathrm{H}$ BAC library (equivalent of 10x genome). The BAC DNA was isolated using Qiagen Plasmid Midi Kit, subjected to complete XhoI digestion and size fractionated in 1\% agarose gel (Pulsed Field Certified Agarose, Bio-Rad) using pulsed field gel electrophoresis (PFGE; 6V/cm, 120 angle, switch time $1^{\prime \prime}-6^{\prime \prime}$, linear ramping factor, $12^{\circ} \mathrm{C}$ for $15 \mathrm{~h}$ ). Two DNA bands of 20-23 $\mathrm{kb}$, one of which was confirmed to contain $\mathrm{D}^{\mathrm{k}}$ gene but not cut by XhoI, were harvested without UV light exposure and purified from the gel (Qiagen Gel Extraction Kit). Purified DNA was subsequently digested with HindIII and fractionated in $1 \%$ agarose gel electrophoresis. As previously described for $\mathrm{H}-2 \mathrm{D}^{\mathrm{b}}$ gene $(123,139)$, a 10-kb HindIII fragment containing entire $\mathrm{D}^{\mathrm{k}}$ gene was purified, cloned into the pBluescript vector and electroporated into XL1-blue cells allowing for blue-white screening. Vector DNA prepared from a positive clone (Qiagen Plasmid Midi Kit) was used for isolation of the $10-\mathrm{kb} \mathrm{D}^{\mathrm{k}}$ transgene.

To verify $\mathrm{H}-2 \mathrm{D}^{\mathrm{k}}$ sequence of the BAC DNA, complete $\mathrm{D}^{\mathrm{k}}$ gene from BAC clones (including $121 \mathrm{~F} 5$ as well as two other $\mathrm{H}-2^{\mathrm{k}}$ BAC clones $201 \mathrm{D} 8$ and $108 \mathrm{P} 20$ ) and $\mathrm{D}^{\mathrm{k}}$ cDNA isolated from the MA/My spleen were sequenced using PCR product amplified with the following primers designed according to the published $\mathrm{H}-2 \mathrm{D}^{\mathrm{k}}$ sequence of 
$\mathrm{C} 3 \mathrm{H} / \mathrm{HeN}$ (124). The $\mathrm{D}^{\mathrm{k}}$ specific primers for sequencing $\mathrm{BAC} \mathrm{D}^{\mathrm{k}}$ were: 5'CTCTAGGGTGTGACTTCTG-3' and 5'-GAACCGGGGCTCTCCGAGGC-3' for the first round PCR amplification and 5'-GGAAACAGTGAGTCGGGCTT-3' and 5'CGGGACACGACGGTCTCGAA-3' for nested PCR (amplified a 732-bp fragment spanning 400bp of the promoter region and exon 1); 5'-GCCCACACTCGCTGAGGTAT-3' and 5'-GCAGCGTCGCATTCCCGAGC-3' (amplified a 721-bp fragment covering exons 2-3); 5'-CACAAGTGGGAGCAGGCTGG-3' and 5'GTTTCCAATCAGGTAAGGCG-3' (amplified a 507-bp fragment from the end of exon 3 to a fourth of intron 3); 5'-CAGTGTAGTGTCAAACAGAC-3' and 5'CTCAGACCCTGCCCTTTCCT-3' (amplified a 644-bp fragment covering exons 4-5); 5'-GGAACACAGCCACACCCCAC-3' and 5'-CCAAGTCCACTCCAGGCA- GC-3' (amplified a 524-bp fragment covering exons 6-8). The following primers sets were used to amplify MA/My $\mathrm{D}^{\mathrm{k}}$ cDNA cloned into the pBluescript vector: 5'GCGGCGGGATCCATGGGGGCGATGGTACCACGC-3' 5'GCAGCGTCGCATTCCCGAGC-3'; 5'-CGGGCCTACCTGGAGGGCAC-3' and 5'CTGGGAGAGACATTTCAGAGC-3'; 5'-CGGGCCTACCTGGAGGGCAC-3' and 5'GCGGCGGAATTCTCACGCTTTACAATCTGGGAGAGACATTTCAG-3’. Finally, this $\mathrm{D}^{\mathrm{k}}$ HindIII fragment after purification (Nucleospin Extract II, MACHEREYNAGEL) was microinjected into fertilized eggs of MCMV-susceptible (MA/My.L-H2 ${ }^{\mathrm{b}} \mathrm{x}$ C57L) $F_{1}$ or (B6 x DBA) $F_{2}$ strains at a concentration of 1-2ng/ $\mu$. The $D^{\mathrm{k}}$ transgenic founders were backcrossed to M.L-H2 ${ }^{\mathrm{b}}$ or $\mathrm{C} 57 \mathrm{~L}$ mice $\left(\mathrm{Cmv}^{\mathrm{s}}\right)$ and $\mathrm{N}_{2}$ backcross progenies with MA/My or C57L NKC haplotypes were used in the virus assays. 


\section{Detection of transgene integration by PCR.}

Transgenic mice were identified by PCR with a polymorphic microsatellite (F: 5'actccctacactagcctgg-3' and R: 5'-gacgggcagtccataatccc-3') located in the intron 3 of H2D gene (123). These primers amplify $\mathrm{D}^{\mathrm{k}}$ gene with a 315 -bp product but $\mathrm{D}^{\mathrm{b}}$ with a $305-$ bp size after 31 cycles at $\mathrm{Tm}=56^{\circ} \mathrm{C}$. To ensure that we detect $\mathrm{D}^{\mathrm{k}}$ gene but not $\mathrm{D}^{\mathrm{b}}$ gene, we used an additional primer set with four (Forward 5'-agatcgccaagggcaatgag-3') and five nucleotides (Reverse 5'-gccggacaaccgctggatcg -3') specific for $H-2 D^{k}$ sequence, allowing specific amplification of $\mathrm{D}^{\mathrm{k}}$ sequence (spanning exons 2-3) at $\mathrm{Tm}=60^{\circ} \mathrm{C}$. PCR products were analyzed on a Genetic Analyzer 3130xl using Data Collection (v3.0) and Genemapper software (v4.0, Applied Biosystems, Foster City, CA) as previously described.

\section{Biochemical analysis.}

Cell surface proteins were biotinylated with EZ-Link Sulfo-NHS-Biotin (Pierce) according to the manufacturer's instruction. Briefly, cells were washed three times with PBS (pH 8.0) and incubated with 2mM EZ-Link Sulfo-NHS-Biotin in PBS (pH 8.0) on ice for $30 \mathrm{~min}$. Biotinylation is quenched by $100 \mathrm{mM}$ glycine in PBS and cells were then washed three times with PBS. For immunoprecipitation (IP) assays, biotinylated cells were lysed in NP-40 lysis buffer (1\% NP-40, $50 \mathrm{mM}$ Tris-HCl, $\mathrm{pH} 8.0,150 \mathrm{mM} \mathrm{NaCl})$ containing protease inhibitor cocktail (Roche) for 30min on ice. Insoluble cell components and debris were removed by centrifugation (BECKMAN Microfuge 22R Centrifuge, 14,000 rpm, $10 \mathrm{~min}, 4^{\circ} \mathrm{C}$ ). The supernatants were precleared with protein $\mathrm{A}$ beads and/or normal rabbit serum (NRS) subjected to primary IP $\left(1^{\circ}\right.$ IP $)$ with anti-D ${ }^{k}(15-$ 
5-5) or anti-K $\mathrm{K}^{\mathrm{k}}$ (36-7-5) mAbs coupled with protein A sepharose (Amersham). After primary IP, immune complexes were dissociated from protein A beads by boiling for 10 min in PBS containing 1\% SDS and $1 \mathrm{ml}$ NP-40 lysis buffer containing 3\% BSA was added afterwards. Sequential IP was then performed by clearing released immune complexes from primary IP with NRS and protein A beads for one hour and followed by secondary IP $\left(2^{\circ} \mathrm{IP}\right)$ using anti-gp34 rabbit serum coupled with protein A beads. Samples were boiled for $5 \mathrm{~min}$ in SDS buffer containing 10\% 2-Mercaptoethanol and separated in $12 \%$ SDS-polyacrylamide gel electrophoresis (SDS-PAGE). The gels were visualized using Streptavidin-HRP $(1 \mathrm{mg} / \mathrm{ml})$ at a dilution of 1:10,000 - 1:20,000 (Pierce, Thermo Fisher Scientific) followed by the substrate (SuperSignal West Pico Substrate, Pierce). 


\section{Bibliography}

1. Huntington, N. D., C. A. Vosshenrich, and J. P. Di Santo. 2007. Developmental pathways that generate natural-killer-cell diversity in mice and humans. Nat Rev Immunol 7: 703-714.

2. Yu, Y. Y., V. Kumar, and M. Bennett. 1992. Murine natural killer cells and marrow graft rejection. Annu Rev Immunol 10: 189-213.

3. Cerwenka, A., and L. L. Lanier. 2001. Natural killer cells, viruses and cancer. Nat Rev Immunol 1: 41-49.

4. Walzer, T., M. Dalod, S. H. Robbins, L. Zitvogel, and E. Vivier. 2005. Naturalkiller cells and dendritic cells: "l'union fait la force". Blood 106: 2252-2258.

5. Degli-Esposti, M. A., and M. J. Smyth. 2005. Close encounters of different kinds: dendritic cells and NK cells take centre stage. Nat Rev Immunol 5: 112-124.

6. Perricone, R., C. Perricone, C. De Carolis, and Y. Shoenfeld. 2008. NK cells in autoimmunity: a two-edg'd weapon of the immune system. Autoimmun Rev 7: 384-390.

7. Dunn, C., M. Brunetto, G. Reynolds, T. Christophides, P. T. Kennedy, P. Lampertico, A. Das, A. R. Lopes, P. Borrow, K. Williams, E. Humphreys, S. Afford, D. H. Adams, A. Bertoletti, and M. K. Maini. 2007. Cytokines induced during chronic hepatitis B virus infection promote a pathway for NK cellmediated liver damage. J Exp Med 204: 667-680.

8. Yokoyama, W. M., S. Kim, and A. R. French. 2004. The dynamic life of natural killer cells. Annu Rev Immunol 22: 405-429.

9. Stetson, D. B., M. Mohrs, R. L. Reinhardt, J. L. Baron, Z. E. Wang, L. Gapin, M. Kronenberg, and R. M. Locksley. 2003. Constitutive cytokine mRNAs mark natural killer (NK) and NK T cells poised for rapid effector function. $J$ Exp Med 198: 1069-1076.

10. Fehniger, T. A., S. F. Cai, X. Cao, A. J. Bredemeyer, R. M. Presti, A. R. French, and T. J. Ley. 2007. Acquisition of murine NK cell cytotoxicity requires the translation of a pre-existing pool of granzyme B and perforin mRNAs. Immunity 26: 798-811.

11. Colucci, F., J. P. Di Santo, and P. J. Leibson. 2002. Natural killer cell activation in mice and men: different triggers for similar weapons? Nat Immunol 3: 807-813.

12. Lanier, L. L. 2005. NK cell recognition. Annu Rev Immunol 23: 225-274.

13. Karlhofer, F. M., R. K. Ribaudo, and W. M. Yokoyama. 1992. MHC class I alloantigen specificity of Ly-49+ IL-2-activated natural killer cells. Nature 358: 66-70.

14. Radaev, S., and P. D. Sun. 2003. Structure and function of natural killer cell surface receptors. Annu Rev Biophys Biomol Struct 32: 93-114.

15. Arase, H., E. S. Mocarski, A. E. Campbell, A. B. Hill, and L. L. Lanier. 2002. Direct recognition of cytomegalovirus by activating and inhibitory NK cell receptors. Science 296: 1323-1326.

16. Smith, H. R., J. W. Heusel, I. K. Mehta, S. Kim, B. G. Dorner, O. V. Naidenko, K. Iizuka, H. Furukawa, D. L. Beckman, J. T. Pingel, A. A. Scalzo, D. H. Fremont, and W. M. Yokoyama. 2002. Recognition of a virus-encoded ligand by 
a natural killer cell activation receptor. Proc Natl Acad Sci U S A 99: 8826-8831.

17. Wilhelm, B. T., L. Gagnier, and D. L. Mager. 2002. Sequence analysis of the ly49 cluster in C57BL/6 mice: a rapidly evolving multigene family in the immune system. Genomics 80: 646-661.

18. Makrigiannis, A. P., A. T. Pau, A. Saleh, R. Winkler-Pickett, J. R. Ortaldo, and S. K. Anderson. 2001. Class I MHC-binding characteristics of the 129/J Ly49 repertoire. J Immunol 166: 5034-5043.

19. Karre, K., H. G. Ljunggren, G. Piontek, and R. Kiessling. 1986. Selective rejection of $\mathrm{H}$-2-deficient lymphoma variants suggests alternative immune defence strategy. Nature 319: 675-678.

20. Ljunggren, H. G., and K. Karre. 1985. Host resistance directed selectively against H-2-deficient lymphoma variants. Analysis of the mechanism. J Exp Med 162: 1745-1759.

21. Ljunggren, H. G., and K. Karre. 1990. In search of the 'missing self': MHC molecules and NK cell recognition. Immunol Today 11: 237-244.

22. Hoglund, P., H. G. Ljunggren, C. Ohlen, L. Ahrlund-Richter, G. Scangos, C. Bieberich, G. Jay, G. Klein, and K. Karre. 1988. Natural resistance against lymphoma grafts conveyed by H-2Dd transgene to C57BL mice. J Exp Med 168: 1469-1474.

23. Ohlen, C., G. Kling, P. Hoglund, M. Hansson, G. Scangos, C. Bieberich, G. Jay, and K. Karre. 1989. Prevention of allogeneic bone marrow graft rejection by $\mathrm{H}-2$ transgene in donor mice. Science 246: 666-668.

24. Bix, M., N. S. Liao, M. Zijlstra, J. Loring, R. Jaenisch, and D. Raulet. 1991. Rejection of class I MHC-deficient haemopoietic cells by irradiated MHCmatched mice. Nature 349: 329-331.

25. Anfossi, N., P. Andre, S. Guia, C. S. Falk, S. Roetynck, C. A. Stewart, V. Breso, C. Frassati, D. Reviron, D. Middleton, F. Romagne, S. Ugolini, and E. Vivier. 2006. Human NK cell education by inhibitory receptors for MHC class I. Immunity 25: 331-342.

26. Cooley, S., F. Xiao, M. Pitt, M. Gleason, V. McCullar, T. L. Bergemann, K. L. McQueen, L. A. Guethlein, P. Parham, and J. S. Miller. 2007. A subpopulation of human peripheral blood NK cells that lacks inhibitory receptors for self-MHC is developmentally immature. Blood 110: 578-586.

27. Kim, S., J. Poursine-Laurent, S. M. Truscott, L. Lybarger, Y. J. Song, L. Yang, A. R. French, J. B. Sunwoo, S. Lemieux, T. H. Hansen, and W. M. Yokoyama. 2005. Licensing of natural killer cells by host major histocompatibility complex class I molecules. Nature 436: 709-713.

28. Fernandez, N. C., E. Treiner, R. E. Vance, A. M. Jamieson, S. Lemieux, and D. H. Raulet. 2005. A subset of natural killer cells achieves self-tolerance without expressing inhibitory receptors specific for self-MHC molecules. Blood 105: 4416-4423.

29. Brown MG, D. A., Rodriguez M and Xie X. 2007. NK cells: Innate sensors and effectors of virus resistance distinguished by genetic diversity. In Everything You Always Wanted to Know About NK cells But Were Afraid to Ask. L. Brossay, ed. Transworld Research Network, Trivandrum, p. 117-145.

30. Orange, J. S. 2002. Human natural killer cell deficiencies and susceptibility to 
infection. Microbes Infect 4: 1545-1558.

31. Biron, C. A., K. B. Nguyen, G. C. Pien, L. P. Cousens, and T. P. Salazar-Mather. 1999. Natural killer cells in antiviral defense: function and regulation by innate cytokines. Annu Rev Immunol 17: 189-220.

32. Rawlinson, W. D. 1999. Broadsheet. Number 50: Diagnosis of human cytomegalovirus infection and disease. Pathology 31: 109-115.

33. Mazzulli, T., R. H. Rubin, M. J. Ferraro, R. T. D'Aquila, S. A. Doveikis, B. R. Smith, T. H. The, and M. S. Hirsch. 1993. Cytomegalovirus antigenemia: clinical correlations in transplant recipients and in persons with AIDS. J Clin Microbiol 31: 2824-2827.

34. Ljungman, P., P. Griffiths, and C. Paya. 2002. Definitions of cytomegalovirus infection and disease in transplant recipients. Clin Infect Dis 34: 1094-1097.

35. Rennekampff, H. O., and K. Hamprecht. 2006. Cytomegalovirus infection in burns: a review. J Med Microbiol 55: 483-487.

36. Revello, M. G., and G. Gerna. 2002. Diagnosis and management of human cytomegalovirus infection in the mother, fetus, and newborn infant. Clin Microbiol Rev 15: 680-715.

37. Reddehase, M. J. 2002. Antigens and immunoevasins: opponents in cytomegalovirus immune surveillance. Nat Rev Immunol 2: 831-844.

38. Sinzger, C., A. Grefte, B. Plachter, A. S. Gouw, T. H. The, and G. Jahn. 1995. Fibroblasts, epithelial cells, endothelial cells and smooth muscle cells are major targets of human cytomegalovirus infection in lung and gastrointestinal tissues. $J$ Gen Virol 76 ( Pt 4): 741-750.

39. Krmpotic, A., I. Bubic, B. Polic, P. Lucin, and S. Jonjic. 2003. Pathogenesis of murine cytomegalovirus infection. Microbes Infect 5: 1263-1277.

40. Rawlinson, W. D., H. E. Farrell, and B. G. Barrell. 1996. Analysis of the complete DNA sequence of murine cytomegalovirus. J Virol 70: 8833-8849.

41. Mocarski, E. S., Jr. 2004. Immune escape and exploitation strategies of cytomegaloviruses: impact on and imitation of the major histocompatibility system. Cell Microbiol 6: 707-717.

42. Beutler, B., K. Crozat, J. A. Koziol, and P. Georgel. 2005. Genetic dissection of innate immunity to infection: the mouse cytomegalovirus model. Curr Opin Immunol 17: 36-43.

43. Reusch, U., W. Muranyi, P. Lucin, H. G. Burgert, H. Hengel, and U. H. Koszinowski. 1999. A cytomegalovirus glycoprotein re-routes MHC class I complexes to lysosomes for degradation. Embo J 18: 1081-1091.

44. Ziegler, H., R. Thale, P. Lucin, W. Muranyi, T. Flohr, H. Hengel, H. Farrell, W. Rawlinson, and U. H. Koszinowski. 1997. A mouse cytomegalovirus glycoprotein retains MHC class I complexes in the ERGIC/cis-Golgi compartments. Immunity 6: 57-66.

45. Kleijnen, M. F., J. B. Huppa, P. Lucin, S. Mukherjee, H. Farrell, A. E. Campbell, U. H. Koszinowski, A. B. Hill, and H. L. Ploegh. 1997. A mouse cytomegalovirus glycoprotein, gp34, forms a complex with folded class I MHC molecules in the ER which is not retained but is transported to the cell surface. Embo J 16: 685694.

46. Kavanagh, D. G., M. C. Gold, M. Wagner, U. H. Koszinowski, and A. B. Hill. 
2001. The multiple immune-evasion genes of murine cytomegalovirus are not redundant: $\mathrm{m} 4$ and $\mathrm{m} 152$ inhibit antigen presentation in a complementary and cooperative fashion. J Exp Med 194: 967-978.

47. Holtappels, R., D. Gillert-Marien, D. Thomas, J. Podlech, P. Deegen, S. Herter, S. A. Oehrlein-Karpi, D. Strand, M. Wagner, and M. J. Reddehase. 2006. Cytomegalovirus encodes a positive regulator of antigen presentation. J Virol 80 : 7613-7624.

48. Lu, X., A. K. Pinto, A. M. Kelly, K. S. Cho, and A. B. Hill. 2006. Murine cytomegalovirus interference with antigen presentation contributes to the inability of CD8 T cells to control virus in the salivary gland. J Virol 80: 4200-4202.

49. Farrell, H. E., H. Vally, D. M. Lynch, P. Fleming, G. R. Shellam, A. A. Scalzo, and N. J. Davis-Poynter. 1997. Inhibition of natural killer cells by a cytomegalovirus MHC class I homologue in vivo. Nature 386: 510-514.

50. Chalmer, J. E., J. S. Mackenzie, and N. F. Stanley. 1977. Resistance to murine cytomegalovirus linked to the major histocompatibility complex of the mouse. $J$ Gen Virol 37: 107-114.

51. Grundy, J. E., J. S. Mackenzie, and N. F. Stanley. 1981. Influence of H-2 and non-H-2 genes on resistance to murine cytomegalovirus infection. Infect Immun 32: 277-286.

52. Scalzo, A. A., N. A. Fitzgerald, A. Simmons, A. B. La Vista, and G. R. Shellam. 1990. Cmv-1, a genetic locus that controls murine cytomegalovirus replication in the spleen. $J$ Exp Med 171: 1469-1483.

53. Allan, J. E., and G. R. Shellam. 1984. Genetic control of murine cytomegalovirus infection: virus titres in resistant and susceptible strains of mice. Arch Virol 81: 139-150.

54. Mercer, J. A., and D. H. Spector. 1986. Pathogenesis of acute murine cytomegalovirus infection in resistant and susceptible strains of mice. $J$ Virol 57: 497-504.

55. Scalzo, A. A., P. A. Lyons, N. A. Fitzgerald, C. A. Forbes, W. M. Yokoyama, and G. R. Shellam. 1995. Genetic mapping of Cmv1 in the region of mouse chromosome 6 encoding the NK gene complex-associated loci Ly49 and musNKR-P1. Genomics 27: 435-441.

56. Rodriguez, M., P. Sabastian, P. Clark, and M. G. Brown. 2004. Cmv1independent antiviral role of NK cells revealed in murine cytomegalovirusinfected New Zealand White mice. J Immunol 173: 6312-6318.

57. Adam, S. G., A. Caraux, N. Fodil-Cornu, J. C. Loredo-Osti, S. Lesjean-Pottier, J. Jaubert, I. Bubic, S. Jonjic, J. L. Guenet, S. M. Vidal, and F. Colucci. 2006. Cmv4, a new locus linked to the NK cell gene complex, controls innate resistance to cytomegalovirus in wild-derived mice. J Immunol 176: 5478-5485.

58. Brown, M. G., A. O. Dokun, J. W. Heusel, H. R. Smith, D. L. Beckman, E. A. Blattenberger, C. E. Dubbelde, L. R. Stone, A. A. Scalzo, and W. M. Yokoyama. 2001. Vital involvement of a natural killer cell activation receptor in resistance to viral infection. Science 292: 934-937.

59. Lee, S. H., S. Girard, D. Macina, M. Busa, A. Zafer, A. Belouchi, P. Gros, and S. M. Vidal. 2001. Susceptibility to mouse cytomegalovirus is associated with deletion of an activating natural killer cell receptor of the C-type lectin 
superfamily. Nat Genet 28: 42-45.

60. Desrosiers, M. P., A. Kielczewska, J. C. Loredo-Osti, S. G. Adam, A. P. Makrigiannis, S. Lemieux, T. Pham, M. B. Lodoen, K. Morgan, L. L. Lanier, and S. M. Vidal. 2005. Epistasis between mouse Klra and major histocompatibility complex class I loci is associated with a new mechanism of natural killer cellmediated innate resistance to cytomegalovirus infection. Nat Genet 37: 593-599.

61. Dighe, A., M. Rodriguez, P. Sabastian, X. Xie, M. McVoy, and M. G. Brown. 2005. Requisite $\mathrm{H} 2 \mathrm{k}$ role in NK cell-mediated resistance in acute murine cytomegalovirus-infected MA/My mice. J Immunol 175: 6820-6828.

62. Barbosa, M. D., Q. A. Nguyen, V. T. Tchernev, J. A. Ashley, J. C. Detter, S. M. Blaydes, S. J. Brandt, D. Chotai, C. Hodgman, R. C. Solari, M. Lovett, and S. F. Kingsmore. 1996. Identification of the homologous beige and Chediak-Higashi syndrome genes. Nature 382: 262-265.

63. Nagle, D. L., M. A. Karim, E. A. Woolf, L. Holmgren, P. Bork, D. J. Misumi, S. H. McGrail, B. J. Dussault, Jr., C. M. Perou, R. E. Boissy, G. M. Duyk, R. A. Spritz, and K. J. Moore. 1996. Identification and mutation analysis of the complete gene for Chediak-Higashi syndrome. Nat Genet 14: 307-311.

64. Roder, J. C. 1979. The beige mutation in the mouse. I. A stem cell predetermined impairment in natural killer cell function. J Immunol 123: 2168-2173.

65. Roder, J. C., M. L. Lohmann-Matthes, W. Domzig, and H. Wigzell. 1979. The beige mutation in the mouse. II. Selectivity of the natural killer (NK) cell defect. $J$ Immunol 123: 2174-2181.

66. Roder, J., and A. Duwe. 1979. The beige mutation in the mouse selectively impairs natural killer cell function. Nature 278: 451-453.

67. Haliotis, T., J. Roder, M. Klein, J. Ortaldo, A. S. Fauci, and R. B. Herberman. 1980. Chediak-Higashi gene in humans I. Impairment of natural-killer function. $J$ Exp Med 151: 1039-1048.

68. Klein, M., J. Roder, T. Haliotis, S. Korec, J. R. Jett, R. B. Herberman, P. Katz, and A. S. Fauci. 1980. Chediak-Higashi gene in humans. II. The selectivity of the defect in natural-killer and antibody-dependent cell-mediated cytotoxicity function. J Exp Med 151: 1049-1058.

69. Shellam, G. R., J. E. Allan, J. M. Papadimitriou, and G. J. Bancroft. 1981. Increased susceptibility to cytomegalovirus infection in beige mutant mice. Proc Natl Acad Sci U S A 78: 5104-5108.

70. Kim, S., K. Iizuka, H. L. Aguila, I. L. Weissman, and W. M. Yokoyama. 2000. In vivo natural killer cell activities revealed by natural killer cell-deficient mice. Proc Natl Acad Sci U S A 97: 2731-2736.

71. Kim, S., Y. J. Song, D. A. Higuchi, H. P. Kang, J. R. Pratt, L. Yang, C. M. Hong, J. Poursine-Laurent, K. Iizuka, A. R. French, J. B. Sunwoo, S. Ishii, A. M. Reimold, and W. M. Yokoyama. 2006. Arrested natural killer cell development associated with transgene insertion into the Atf2 locus. Blood 107: 1024-1030.

72. Loh, J., D. T. Chu, A. K. O'Guin, W. M. Yokoyama, and H. W. t. Virgin. 2005. Natural killer cells utilize both perforin and gamma interferon to regulate murine cytomegalovirus infection in the spleen and liver. J Virol 79: 661-667.

73. Tay, C. H., and R. M. Welsh. 1997. Distinct organ-dependent mechanisms for the control of murine cytomegalovirus infection by natural killer cells. $J$ Virol 71: 
267-275.

74. van Dommelen, S. L., N. Sumaria, R. D. Schreiber, A. A. Scalzo, M. J. Smyth, and M. A. Degli-Esposti. 2006. Perforin and granzymes have distinct roles in defensive immunity and immunopathology. Immunity 25: 835-848.

75. Riera, L., M. Gariglio, G. Valente, A. Mullbacher, C. Museteanu, S. Landolfo, and M. M. Simon. 2000. Murine cytomegalovirus replication in salivary glands is controlled by both perforin and granzymes during acute infection. Eur J Immunol 30: 1350-1355.

76. Fernandez, J. A., E. G. Rodrigues, and M. Tsuji. 2000. Multifactorial protective mechanisms to limit viral replication in the lung of mice during primary murine cytomegalovirus infection. Viral Immunol 13: 287-295.

77. Depatie, C., E. Muise, P. Lepage, P. Gros, and S. M. Vidal. 1997. High-resolution linkage map in the proximity of the host resistance locus Cmv1. Genomics 39: 154-163.

78. Forbes, C. A., M. G. Brown, R. Cho, G. R. Shellam, W. M. Yokoyama, and A. A. Scalzo. 1997. The Cmv1 host resistance locus is closely linked to the Ly49 multigene family within the natural killer cell gene complex on mouse chromosome 6. Genomics 41: 406-413.

79. Brown, M. G., J. Zhang, Y. Du, J. Stoll, W. M. Yokoyama, and A. A. Scalzo. 1999. Localization on a physical map of the NKC-linked Cmv1 locus between Ly49b and the Prp gene cluster on mouse chromosome 6. J Immunol 163: 19911999.

80. Sjolin, H., E. Tomasello, M. Mousavi-Jazi, A. Bartolazzi, K. Karre, E. Vivier, and C. Cerboni. 2002. Pivotal role of KARAP/DAP12 adaptor molecule in the natural killer cell-mediated resistance to murine cytomegalovirus infection. $J$ Exp Med 195: 825-834.

81. Lee, S. H., A. Zafer, Y. de Repentigny, R. Kothary, M. L. Tremblay, P. Gros, P. Duplay, J. R. Webb, and S. M. Vidal. 2003. Transgenic expression of the activating natural killer receptor Ly49H confers resistance to cytomegalovirus in genetically susceptible mice. $J$ Exp Med 197: 515-526.

82. Daniels, K. A., G. Devora, W. C. Lai, C. L. O'Donnell, M. Bennett, and R. M. Welsh. 2001. Murine cytomegalovirus is regulated by a discrete subset of natural killer cells reactive with monoclonal antibody to Ly49H. J Exp Med 194: 29-44.

83. Dokun, A. O., S. Kim, H. R. Smith, H. S. Kang, D. T. Chu, and W. M. Yokoyama. 2001. Specific and nonspecific NK cell activation during virus infection. Nat Immunol 2: 951-956.

84. Bubic, I., M. Wagner, A. Krmpotic, T. Saulig, S. Kim, W. M. Yokoyama, S. Jonjic, and U. H. Koszinowski. 2004. Gain of virulence caused by loss of a gene in murine cytomegalovirus. J Virol 78: 7536-7544.

85. Voigt, V., C. A. Forbes, J. N. Tonkin, M. A. Degli-Esposti, H. R. Smith, W. M. Yokoyama, and A. A. Scalzo. 2003. Murine cytomegalovirus m157 mutation and variation leads to immune evasion of natural killer cells. Proc Natl Acad Sci US A 100: 13483-13488.

86. French, A. R., J. T. Pingel, M. Wagner, I. Bubic, L. Yang, S. Kim, U. Koszinowski, S. Jonjic, and W. M. Yokoyama. 2004. Escape of mutant doublestranded DNA virus from innate immune control. Immunity 20: 747-756. 
87. Scalzo, A. A., M. Manzur, C. A. Forbes, M. G. Brown, and G. R. Shellam. 2005. NK gene complex haplotype variability and host resistance alleles to murine cytomegalovirus in wild mouse populations. Immunol Cell Biol 83: 144-149.

88. Bancroft, G. J., G. R. Shellam, and J. E. Chalmer. 1981. Genetic influences on the augmentation of natural killer (NK) cells during murine cytomegalovirus infection: correlation with patterns of resistance. J Immunol 126: 988-994.

89. Shellam, G. R., J. P. Flexman, H. E. Farrell, and J. M. Papadimitriou. 1985. The genetic background modulates the effect of the beige gene on susceptibility to cytomegalovirus infection in mice. Scand J Immunol 22: 147-155.

90. Brown, M. G., A. A. Scalzo, L. R. Stone, P. Y. Clark, Y. Du, B. Palanca, and W. M. Yokoyama. 2001. Natural killer gene complex (Nkc) allelic variability in inbred mice: evidence for Nkc haplotypes. Immunogenetics 53: 584-591.

91. Wagner, M., A. Gutermann, J. Podlech, M. J. Reddehase, and U. H. Koszinowski. 2002. Major histocompatibility complex class I allele-specific cooperative and competitive interactions between immune evasion proteins of cytomegalovirus. $J$ Exp Med 196: 805-816.

92. Tomasec, P., V. M. Braud, C. Rickards, M. B. Powell, B. P. McSharry, S. Gadola, V. Cerundolo, L. K. Borysiewicz, A. J. McMichael, and G. W. Wilkinson. 2000. Surface expression of HLA-E, an inhibitor of natural killer cells, enhanced by human cytomegalovirus gpUL40. Science 287: 1031.

93. Braud, V. M., D. S. Allan, C. A. O'Callaghan, K. Soderstrom, A. D'Andrea, G. S. Ogg, S. Lazetic, N. T. Young, J. I. Bell, J. H. Phillips, L. L. Lanier, and A. J. McMichael. 1998. HLA-E binds to natural killer cell receptors CD94/NKG2A, B and C. Nature 391: 795-799.

94. Ulbrecht, M., S. Martinozzi, M. Grzeschik, H. Hengel, J. W. Ellwart, M. Pla, and E. H. Weiss. 2000. Cutting edge: the human cytomegalovirus UL40 gene product contains a ligand for HLA-E and prevents NK cell-mediated lysis. J Immunol 164: 5019-5022.

95. Wang, E. C., B. McSharry, C. Retiere, P. Tomasec, S. Williams, L. K. Borysiewicz, V. M. Braud, and G. W. Wilkinson. 2002. UL40-mediated NK evasion during productive infection with human cytomegalovirus. Proc Natl Acad Sci U S A 99: 7570-7575.

96. Tomasec, P., E. C. Wang, A. J. Davison, B. Vojtesek, M. Armstrong, C. Griffin, B. P. McSharry, R. J. Morris, S. Llewellyn-Lacey, C. Rickards, A. Nomoto, C. Sinzger, and G. W. Wilkinson. 2005. Downregulation of natural killer cellactivating ligand CD155 by human cytomegalovirus UL141. Nat Immunol 6: 181188.

97. Wills, M. R., O. Ashiru, M. B. Reeves, G. Okecha, J. Trowsdale, P. Tomasec, G. W. Wilkinson, J. Sinclair, and J. G. Sissons. 2005. Human cytomegalovirus encodes an MHC class I-like molecule (UL142) that functions to inhibit NK cell lysis. J Immunol 175: 7457-7465.

98. Harnett, G. B., and G. R. Shellam. 1982. Variation in murine cytomegalovirus replication in fibroblasts from different mouse strains in vitro: correlation with in vivo resistance. J Gen Virol 62 (Pt 1): 39-47.

99. Orange, J. S., B. Wang, C. Terhorst, and C. A. Biron. 1995. Requirement for natural killer cell-produced interferon gamma in defense against murine 
cytomegalovirus infection and enhancement of this defense pathway by interleukin 12 administration. $J$ Exp Med 182: 1045-1056.

100. Martinotti, M. G., G. Gribaudo, M. Gariglio, A. Angeretti, G. Cavallo, and S. Landolfo. 1992. Effects of interferon alpha on murine cytomegalovirus replication. Microbiologica 15: 183-186.

101. Tabeta, K., P. Georgel, E. Janssen, X. Du, K. Hoebe, K. Crozat, S. Mudd, L. Shamel, S. Sovath, J. Goode, L. Alexopoulou, R. A. Flavell, and B. Beutler. 2004. Toll-like receptors 9 and 3 as essential components of innate immune defense against mouse cytomegalovirus infection. Proc Natl Acad Sci U S A 101: 35163521.

102. Andoniou, C. E., S. L. van Dommelen, V. Voigt, D. M. Andrews, G. Brizard, C. Asselin-Paturel, T. Delale, K. J. Stacey, G. Trinchieri, and M. A. Degli-Esposti. 2005. Interaction between conventional dendritic cells and natural killer cells is integral to the activation of effective antiviral immunity. Nat Immunol 6: 10111019.

103. Delale, T., A. Paquin, C. Asselin-Paturel, M. Dalod, G. Brizard, E. E. Bates, P. Kastner, S. Chan, S. Akira, A. Vicari, C. A. Biron, G. Trinchieri, and F. Briere. 2005. MyD88-dependent and -independent murine cytomegalovirus sensing for IFN-alpha release and initiation of immune responses in vivo. J Immunol 175: 6723-6732.

104. Fauci, A. S., D. Mavilio, and S. Kottilil. 2005. NK cells in HIV infection: paradigm for protection or targets for ambush. Nat Rev Immunol 5: 835-843.

105. Khakoo, S. I., C. L. Thio, M. P. Martin, C. R. Brooks, X. Gao, J. Astemborski, J. Cheng, J. J. Goedert, D. Vlahov, M. Hilgartner, S. Cox, A. M. Little, G. J. Alexander, M. E. Cramp, S. J. O'Brien, W. M. Rosenberg, D. L. Thomas, and M. Carrington. 2004. HLA and NK cell inhibitory receptor genes in resolving hepatitis C virus infection. Science 305: 872-874.

106. Gasser, S., and D. H. Raulet. 2006. Activation and self-tolerance of natural killer cells. Immunol Rev 214: 130-142.

107. Brown, M. G., and A. A. Scalzo. 2008. NK gene complex dynamics and selection for NK cell receptors. Semin Immunol 20: 361-368.

108. Xie, X., A. Dighe, P. Clark, P. Sabastian, S. Buss, and M. G. Brown. 2007. Deficient major histocompatibility complex-linked innate murine cytomegalovirus immunity in MA/My.L-H2b mice and viral downregulation of H-2k class I proteins. J Virol 81: 229-236.

109. Polic, B., H. Hengel, A. Krmpotic, J. Trgovcich, I. Pavic, P. Luccaronin, S. Jonjic, and U. H. Koszinowski. 1998. Hierarchical and redundant lymphocyte subset control precludes cytomegalovirus replication during latent infection. $J$ Exp Med 188: 1047-1054.

110. Robbins, S. H., G. Bessou, A. Cornillon, N. Zucchini, B. Rupp, Z. Ruzsics, T. Sacher, E. Tomasello, E. Vivier, U. H. Koszinowski, and M. Dalod. 2007. Natural killer cells promote early CD8 T cell responses against cytomegalovirus. PLoS Pathog 3: e123.

111. Silver, E. T., K. J. Lavender, D. E. Gong, B. Hazes, and K. P. Kane. 2002. Allelic variation in the ectodomain of the inhibitory Ly-49G2 receptor alters its specificity for allogeneic and xenogeneic ligands. J Immunol 169: 4752-4760. 
112. Tay, C. H., L. Y. Yu, V. Kumar, L. Mason, J. R. Ortaldo, and R. M. Welsh. 1999. The role of LY49 NK cell subsets in the regulation of murine cytomegalovirus infections. J Immunol 162: 718-726.

113. Depatie, C., A. Chalifour, C. Pare, S. H. Lee, S. M. Vidal, and S. Lemieux. 1999. Assessment of $\mathrm{Cmv} 1$ candidates by genetic mapping and in vivo antibody depletion of NK cell subsets. Int Immunol 11: 1541-1551.

114. Hollyoake, M., R. D. Campbell, and B. Aguado. 2005. NKp30 (NCR3) is a pseudogene in 12 inbred and wild mouse strains, but an expressed gene in Mus caroli. Mol Biol Evol 22: 1661-1672.

115. Orange, J. S., and C. A. Biron. 1996. Characterization of early IL-12, IFNalphabeta, and TNF effects on antiviral state and NK cell responses during murine cytomegalovirus infection. J Immunol 156: 4746-4756.

116. Yerkovich, S. T., S. D. Olver, J. C. Lenzo, C. D. Peacock, and P. Price. 1997. The roles of tumour necrosis factor-alpha, interleukin-1 and interleukin-12 in murine cytomegalovirus infection. Immunology 91: 45-52.

117. Schneider, K., A. Loewendorf, C. De Trez, J. Fulton, A. Rhode, H. Shumway, S. Ha, G. Patterson, K. Pfeffer, S. A. Nedospasov, C. F. Ware, and C. A. Benedict. 2008. Lymphotoxin-mediated crosstalk between B cells and splenic stroma promotes the initial type I interferon response to cytomegalovirus. Cell Host Microbe 3: 67-76.

118. Hengel, H., U. Reusch, A. Gutermann, H. Ziegler, S. Jonjic, P. Lucin, and U. H. Koszinowski. 1999. Cytomegaloviral control of MHC class I function in the mouse. Immunol Rev 168: 167-176.

119. Ortaldo, J. R., A. T. Mason, R. Winkler-Pickett, A. Raziuddin, W. J. Murphy, and L. H. Mason. 1999. Ly-49 receptor expression and functional analysis in multiple mouse strains. J Leukoc Biol 66: 512-520.

120. Makrigiannis, A. P., E. Rousselle, and S. K. Anderson. 2004. Independent control of Ly49g alleles: implications for NK cell repertoire selection and tumor cell killing. J Immunol 172: 1414-1425.

121. Bashirova, A. A., M. P. Martin, D. W. McVicar, and M. Carrington. 2006. The killer immunoglobulin-like receptor gene cluster: tuning the genome for defense. Annu Rev Genomics Hum Genet 7: 277-300.

122. Nedrud, J. G., A. M. Collier, and J. S. Pagano. 1979. Cellular basis for susceptibility to mouse cytomegalovirus: evidence from tracheal organ culture. $J$ Gen Virol 45: 737-744.

123. Azoulay, A., M. Brahic, and J. F. Bureau. 1994. FVB mice transgenic for the H$2 \mathrm{Db}$ gene become resistant to persistent infection by Theiler's virus. J Virol 68 : 4049-4052.

124. Watts, S., J. M. Vogel, W. D. Harriman, T. Itoh, H. J. Stauss, and R. S. Goodenow. 1987. DNA sequence analysis of the C3H H-2Kk and H-2Dk loci. Evolutionary relationships to H-2 genes from four other mouse strains. J Immunol 139: 3878-3885.

125. Kimura, A., A. Israel, O. Le Bail, and P. Kourilsky. 1986. Detailed analysis of the mouse $\mathrm{H}-2 \mathrm{~Kb}$ promoter: enhancer-like sequences and their role in the regulation of class I gene expression. Cell 44: 261-272.

126. Arnold, B., and G. J. Hammerling. 1991. MHC class-I transgenic mice. Annu Rev 
Immunol 9: 297-322.

127. Kielczewska, A., M. Pyzik, T. Sun, A. Krmpotic, M. B. Lodoen, M. W. Munks, M. Babic, A. B. Hill, U. H. Koszinowski, S. Jonjic, L. L. Lanier, and S. M. Vidal. 2009. Ly49P recognition of cytomegalovirus-infected cells expressing H2-Dk and $\mathrm{CMV}$-encoded m04 correlates with the NK cell antiviral response. J Exp Med 206: 515-523.

128. Martin, M. P., X. Gao, J. H. Lee, G. W. Nelson, R. Detels, J. J. Goedert, S. Buchbinder, K. Hoots, D. Vlahov, J. Trowsdale, M. Wilson, S. J. O'Brien, and M. Carrington. 2002. Epistatic interaction between KIR3DS1 and HLA-B delays the progression to AIDS. Nat Genet 31: 429-434.

129. Qi, Y., M. P. Martin, X. Gao, L. Jacobson, J. J. Goedert, S. Buchbinder, G. D. Kirk, S. J. O'Brien, J. Trowsdale, and M. Carrington. 2006. KIR/HLA pleiotropism: protection against both HIV and opportunistic infections. PLoS Pathog 2: e79.

130. Martin, M. P., Y. Qi, X. Gao, E. Yamada, J. N. Martin, F. Pereyra, S. Colombo, E. E. Brown, W. L. Shupert, J. Phair, J. J. Goedert, S. Buchbinder, G. D. Kirk, A. Telenti, M. Connors, S. J. O'Brien, B. D. Walker, P. Parham, S. G. Deeks, D. W. McVicar, and M. Carrington. 2007. Innate partnership of HLA-B and KIR3DL1 subtypes against HIV-1. Nat Genet 39: 733-740.

131. Alter, G., M. P. Martin, N. Teigen, W. H. Carr, T. J. Suscovich, A. Schneidewind, H. Streeck, M. Waring, A. Meier, C. Brander, J. D. Lifson, T. M. Allen, M. Carrington, and M. Altfeld. 2007. Differential natural killer cell-mediated inhibition of HIV-1 replication based on distinct KIR/HLA subtypes. J Exp Med 204: 3027-3036.

132. Raulet, D. H., and R. E. Vance. 2006. Self-tolerance of natural killer cells. Nat Rev Immunol 6: 520-531.

133. Yokoyama, W. M., and S. Kim. 2006. How do natural killer cells find self to achieve tolerance? Immunity 24: 249-257.

134. Chalifour, A., L. Scarpellino, J. Back, P. Brodin, E. Devevre, F. Gros, F. Levy, G. Leclercq, P. Hoglund, F. Beermann, and W. Held. 2009. A Role for cis Interaction between the Inhibitory Ly49A receptor and MHC class I for natural killer cell education. Immunity 30: 337-347.

135. Scalzo, A. A., M. G. Brown, D. T. Chu, J. W. Heusel, W. M. Yokoyama, and C. A. Forbes. 1999. Development of intra-natural killer complex (NKC) recombinant and congenic mouse strains for mapping and functional analysis of $\mathrm{NK}$ cell regulatory loci. Immunogenetics 49: 238-241.

136. Scalzo, A. A., R. Wheat, C. Dubbelde, L. Stone, P. Clark, Y. Du, N. Dong, J. Stoll, W. M. Yokoyama, and M. G. Brown. 2003. Molecular genetic characterization of the distal $\mathrm{NKC}$ recombination hotspot and putative murine CMV resistance control locus. Immunogenetics 55: 370-378.

137. Scalzo, A. A., H. E. Farrell, and G. Karupiah. 2000. Techniques for studying murine natural killer cells in defense against viral infection. Methods Mol Biol 121: 163-177.

138. Wheat, R. L., P. Y. Clark, and M. G. Brown. 2003. Quantitative measurement of infectious murine cytomegalovirus genomes in real-time PCR. J Virol Methods 112: 107-113. 
139. Allen, H., D. Wraith, P. Pala, B. Askonas, and R. A. Flavell. 1984. Domain interactions of $\mathrm{H}-2$ class I antigens alter cytotoxic T-cell recognition sites. Nature 309: 279-281. 


\section{VITA}

Xuefang Xie grew up in a rural village on the coast of Southeast China. From early on she became aware that a large percent of the Chinese population suffered from chronic viral infection and determined to understand why the immune system fails to clear these infections. In 2003, she graduated from Zhejiang University and got her bachelor's degree in Biotechnology. After that she attended the University of Virginia where her graduate studies focused on host defense to viral infection, generally, and Natural Killer cell-mediated viral immunity, in particular. She has published in the Journal of Immunology and the Journal of Virology and presented her work at the American Association of Immunologists, the Keystone symposium for NK and NKT Cell Biology and the International Herpesvirus Workshop.

\section{PUBLICATIONS}

1. Xie X, Stadnisky M, Brown MG. MHC class I $D^{k}$ locus and Ly49G2 NK cells confer $\mathrm{H}-2^{\mathrm{k}}$ resistance to murine cytomegalovirus. J Immunol. 2009 in press.

2. Xie X, Dighe A, Clark P, Sabastian P, Buss S, Brown MG. Deficient major histocompatibility complex-linked innate murine cytomegalovirus immunity in MA/My.L-H2 ${ }^{b}$ mice and viral downregulation of $\mathrm{H}-2^{\mathrm{k}}$ class I proteins. $J$ Virol. 2007 Jan;81(1):229-36.

3. Dighe A, Rodriguez M, Sabastian P, Xie X, McVoy M, Brown MG. Requisite $\mathrm{H} 2^{\mathrm{k}}$ role in $\mathrm{NK}$ cell-mediated resistance in acute murine cytomegalovirus infected MA/My mice. J Immunol. 2005 Nov 15;175(10):6820-8. 